\title{
Sequence Analysis and Structure Prediction of Malaysia SARS-CoV-2 Strain's Structural and Accessory Proteins
}

\author{
Asita Elengoe 1,*iD, Shalini Selvam 2, Mogana Selvarajah 2, Herooshini Manikam 2, Rajaswary Vijaya \\ Kumar $^{2}$
}

1 Department of Biotechnology, Faculty of Science, Lincoln University College, 47301 Petaling Jaya, Selangor, Malaysia; asitaelengoe@yahoo.com (A.E.);

2 School of Biotechnology, Manipal International University (MIU), 71800, Putra Nilai, Negeri Sembilan, Malaysia; shaliniselvam08@gmail.com (S.S.); mogana5070@gmail.com (M.S.); herooshini23@gmail.com (H.M.); rajaswaryvijayakumar@gmail.com (R.V.K.);

* Correspondence: asitaelengoe@yahoo.com (A.E.)

Scopus Author ID 56118646500

Received: 15.06.2021; Revised: 22.07.2021; Accepted: 26.07.2021; Published: 8.08.2021

\begin{abstract}
Severe acute respiratory syndrome coronavirus 2 (SARS-CoV-2) that transmitted from animal to human became a life-threatening pandemic in 2020. Scientists are currently testing several drugs to eradicate the COVID-19 outbreak. However, there is no $100 \%$ effective drug or vaccine against SARS-CoV-2 has been discovered so far. In this study, we explored the structure prediction and functional analysis of 75 Malaysia SARS-CoV-2 strain's structural and accessory proteins without the presence of experimental models. Physiochemical analysis, secondary structure analysis, structure prediction, functional characterization, active site identification, and evolutionary analysis based on the amino acid sequences retrieved from National Centre for Biotechnology Information (NCBI). Threedimensional (3-D) protein structures were built using the Swiss model. The quality of protein models was verified by ERRAT, PROCHECK, and Verify 3D tools. Active prediction analysis revealed the high potential active sites of proteins where the anti-viral drug or vaccine may bind and inhibit the viral activities. Molecular phylogenetic analysis of ORF10, ORF8, and ORF6 proteins from five different species was analyzed. The results from this analysis proved that Homo sapiens SARS-CoV-2 had high genetic similarity with the bat coronavirus. These analyses may help in designing structure-based antiviral drugs or to develop potential vaccines for SARS-CoV-2.
\end{abstract}

Keywords: SARS-CoV-2; Malaysia; sequence analysis; structure prediction; evolutionary analysis.

(C) 2021 by the authors. This article is an open-access article distributed under the terms and conditions of the Creative Commons Attribution (CC BY) license (https://creativecommons.org/licenses/by/4.0/).

\section{Introduction}

Since the year 1000, when poxvirus spread through China extensively, virus infection remains a serious issue [1]. In the year 2020, severe acute respiratory syndrome coronavirus 2, or SARS-CoV-2, which was reported firstly from Wuhan City, Hubei Province, China in December 2019, became a life-threatening zoonotic disease that spreads through several continents [2]. SARS-CoV-2 is a beta coronavirus that belongs to the family Coronaviridae and is the reason for the coronavirus disease 2019 or COVID-19 outbreak [3]. COVID-19 was declared as a global pandemic, a disease that people are not immune to, which spreads across larger regions (e.g., several continents) on March 11, 2020, by World Health Organization (WHO) [4]. As of $11^{\text {th }}$ June 2021, United States has recorded the highest number of COVID19 cases, surpassing more than 34,000,000 total cases, followed by India and Brazil [5]. 
The COVID-19 is a zoonotic disease because the virus was transmitted between animals and humans. The recent zoonotic disease that spread through several continents before COVID-19 is the West Nile virus in 2019 which was transmitted from birds to humans. Even though coronavirus is common in camels and cattle, all virus samples obtained from humans so far are genetically related to coronaviruses extracted from bat inhabitants, notably Rhinolophus bats, which can be found across Asia, Africa, the Middle East, and European regions. Genetic sequences of coronavirus isolated from humans indicate that this COVID-19 outbreak has resulted from single point introduction in the human population [6].

The size of SARS-CoV-2, which belongs to beta coronavirus, varies from 70 to $90 \mathrm{~nm}$. The length of DNA nucleotides is 29,903. The outer surface of viral protein spike (S), envelope (E), and membrane (M) of coronavirus are embedded in host membrane-derived lipid bilayer encapsulating the helical nucleocapsid $(\mathrm{N})$ encompassing viral RNA [7,8]. It consists of seven open reading frames (Orf1a, Orf1b, Orf3a, Orf6, Orf7a, Orf8, and Orf10). The first two Orfs (Orf1a, Orf1b) play a vital role in co-translation proteolysis activity. While the five accessory proteins (Orf3a, Orf6, Orf7a, Orf8, and Orf10) attribute to pathogenesis. Coronavirus is sensitive to heat and ultraviolet radiation [9]. The analysis of the virus genome sequences also indicates that SARS-CoV-2 is very well adapted to human cell receptors, which allows it to invade human cells and easily infect people.

SARS-CoV-2 was primarily transmitted from person to person. It has an incubation period of 14 days, and it can be transmitted between this period [10]. This virus is transmitted widely between people through direct and indirect contact. When an infected person sneezes, coughs, or talks, the respiratory droplet is expelled and transmitted from them to the another person's mucosae (nose and mouth), or conjunctiva (eyes), which is within $1 \mathrm{~m}$ distance is known as direct transmission. Indirect transmission occurs when a healthy individual is infected from equipment touched by or used to treat COVID-19 patients $[11,12]$.

Worldwide, Malaysia ranked at the $39^{\text {th }}$ position for the sum of COVID-19 infected cases on $10^{\text {th }}$ June 2021 [5]. According to the Ministry of Health (MOH) Malaysia, there were 639,562 total infected cases, including 556,030 recovered cases and 3,684 cases reported as of $10^{\text {th }}$ June 2021[13]. The three most dangerous mutant strains (B.1.1.7 (alpha), B.1.351 (beta), and B.1.617.2 (gamma)) were already detected in Malaysia on $1^{\text {st }}$ January 2021, $11^{\text {th }}$ January 2021, and $21^{\text {st }}$ April 2021, respectively [13]. The number of COVID-19 cases increases exponentially from $15^{\text {th }}$ May (4,140 cases) to $29^{\text {th }}$ May 2021 (9,020 cases) [13]. Many repurposed anti-viral treatments have been proven to be ineffective in high-risk COVID-19 patients. The WHO COVID-19 Solidarity Trial for COVID-19 Treatments (SOLIDARITY), which included Malaysia, found insufficient evidence for the use of remdesivir, hydroxychloroquine, interferon, and lopinavir to reduce the mortality rate among COVID-19 patients [14]. Currently, the Malaysia Consensus Management Guidelines for COVID-19 continue to recommend favipiravir as the only anti-viral treatment for COVID-19 cases [15]. However, this recommendation may change if any other new anti-viral drug is available to use safely without any side effects that are proven in clinical trials. The development of effective pharmacologic therapies for COVID-19 is still a work in progress.

Therefore, we explored physiochemical analysis, secondary structure analysis, structure prediction, functional characterization, active site identification, and evolutionary analysis based on the amino acid sequences of Malaysia SARS-CoV-2 strain's structural and accessory proteins that were retrieved from the National Centre for Biotechnology Information (NCBI). 


\section{Materials and Methods}

\subsection{Sequence retrieval.}

The NCBI protein database obtained the amino acid sequences of 75 Malaysia SARSCoV-2 strain's structural and accessory proteins [16]. The description of the amino acid sequences was tabulated. The description includes protein name, gene id, description, number of amino acids (aa), accession number, author of the article, and publication date.

\subsection{Analysis of physiochemical properties.}

Sequence analyses of Malaysia SARS-CoV-2 strain's structural and accessory proteins were carried out using ExPASy proteomic tools (https://www.expasy.org/tools) [17]. ProtParam tool used to measure physiochemical parameters of the protein sequences. The study is entirely based on the input sequence and relies on the characteristics of the amino acids. A detailed annotation of the protein was performed by the tool. The amino acid sequence was submitted in FASTA format. The computed parameters include the molecular weight $(\mathrm{kDa})$, isoelectric point ( $\mathrm{pI}$ ), the composition of amino acid, carbon, hydrogen, nitrogen, oxygen, and sulfur atomic composition, extinction coefficient $\left(\mathrm{M}^{-1} \mathrm{~cm}^{-1}\right)$ that calculated in water at $280 \mathrm{~nm}$, estimated half-life, instability index (II), aliphatic index, and grand average of hydropathicity (GRAVY) [18]. All the parameters of the protein sequences were tabulated.

\subsection{Secondary structure analysis.}

The secondary structure of the retrieved SARS-CoV-2 strain's structural and accessory protein sequences was determined using the self-optimized prediction method (SOPMA) [19]. SOPMA is a free online executable tool for the structural annotation of proteins. SOPMA has been a significant improvement in protein secondary structure prediction by consensus prediction from multiple alignments. The secondary structure was analyzed through the SOPMA server with the default parameter [18]. The tool predicts detailed secondary structural protein confirmation for each amino acid in it. Based on SOPMA annotations, the percentage composition of each type of secondary structure, such as helix, coil, extended strand, etc., can be determined [20]. The number of residues for alpha-helix, which stabilizes the protein structure, was also calculated based on the SOPMA result, and the data were tabulated.

\subsection{Protein modeling.}

The 3-D SARS-CoV-2 experimental protein structures were not available in the protein database. Therefore, the protein model generations of SARS-CoV-2 sequences were carried out using protein modeling servers. First, template searches were done using the Swiss model to determine the most suitable protein modeling for the target protein based on the sequence identity. Comparative modeling was performed for the target sequence, which had the sequence identity above $25 \%$, while ab initio modeling was carried out for sequence identity below $25 \%$. Thus, the protein model generations of SARS-CoV-2 sequences were done using a fully automated protein structure homology modeling server (SWISS-MODEL) (https://swissmodel.expasy.org/) for comparative modeling [21]. Ab initio modeling was performed using the QUARK server (https://zhanglab.ccmb.med.umich.edu/QUARK/). The FASTA sequences were pasted into the SWISS-MODEL server, and the best template model was chosen based on the Global Model Quality Estimation (GMQE). The highest percentage 
of query coverage and sequence identity were considered when sorting out the best protein models. The top-ranked 3-D protein models were generated and saved as a PDB file. Chimera version 1.8.1 was then used to view the 3 -D structures.

\subsection{Protein model evaluation.}

The non-bond interactions of the 3D protein model of the SARS-CoV-2 strain's structural and accessory protein sequences were analyzed by using the ERRAT tool [22]. The verification of the 3D model compatibility of the sequences with their amino acid sequences was performed using Verify 3D program [23]. The validation of the SARS-CoV-2 strain's structural accessory protein structures was determined using PROCHECK (Ramachandran Plot) to analyze the residue and overall structure geometry [24].

\subsection{Biochemical function prediction.}

The biochemical SARS-CoV-2 strain's structural and accessory protein functions from 3D predicted structures were analyzed using the ProFunc server ((http://www.ebi.ac.uk/thornton-srv/databases/ProFunc) [25]. The summary of the predicted function of the proteins involves cellular components, biological processes, and biochemical functions [18].

\subsection{Functional annotation of sequences.}

InterProScan ((http://www.ebi.ac.uk/InterProScan/) was used for the classification of SARS-CoV-2 strain's structural and accessory based on the protein families and their domains [26].

\subsection{Active site identification.}

The binding sites and the target proteins' cavities were computed using active site prediction of protein server (SCFBio) [27].

\subsection{Molecular phylogenetic analysis.}

The SARS- CoV-2 accessory proteins, ORF10, ORF8, and ORF6 of pangolin coronavirus (GI: 1817836146), human severe acute respiratory syndrome coronavirus (GI: 1836444959), human severe acute respiratory syndrome coronavirus 2 (GI: 1835438422), bat coronavirus RacCS271 (GI: 1954663994) and civet SARS CoV 007/2004 (GI: 51475458) were retrieved from NCBI database for evolutionary analysis. ClustalW 1.6, which is included in the MEGA X software, was used to align the amino sequences for the phylogenetic study [28]. The evolutionary history was inferred by using Maximum Parsimony Tree methods [34]. The replicate trees' percentage in which the associated taxa clustered together in the bootstrap test (1000 replicates). The initial tree(s) for the heuristic search were automatically acquired using the Neighbor-Joining method [28]. 


\section{Results and Discussion}

\subsection{Sequence retrieval.}

On $25^{\text {th }}$ January 2020, Malaysia reported the first COVID-19 positive case within fortyeight hours after the first case was reported in Singapore. On $3^{\text {rd }}$ February 2020, the first Malaysian tested positive for COVID-19, which had a history of business meetings traveling to Singapore's neighbor country. He attended a meeting with China delegates [29]. Once he returned from Singapore, that 41-years older adult developed a fever and a cough. He was quarantined at Sungai Buloh Hospital, Selangor. On $6^{\text {th }}$ February 2020, a 40-year-old female Malaysian whom younger sister of that first reported 41-year-old man was confirmed with COVID-19 positive. She was the first COVID-19 patient who was affected through local transmission since she had no travel history to infected areas. She was isolated at Sultanah Bahiyah Hospital, Alor Setar, on $3^{\text {rd }}$ February 2020 [30].

On $12^{\text {th }}$ March 2020, Malaysia reported the first COVID-19 sporadic case where the infected person either had a travel history to an infected area or had close contact with an infected person [31]. In March 2020, there was an exponential rise of COVID-19 cases after a religious mass gathering event took place at Sri Petaling, Kuala Lumpur, for 4-days with 1,600 participants [32]. About 1,500 people participated from outside Malaysia. The highest number of COVID-19 positive cases was recorded in South East Asia. Since then, the transmissions of sporadic cases among the local community were reported. The Prime Minister of Malaysia was declared a Movement Control Order (MCO) on 16 ${ }^{\text {th }}$ March 2020 after COVID-19 positive cases increased exponentially in order to reduce the spread of COVID-19 [33]. Authorities had instructed to trace the close contacts of the infected individual and to hospitalize the infected person until their recovery or death. RT-PCR was used to detect whether a person is infected with SARS-CoV-2 or not.

The amino acid sequences of the Malaysia SARS-CoV-2 strain were deposited in NCBI. The descriptions of the total of 75 SARS-CoV-2 strain's structural and accessory amino acid sequences identified in Malaysia were obtained from the NCBI protein database and tabulated (Table 1).

Table 1. The SARS-CoV-2 strain's structural and accessory proteins that identified in Malaysia.

\begin{tabular}{|c|c|c|c|c|c|c|c|}
\hline No. & Gene ID & Description & Source & $\begin{array}{l}\text { Number of } \\
\text { Amino } \\
\text { Acids }\end{array}$ & $\begin{array}{l}\text { Accession } \\
\text { Number }\end{array}$ & $\begin{array}{l}\text { Author of } \\
\text { Article }\end{array}$ & $\begin{array}{l}\text { Date of } \\
\text { Article } \\
\text { Published } \\
\end{array}$ \\
\hline 1 & 1914445506 & $\begin{array}{l}\text { Severe acute } \\
\text { respiratory } \\
\text { system }\end{array}$ & $\begin{array}{l}\text { Homo } \\
\text { sapiens }\end{array}$ & 38 & Q0153601 & Ahmad, H.F & $7 / 10 / 2020$ \\
\hline 2 & 1914445505 & $\begin{array}{l}\text { Severe acute } \\
\text { respiratory } \\
\text { system }\end{array}$ & $\begin{array}{l}\text { Homo } \\
\text { sapiens }\end{array}$ & 419 & QO153600 & Ahmad, H.F & $7 / 10 / 2020$ \\
\hline 3 & 1914445504 & $\begin{array}{l}\text { Severe acute } \\
\text { respiratory } \\
\text { system }\end{array}$ & $\begin{array}{l}\text { Homo } \\
\text { sapiens }\end{array}$ & 121 & Q0153599 & Ahmad, H.F & $7 / 10 / 2020$ \\
\hline 4 & 1914445503 & $\begin{array}{l}\text { Severe acute } \\
\text { respiratory } \\
\text { system }\end{array}$ & $\begin{array}{l}\text { Homo } \\
\text { sapiens }\end{array}$ & 43 & Q0163598 & Ahmad, H.F & $7 / 10 / 2020$ \\
\hline 5 & 1914445502 & $\begin{array}{l}\text { Severe acute } \\
\text { respiratory } \\
\text { system }\end{array}$ & $\begin{array}{l}\text { Homo } \\
\text { sapiens }\end{array}$ & 121 & Q0153597 & Ahmad, H.F & $7 / 10 / 2020$ \\
\hline 6 & 1914445501 & $\begin{array}{l}\text { Severe acute } \\
\text { respiratory } \\
\text { system }\end{array}$ & $\begin{array}{l}\text { Homo } \\
\text { sapiens }\end{array}$ & 61 & Q0153596 & $\begin{array}{l}\text { Ahmad, } \\
\text { H.F }\end{array}$ & $7 / 10 / 2020$ \\
\hline
\end{tabular}




\begin{tabular}{|c|c|c|c|c|c|c|c|}
\hline No. & Gene ID & Description & Source & $\begin{array}{l}\text { Number of } \\
\text { Amino } \\
\text { Acids }\end{array}$ & $\begin{array}{l}\text { Accession } \\
\text { Number }\end{array}$ & $\begin{array}{l}\text { Author of } \\
\text { Article }\end{array}$ & $\begin{array}{l}\text { Date of } \\
\text { Article } \\
\text { Published }\end{array}$ \\
\hline 7 & 1914445500 & $\begin{array}{l}\text { Severe acute } \\
\text { respiratory } \\
\text { system }\end{array}$ & $\begin{array}{l}\text { Homo } \\
\text { sapiens }\end{array}$ & 222 & Q0153595 & Ahmad, H.F & $7 / 10 / 2020$ \\
\hline 8 & 1914445499 & $\begin{array}{l}\text { Severe acute } \\
\text { respiratory } \\
\text { system }\end{array}$ & $\begin{array}{l}\text { Homo } \\
\text { sapiens }\end{array}$ & 75 & QOI53594 & Ahmad, H.F & $7 / 10 / 2020$ \\
\hline 9 & 1914445498 & $\begin{array}{l}\text { Severe acute } \\
\text { respiratory } \\
\text { system }\end{array}$ & $\begin{array}{l}\text { Homo } \\
\text { sapiens }\end{array}$ & 275 & QOI53593 & Ahmad, H.F & $7 / 10 / 2020$ \\
\hline 10 & 1914445497 & $\begin{array}{l}\text { Severe acute } \\
\text { respiratory } \\
\text { system }\end{array}$ & $\begin{array}{l}\text { Homo } \\
\text { sapiens }\end{array}$ & 1273 & QOI53592 & Ahmad, H.F & $7 / 10 / 2020$ \\
\hline 11 & 1914445496 & $\begin{array}{l}\text { Severe acute } \\
\text { respiratory } \\
\text { system }\end{array}$ & $\begin{array}{l}\text { Homo } \\
\text { sapiens }\end{array}$ & 4405 & QOI53591 & Ahmad, H.F & $7 / 10 / 2020$ \\
\hline 12 & 1914445495 & $\begin{array}{l}\text { Severe acute } \\
\text { respiratory } \\
\text { system }\end{array}$ & $\begin{array}{l}\text { Homo } \\
\text { sapiens }\end{array}$ & 7096 & QOI53590 & Ahmad, H.F & $7 / 10 / 2020$ \\
\hline 13 & 1914445474 & $\begin{array}{l}\text { Severe acute } \\
\text { respiratory } \\
\text { system }\end{array}$ & $\begin{array}{l}\text { Homo } \\
\text { sapiens }\end{array}$ & 38 & QOI53589 & Ahmad, H.F & $7 / 10 / 2020$ \\
\hline 14 & 1914445473 & $\begin{array}{l}\text { Severe acute } \\
\text { respiratory } \\
\text { system }\end{array}$ & $\begin{array}{l}\text { Homo } \\
\text { sapiens }\end{array}$ & 419 & QOI53588 & Ahmad, H.F & $7 / 10 / 2020$ \\
\hline 15 & 1914445472 & $\begin{array}{l}\text { Severe acute } \\
\text { respiratory } \\
\text { system }\end{array}$ & $\begin{array}{l}\text { Homo } \\
\text { sapiens }\end{array}$ & 121 & QOI53587 & Ahmad, H.F & $7 / 10 / 2020$ \\
\hline 16 & 1914445471 & $\begin{array}{l}\text { Severe acute } \\
\text { respiratory } \\
\text { system }\end{array}$ & $\begin{array}{l}\text { Homo } \\
\text { sapiens }\end{array}$ & 43 & QOI53586 & Ahmad, H.F & $7 / 10 / 2020$ \\
\hline 17 & 1914445470 & $\begin{array}{l}\text { Severe acute } \\
\text { respiratory } \\
\text { system }\end{array}$ & $\begin{array}{l}\text { Homo } \\
\text { sapiens }\end{array}$ & 121 & QOI53585 & Ahmad, H.F & $7 / 10 / 2020$ \\
\hline 18 & 1914445469 & $\begin{array}{l}\text { Severe acute } \\
\text { respiratory } \\
\text { system }\end{array}$ & $\begin{array}{l}\text { Homo } \\
\text { sapiens }\end{array}$ & 61 & QOI53584 & Ahmad, H.F & $7 / 10 / 2020$ \\
\hline 19 & 1914445468 & $\begin{array}{l}\text { Severe acute } \\
\text { respiratory } \\
\text { system }\end{array}$ & $\begin{array}{l}\text { Homo } \\
\text { sapiens }\end{array}$ & 222 & QOI53583 & Ahmad, H.F & $7 / 10 / 2020$ \\
\hline 20 & 1914445467 & $\begin{array}{l}\text { Severe acute } \\
\text { respiratory } \\
\text { system }\end{array}$ & $\begin{array}{l}\text { Homo } \\
\text { sapiens }\end{array}$ & 75 & QOI53582 & Ahmad, H.F & $7 / 10 / 2020$ \\
\hline 21 & 1914445466 & $\begin{array}{l}\text { Severe acute } \\
\text { respiratory } \\
\text { system }\end{array}$ & $\begin{array}{l}\text { Homo } \\
\text { sapiens }\end{array}$ & 275 & QOI53581 & Ahmad, H.F & $7 / 10 / 2020$ \\
\hline 22 & 1914445465 & $\begin{array}{l}\text { Severe acute } \\
\text { respiratory } \\
\text { system }\end{array}$ & $\begin{array}{l}\text { Homo } \\
\text { sapiens }\end{array}$ & 1273 & QOI53580 & Ahmad, H.F & $7 / 10 / 2020$ \\
\hline 23 & 1914445464 & $\begin{array}{l}\text { Severe acute } \\
\text { respiratory } \\
\text { system }\end{array}$ & $\begin{array}{l}\text { Homo } \\
\text { sapiens }\end{array}$ & 4405 & QOI53579 & Ahmad, H.F & $7 / 10 / 2020$ \\
\hline 24 & 1914445463 & $\begin{array}{l}\text { Severe acute } \\
\text { respiratory } \\
\text { system }\end{array}$ & $\begin{array}{l}\text { Homo } \\
\text { sapiens }\end{array}$ & 7096 & QOI53578 & Ahmad, H.F & $7 / 10 / 2020$ \\
\hline 25 & 1834374001 & $\begin{array}{l}\text { Severe acute } \\
\text { respiratory } \\
\text { system }\end{array}$ & $\begin{array}{l}\text { Homo } \\
\text { sapiens }\end{array}$ & 222 & QJD23261 & Chan, Y.F & $7 / 10 / 2020$ \\
\hline 26 & 1834373991 & $\begin{array}{l}\text { Severe acute } \\
\text { respiratory } \\
\text { system }\end{array}$ & $\begin{array}{l}\text { Homo } \\
\text { sapiens }\end{array}$ & 222 & QJD23252 & Chan, Y.F & $7 / 10 / 2020$ \\
\hline 27 & 1834374010 & $\begin{array}{l}\text { Severe acute } \\
\text { respiratory } \\
\text { system }\end{array}$ & $\begin{array}{l}\text { Homo } \\
\text { sapiens }\end{array}$ & 1273 & QJD23270 & Chan, Y.F & $7 / 10 / 2020$ \\
\hline 28 & 1834373988 & $\begin{array}{l}\text { Severe acute } \\
\text { respiratory } \\
\text { system }\end{array}$ & $\begin{array}{l}\text { Homo } \\
\text { sapiens }\end{array}$ & 1273 & QJD23249 & Chan, Y.F & $7 / 10 / 2020$ \\
\hline
\end{tabular}




\begin{tabular}{|c|c|c|c|c|c|c|c|}
\hline No. & Gene ID & Description & Source & $\begin{array}{l}\text { Number of } \\
\text { Amino } \\
\text { Acids }\end{array}$ & $\begin{array}{l}\text { Accession } \\
\text { Number }\end{array}$ & $\begin{array}{l}\text { Author of } \\
\text { Article }\end{array}$ & $\begin{array}{l}\text { Date of } \\
\text { Article } \\
\text { Published }\end{array}$ \\
\hline 29 & 1834374009 & $\begin{array}{l}\text { Severe acute } \\
\text { respiratory } \\
\text { system }\end{array}$ & $\begin{array}{l}\text { Homo } \\
\text { sapiens }\end{array}$ & 4386 & QJD23269 & Chan, Y.F & $7 / 10 / 2020$ \\
\hline 30 & 1834374008 & $\begin{array}{l}\text { Severe acute } \\
\text { respiratory } \\
\text { system }\end{array}$ & $\begin{array}{l}\text { Homo } \\
\text { sapiens }\end{array}$ & 7077 & QJD23268 & Chan, Y.F & $7 / 10 / 2020$ \\
\hline 31 & 1834374007 & $\begin{array}{l}\text { Severe acute } \\
\text { respiratory } \\
\text { system }\end{array}$ & $\begin{array}{l}\text { Homo } \\
\text { sapiens }\end{array}$ & 38 & QJD23267 & Chan, Y.F & $7 / 10 / 2020$ \\
\hline 32 & 1834374006 & $\begin{array}{l}\text { Severe acute } \\
\text { respiratory } \\
\text { system }\end{array}$ & $\begin{array}{l}\text { Homo } \\
\text { sapiens }\end{array}$ & 419 & QJD23266 & Chan, Y.F & $7 / 10 / 2020$ \\
\hline 33 & 1834374005 & $\begin{array}{l}\text { Severe acute } \\
\text { respiratory } \\
\text { system }\end{array}$ & $\begin{array}{l}\text { Homo } \\
\text { sapiens }\end{array}$ & 121 & QJD23265 & Chan, Y.F & $7 / 10 / 2020$ \\
\hline 34 & 1834374004 & $\begin{array}{l}\text { Severe acute } \\
\text { respiratory } \\
\text { system }\end{array}$ & $\begin{array}{l}\text { Homo } \\
\text { sapiens }\end{array}$ & 43 & QJD23264 & Chan, Y.F & $7 / 10 / 2020$ \\
\hline 35 & 1834374003 & $\begin{array}{l}\text { Severe acute } \\
\text { respiratory } \\
\text { system }\end{array}$ & $\begin{array}{l}\text { Homo } \\
\text { sapiens }\end{array}$ & 121 & QJD23263 & Chan, Y.F & $7 / 10 / 2020$ \\
\hline 36 & 1834374002 & $\begin{array}{l}\text { Severe acute } \\
\text { respiratory } \\
\text { system }\end{array}$ & $\begin{array}{l}\text { Homo } \\
\text { sapiens }\end{array}$ & 61 & QJD23262 & Chan, Y.F & $7 / 10 / 2020$ \\
\hline 37 & 1834374000 & $\begin{array}{l}\text { Severe acute } \\
\text { respiratory } \\
\text { system }\end{array}$ & $\begin{array}{l}\text { Homo } \\
\text { sapiens }\end{array}$ & 75 & QJD23260 & Chan, Y.F & $7 / 10 / 2020$ \\
\hline 38 & 1834373999 & $\begin{array}{l}\text { Severe acute } \\
\text { respiratory } \\
\text { system }\end{array}$ & $\begin{array}{l}\text { Homo } \\
\text { sapiens }\end{array}$ & 275 & QJD23259 & Chan, Y.F & $7 / 10 / 2020$ \\
\hline 39 & 1834373997 & $\begin{array}{l}\text { Severe acute } \\
\text { respiratory } \\
\text { system }\end{array}$ & $\begin{array}{l}\text { Homo } \\
\text { sapiens }\end{array}$ & 38 & QJD23258 & Chan, Y.F & $7 / 10 / 2020$ \\
\hline 40 & 1834373996 & $\begin{array}{l}\text { Severe acute } \\
\text { respiratory } \\
\text { system }\end{array}$ & $\begin{array}{l}\text { Homo } \\
\text { sapiens }\end{array}$ & 419 & QJD23257 & Chan, Y.F & $7 / 10 / 2020$ \\
\hline 41 & 1834373995 & $\begin{array}{l}\text { Severe acute } \\
\text { respiratory } \\
\text { system }\end{array}$ & $\begin{array}{l}\text { Homo } \\
\text { sapiens }\end{array}$ & 121 & QJD23256 & Chan, Y.F & $7 / 10 / 2020$ \\
\hline 42 & 1834373994 & $\begin{array}{l}\text { Severe acute } \\
\text { respiratory } \\
\text { system }\end{array}$ & $\begin{array}{l}\text { Homo } \\
\text { sapiens }\end{array}$ & 43 & QJD23255 & Chan, Y.F & $7 / 10 / 2020$ \\
\hline 43 & 1834373993 & $\begin{array}{l}\text { Severe acute } \\
\text { respiratory } \\
\text { system }\end{array}$ & $\begin{array}{l}\text { Homo } \\
\text { sapiens }\end{array}$ & 121 & QJD23254 & Chan, Y.F & $7 / 10 / 2020$ \\
\hline 44 & 1834373992 & $\begin{array}{l}\text { Severe acute } \\
\text { respiratory } \\
\text { system }\end{array}$ & $\begin{array}{l}\text { Homo } \\
\text { sapiens }\end{array}$ & 61 & QJD23253 & Chan, Y.F & $7 / 10 / 2020$ \\
\hline 45 & 1834373990 & $\begin{array}{l}\text { Severe acute } \\
\text { respiratory } \\
\text { system }\end{array}$ & $\begin{array}{l}\text { Homo } \\
\text { sapiens }\end{array}$ & 75 & QJD23251 & Chan, Y.F & $7 / 10 / 2020$ \\
\hline 46 & 1834373989 & $\begin{array}{l}\text { Severe acute } \\
\text { respiratory } \\
\text { system }\end{array}$ & $\begin{array}{l}\text { Homo } \\
\text { sapiens }\end{array}$ & 275 & QJD23250 & Chan, Y.F & $7 / 10 / 2020$ \\
\hline 47 & 1834373987 & $\begin{array}{l}\text { Severe acute } \\
\text { respiratory } \\
\text { system }\end{array}$ & $\begin{array}{l}\text { Homo } \\
\text { sapiens }\end{array}$ & 4405 & QJD23250 & Chan, Y.F & $7 / 10 / 2020$ \\
\hline 48 & 1834373986 & $\begin{array}{l}\text { Severe acute } \\
\text { respiratory } \\
\text { system }\end{array}$ & $\begin{array}{l}\text { Homo } \\
\text { sapiens }\end{array}$ & 7096 & QJD23247 & Chan, Y.F & $7 / 10 / 2020$ \\
\hline 49 & 1834373984 & $\begin{array}{l}\text { Severe acute } \\
\text { respiratory } \\
\text { system }\end{array}$ & $\begin{array}{l}\text { Homo } \\
\text { sapiens }\end{array}$ & 38 & QJD23246 & Chan, Y.F & $7 / 10 / 2020$ \\
\hline 50 & 1834373983 & $\begin{array}{l}\text { Severe acute } \\
\text { respiratory } \\
\text { system }\end{array}$ & $\begin{array}{l}\text { Homo } \\
\text { sapiens }\end{array}$ & 419 & QJD23245 & Chan, Y.F & $7 / 10 / 2020$ \\
\hline
\end{tabular}




\begin{tabular}{|c|c|c|c|c|c|c|c|}
\hline No. & Gene ID & Description & Source & $\begin{array}{l}\text { Number of } \\
\text { Amino } \\
\text { Acids }\end{array}$ & $\begin{array}{l}\text { Accession } \\
\text { Number }\end{array}$ & $\begin{array}{l}\text { Author of } \\
\text { Article }\end{array}$ & $\begin{array}{l}\text { Date of } \\
\text { Article } \\
\text { Published }\end{array}$ \\
\hline 51 & 1834373982 & $\begin{array}{l}\text { Severe acute } \\
\text { respiratory } \\
\text { system }\end{array}$ & $\begin{array}{l}\text { Homo } \\
\text { sapiens }\end{array}$ & 121 & QJD23244 & Chan, Y.F & $7 / 10 / 2020$ \\
\hline 52 & 1834373981 & $\begin{array}{l}\text { Severe acute } \\
\text { respiratory } \\
\text { system }\end{array}$ & $\begin{array}{l}\text { Homo } \\
\text { sapiens }\end{array}$ & 43 & QJD23243 & Chan, Y.F & $7 / 10 / 2020$ \\
\hline 53 & 1834373980 & $\begin{array}{l}\text { Severe acute } \\
\text { respiratory } \\
\text { system }\end{array}$ & $\begin{array}{l}\text { Homo } \\
\text { sapiens }\end{array}$ & 121 & QJD23242 & Chan, Y.F & $7 / 10 / 2020$ \\
\hline 54 & 1834373979 & $\begin{array}{l}\text { Severe acute } \\
\text { respiratory } \\
\text { system }\end{array}$ & $\begin{array}{l}\text { Homo } \\
\text { sapiens }\end{array}$ & 61 & QJD23241 & Chan, Y.F & $7 / 10 / 2020$ \\
\hline 55 & 1834373978 & $\begin{array}{l}\text { Severe acute } \\
\text { respiratory } \\
\text { system }\end{array}$ & $\begin{array}{l}\text { Homo } \\
\text { sapiens }\end{array}$ & 222 & QJD23240 & Chan, Y.F & $7 / 10 / 2020$ \\
\hline 56 & 1834373977 & $\begin{array}{l}\text { Severe acute } \\
\text { respiratory } \\
\text { system }\end{array}$ & $\begin{array}{l}\text { Homo } \\
\text { sapiens }\end{array}$ & 75 & QJD23239 & Chan, Y.F & $7 / 10 / 2020$ \\
\hline 57 & 1834373976 & $\begin{array}{l}\text { Severe acute } \\
\text { respiratory } \\
\text { system }\end{array}$ & $\begin{array}{l}\text { Homo } \\
\text { sapiens }\end{array}$ & 275 & QJD23238 & Chan, Y.F & $7 / 10 / 2020$ \\
\hline 58 & 1834373975 & $\begin{array}{l}\text { Severe acute } \\
\text { respiratory } \\
\text { system }\end{array}$ & $\begin{array}{l}\text { Homo } \\
\text { sapiens }\end{array}$ & 1273 & QJD23237 & Chan, Y.F & $7 / 10 / 2020$ \\
\hline 59 & 1834373974 & $\begin{array}{l}\text { Severe acute } \\
\text { respiratory } \\
\text { system }\end{array}$ & $\begin{array}{l}\text { Homo } \\
\text { sapiens }\end{array}$ & 4405 & QJD23236 & Chan, Y.F & $7 / 10 / 2020$ \\
\hline 60 & 1834373973 & $\begin{array}{l}\text { Severe acute } \\
\text { respiratory } \\
\text { system }\end{array}$ & $\begin{array}{l}\text { Homo } \\
\text { sapiens }\end{array}$ & 7096 & QJD23235 & Chan, Y.F & $7 / 10 / 2020$ \\
\hline 61 & 1834373971 & $\begin{array}{l}\text { Severe acute } \\
\text { respiratory } \\
\text { system }\end{array}$ & $\begin{array}{l}\text { Homo } \\
\text { sapiens }\end{array}$ & 38 & QJD23234 & Chan, Y.F & $7 / 10 / 2020$ \\
\hline 62 & 1834373970 & $\begin{array}{l}\text { Severe acute } \\
\text { respiratory } \\
\text { system }\end{array}$ & $\begin{array}{l}\text { Homo } \\
\text { sapiens }\end{array}$ & 419 & QJD23233 & Chan, Y.F & $7 / 10 / 2020$ \\
\hline 63 & 1834373969 & $\begin{array}{l}\text { Severe acute } \\
\text { respiratory } \\
\text { system }\end{array}$ & $\begin{array}{l}\text { Homo } \\
\text { sapiens }\end{array}$ & 121 & QJD23232 & Chan, Y.F & $7 / 10 / 2020$ \\
\hline 64 & 1834373968 & $\begin{array}{l}\text { Severe acute } \\
\text { respiratory } \\
\text { system }\end{array}$ & $\begin{array}{l}\text { Homo } \\
\text { sapiens }\end{array}$ & 43 & QJD23231 & Chan, Y.F & $7 / 10 / 2020$ \\
\hline 65 & 1834373967 & $\begin{array}{l}\text { Severe acute } \\
\text { respiratory } \\
\text { system }\end{array}$ & $\begin{array}{l}\text { Homo } \\
\text { sapiens }\end{array}$ & 121 & QJD23230 & Chan, Y.F & $7 / 10 / 2020$ \\
\hline 66 & 1834373966 & $\begin{array}{l}\text { Severe acute } \\
\text { respiratory } \\
\text { system }\end{array}$ & $\begin{array}{l}\text { Homo } \\
\text { sapiens }\end{array}$ & 61 & QJD23229 & Chan, Y.F & $7 / 10 / 2020$ \\
\hline 67 & 1834373965 & $\begin{array}{l}\text { Severe acute } \\
\text { respiratory } \\
\text { system }\end{array}$ & $\begin{array}{l}\text { Homo } \\
\text { sapiens }\end{array}$ & 222 & QJD23228 & Chan, Y.F & $7 / 10 / 2020$ \\
\hline 68 & 1834373964 & $\begin{array}{l}\text { Severe acute } \\
\text { respiratory } \\
\text { system }\end{array}$ & $\begin{array}{l}\text { Homo } \\
\text { sapiens }\end{array}$ & 75 & QJD23227 & Chan, Y.F & $7 / 10 / 2020$ \\
\hline 69 & 1834373963 & $\begin{array}{l}\text { Severe acute } \\
\text { respiratory } \\
\text { system }\end{array}$ & $\begin{array}{l}\text { Homo } \\
\text { sapiens }\end{array}$ & 275 & QJD23226 & Chan, Y.F & $7 / 10 / 2020$ \\
\hline 70 & 1834373963 & $\begin{array}{l}\text { Severe acute } \\
\text { respiratory } \\
\text { system }\end{array}$ & $\begin{array}{l}\text { Homo } \\
\text { sapiens }\end{array}$ & 1273 & QJD23225 & Chan, Y.F & $7 / 10 / 2020$ \\
\hline 71 & 1834373961 & $\begin{array}{l}\text { Severe acute } \\
\text { respiratory } \\
\text { system }\end{array}$ & $\begin{array}{l}\text { Homo } \\
\text { sapiens }\end{array}$ & 4405 & QJD23224 & Chan, Y.F & $7 / 10 / 2020$ \\
\hline 72 & 1834373960 & $\begin{array}{l}\text { Severe acute } \\
\text { respiratory } \\
\text { system }\end{array}$ & $\begin{array}{l}\text { Homo } \\
\text { sapiens }\end{array}$ & 7096 & QJD23223 & Chan, Y.F & $7 / 10 / 2020$ \\
\hline
\end{tabular}




\begin{tabular}{|c|c|c|c|c|c|c|c|}
\hline No. & Gene ID & Description & Source & $\begin{array}{l}\text { Number of } \\
\text { Amino } \\
\text { Acids }\end{array}$ & $\begin{array}{l}\text { Accession } \\
\text { Number }\end{array}$ & $\begin{array}{l}\text { Author of } \\
\text { Article }\end{array}$ & $\begin{array}{l}\text { Date of } \\
\text { Article } \\
\text { Published }\end{array}$ \\
\hline 73 & 1809484492 & $\begin{array}{l}\text { Severe acute } \\
\text { respiratory } \\
\text { system }\end{array}$ & $\begin{array}{l}\text { Homo } \\
\text { sapiens }\end{array}$ & 96 & QIA98594 & $\begin{array}{l}\text { Yu Kie, C., } \\
\text { Norazimah, } \\
\text { T., Rehan } \\
\text { Shuhada, } \\
\text { A.B., } \\
\text { Selvanesan, } \\
\text { S., } \\
\text { Noorliza, } \\
\text { M.N. and } \\
\text { Hani, M.H. }\end{array}$ & $7 / 10 / 2020$ \\
\hline 74 & 1809484490 & $\begin{array}{l}\text { Severe acute } \\
\text { respiratory } \\
\text { system }\end{array}$ & $\begin{array}{l}\text { Homo } \\
\text { sapiens }\end{array}$ & 96 & QIA98593 & $\begin{array}{l}\text { Yu Kie, C., } \\
\text { Norazimah, } \\
\text { T., Rehan } \\
\text { Shuhada, } \\
\text { A.B., } \\
\text { Selvanesan, } \\
\text { S., } \\
\text { Noorliza, } \\
\text { M.N. and } \\
\text { Hani, M.H. }\end{array}$ & $7 / 10 / 2020$ \\
\hline 75 & 1809484488 & $\begin{array}{l}\text { Severe acute } \\
\text { respiratory } \\
\text { system }\end{array}$ & $\begin{array}{l}\text { Homo } \\
\text { sapiens }\end{array}$ & 96 & QIA98592 & $\begin{array}{l}\text { Yu Kie, C., } \\
\text { Norazimah, } \\
\text { T., Rehan } \\
\text { Shuhada, } \\
\text { A.B., } \\
\text { Selvanesan, } \\
\text { S., } \\
\text { Noorliza, } \\
\text { M.N. and } \\
\text { Hani, M.H. }\end{array}$ & $7 / 10 / 2020$ \\
\hline
\end{tabular}

\subsection{Physiochemical character analysis.}

The various physiochemical properties that can be deduced from the Malaysia SARSCoV-2 strain's structural and accessory protein sequences were computed using the ProtParam tool. The parameters computed by ProtParam include the molecular weight, theoretical pI, chemical formula, instability index, aliphatic index, and grand average of hydropathicity (GRAVY), shown in Table 2.

In ProtParam, the average isotopic masses of amino acids in the given protein are added to the average isotopic mass of one water molecule to compute the molecular weight of the protein. The pKa values of amino acids are used to compute the protein $\mathrm{pI}$. The side chain of amino acid determines its $\mathrm{pKa}$ value. It plays a crucial role in determining a protein's $\mathrm{pH}$ dependent properties. As shown in Table 2, the computed isoelectric point (pI) value indicates acidic characteristic when less than 7 and alkaline characteristic when more than 7 . Based on the results, the pI value and molecular weight (Da) for ORF10 protein (QOI53601) were 7.93 and 4449.23, nucleocapsid phosphoprotein (QOI53600) was 10.07 and 45641.74, ORF8 protein (QOI53599) was 5.42 and 13831.01, ORF7b was 4.17 and 5180.27, ORF7a protein (QOI53598) was 8.23 and 13744.17, ORF6 protein (QOI53596) was 4.60 and 7272.54, membrane glycoprotein (QOI53595) was 9.51 and 25146.62, an envelope protein (QOI53594) was 8.57 and 8365.04, ORF3a protein (QOI53593) was 5.55 and 31122.94, surface glycoprotein (QOI53592) was 6.24 and 141160.44, ORF1a polyprotein (QOI53591) was 6.05 and 490048.1, ORF1ab polyprotein (QOI53590) was 6.33 and 794145.11and orf1ab polyprotein, partial (QJD23268) was 8.90 and 11239.26.

The instability index is a measurement of a protein's stability in a test tube. A protein with an instability index of less than 40 is considered stable; a number of more than 40 indicates 
that the protein could be unstable [17]. Therefore, based on Table 2, ORF10 protein, ORF6 protein, membrane glycoprotein, envelope protein, ORF3a protein, surface glycoprotein ORF1a polyprotein, ORF1ab polyprotein, and ORF1ab (partial) polyprotein are considered stable.

The proportional volume filled by aliphatic side chains such as alanine, valine, isoleucine, and leucine is characterized as the aliphatic index of a protein. It could be viewed as a beneficial factor in the increase of globular protein thermostability. The grand average of hydropathy (GRAVY) value for a peptide or protein is measured as the total of all the amino acids' hydropathy values that are divided by the residues' number in the sequence. Based on the GRAVY index values in Table 2, the results show that the proteins analyzed contain both hydrophilic (negative GRAVY value) and hydrophobic (positive GRAVY value) in nature. Nucleocapsid phosphoprotein with a GRAVY value of -0.958 is the most potent hydrophilic molecule, while ORF7b is the most potent hydrophobic with a GRAVY value of 1.449 .

\subsection{Secondary structure prediction.}

The secondary structures such as alpha-helix, extended strand, beta-turn, and the random coil of Malaysia SARS-CoV-2 strain's structural and accessory protein sequences were obtained by the SOPMA tool (Table 3). The composition of $\alpha$ helix for Malaysia SARS-CoV2 protein sequences was shown in Table 4. ORF1ab polyprotein had the longest $\alpha$-helix residues (124), while ORF10 protein had the shortest $\alpha$-helix residues [11]. Based on this study, the longer SARS-CoV-2 amino acid sequences have the higher $\alpha$-helix residues values; therefore, $\alpha$-helix residue values are different for each strain based on their sequence length. The $\alpha$-helices in target proteins are developed by the hydrogen bond between carboxy $(\mathrm{C}=\mathrm{O})$ terminal and amino $(\mathrm{N}=\mathrm{H})$ terminal groups that are close together in the polypeptide chain. The significance of the helix is to create the dipole moments between the small charged molecules (drug) to the target protein (SARS-CoV-2 protein). The individual peptide dipoles in helices contribute to making a macrodipole, with the amino-terminal end of the helix polarized positively and the carboxy-terminal end polarized negatively. In helices, favorable electrostatic interactions are established between positively charged species and the end of the helix dipole, whereas negatively charged side chains and cations interacting with the carboxyterminal ends [34].

\subsection{Homology modeling.}

The top-ranked 3-D SARS-CoV-2 protein models were generated based on the selected template using comparative modeling and $a b$ initio modeling methods (Table 5). When the sequence identity in a sequence alignment falls below 20\%, homology modeling may not generate a good prediction, whereas ab initio modeling can produce a significant result. The best template was chosen based on the highest percentage of query coverage, sequence identity, and QMQE. The amino acid sequence of the template was statistically significant if all these criteria met up. All the target proteins were created using comparative modeling (ORF1ab, ORF1a, surface glycoprotein, ORF3a, envelope, ORF7a, nucleocapsid phosphoprotein, and ORF8) except membrane protein, ORF6, and ORF7b ( $a$ b initio modeling). A total of 53 protein models were developed successfully out of 75 protein sequences. No suitable templates were found for the balance 22 protein sequences. 
Table 2. Physiochemical parameters of Malaysia SARS CoV-2 strain's structural and accessory proteins.

\begin{tabular}{|c|c|c|c|c|c|c|c|c|}
\hline Protein & Accession no. & Length & MW (Da) & pI & Chemical formula & Instability index & Aliphatic index & $\begin{array}{l}\text { Grand average of } \\
\text { hydropathicity (GRAVY) }\end{array}$ \\
\hline ORF10 protein & QOI53601 & 38 & 4449.23 & 7.93 & $\mathrm{C}_{206} \mathrm{H}_{312} \mathrm{~N}_{50054} \mathrm{~S}_{3}$ & 16.06 & 107.63 & 0.637 \\
\hline nucleocapsid phosphoprotein & QOI53600 & 419 & 45641.74 & 10.07 & $\mathrm{C}_{1972} \mathrm{H}_{3141} \mathrm{~N}_{607} \mathrm{O}_{629} \mathrm{~S}_{7}$ & 55.27 & 53.46 & -0.958 \\
\hline ORF8 protein & QOI53599 & 121 & 13831.01 & 5.42 & $\mathrm{C}_{633} \mathrm{H}_{961} \mathrm{~N}_{155} \mathrm{O}_{177} \mathrm{~S}_{8}$ & 45.79 & 97.36 & 0.219 \\
\hline ORF7b & QOI53598 & 43 & 5180.27 & 4.17 & $\mathrm{C}_{251} \mathrm{H}_{374} \mathrm{~N}_{50} \mathrm{O}_{60} \mathrm{~S}_{4}$ & 50.96 & 156.51 & 1.449 \\
\hline ORF7a protein & QOI53597 & 121 & 13744.17 & 8.23 & $\mathrm{C}_{633} \mathrm{H}_{988} \mathrm{~N}_{156} \mathrm{O}_{171} \mathrm{~S}_{7}$ & 48.66 & 100.74 & 0.318 \\
\hline ORF6 protein & QOI53596 & 61 & 7272.54 & 4.60 & $\mathrm{C}_{334} \mathrm{H}_{532} \mathrm{~N}_{78} \mathrm{O}_{96} \mathrm{~S}_{3}$ & 31.16 & 130.98 & 0.233 \\
\hline membrane glycoprotein & QOI53595 & 222 & 25146.62 & 9.51 & $\mathrm{C}_{1165} \mathrm{H}_{1823} \mathrm{~N}_{303} \mathrm{O}_{301} \mathrm{~S}_{8}$ & 39.14 & 120.86 & 0.446 \\
\hline envelope protein & QOI53594 & 75 & 8365.04 & 8.57 & $\mathrm{C}_{390} \mathrm{H}_{625} \mathrm{~N}_{91} \mathrm{O}_{103} \mathrm{~S}_{4}$ & 38.68 & 144.00 & 1.128 \\
\hline ORF3a protein & QOI53593 & 275 & 31122.94 & 5.55 & $\mathrm{C}_{1440} \mathrm{H}_{2189} \mathrm{~N}_{343} \mathrm{O}_{404} \mathrm{~S}_{11}$ & 32.96 & 103.42 & 0.275 \\
\hline surface glycoprotein & QOI53592 & 1273 & 141160.44 & 6.24 & $\mathrm{C}_{6337} \mathrm{H}_{9772} \mathrm{~N}_{1656} \mathrm{O}_{1894 \mathrm{~S}_{53}}$ & 33.17 & 84.98 & -0.077 \\
\hline ORF1a polyprotein & QOI53591 & 4405 & 490048.17 & 6.05 & \# & 34.99 & 88.81 & -0.025 \\
\hline ORF1ab polyprotein & QOI53590 & 7096 & 794145.11 & 6.33 & $\#$ & 33.35 & 86.78 & -0.071 \\
\hline ORF10 protein & QOI53589 & 38 & 4449.23 & 7.93 & $\mathrm{C}_{206} \mathrm{H}_{312} \mathrm{~N}_{50} \mathrm{O}_{54} \mathrm{~S}_{3}$ & 16.06 & 107.63 & 0.637 \\
\hline nucleocapsid phosphoprotein & QOI53588 & 419 & 45625.70 & 10.07 & $\mathrm{C}_{1971} \mathrm{H}_{3137} \mathrm{~N}_{607} \mathrm{O}_{629} \mathrm{~S}_{7}$ & 55.09 & 52.53 & -0.971 \\
\hline ORF8 protein & QOI53587 & 121 & 13891.10 & 5.42 & $\mathrm{C}_{639} \mathrm{H}_{965} \mathrm{~N}_{155} \mathrm{O}_{176} \mathrm{~S}_{8}$ & 44.55 & 97.36 & 0.249 \\
\hline ORF7b & QOI53586 & 43 & 5180.27 & 4.17 & $\mathrm{C}_{251} \mathrm{H}_{374} \mathrm{~N}_{50} \mathrm{O}_{60} \mathrm{~S}_{4}$ & 50.96 & 156.51 & 1.449 \\
\hline ORF7a protein & QOI53585 & 121 & 13744.17 & 8.23 & $\mathrm{C}_{633} \mathrm{H}_{988} \mathrm{~N}_{156} \mathrm{O}_{171} \mathrm{~S}_{7}$ & 48.66 & 100.74 & 0.318 \\
\hline ORF6 protein & QOI53584 & 61 & 7272.54 & 4.60 & $\mathrm{C}_{334} \mathrm{H}_{532} \mathrm{~N}_{78} \mathrm{O}_{96} \mathrm{~S}_{3}$ & 31.16 & 130.98 & 0.233 \\
\hline membrane glycoprotein & QOI53583 & 222 & 25146.62 & 9.51 & $\mathrm{C}_{1165} \mathrm{H}_{1823} \mathrm{~N}_{303} \mathrm{O}_{301} \mathrm{~S}_{8}$ & 39.14 & 120.86 & 0.446 \\
\hline envelope protein & QOI53582 & 75 & 8365.04 & 8.57 & $\mathrm{C}_{390} \mathrm{H}_{625} \mathrm{~N}_{91} \mathrm{O}_{103} \mathrm{~S}_{4}$ & 38.68 & 144.00 & 1.128 \\
\hline ORF3a protein & QOI53581 & 275 & 31131.95 & 5.66 & $\mathrm{C}_{1441} \mathrm{H}_{2188} \mathrm{~N}_{344} \mathrm{O}_{403} \mathrm{~S}_{11}$ & 31.36 & 103.42 & 0.276 \\
\hline surface glycoprotein & QOI53580 & 1273 & undefined & $*$ & $\#$ & 31.89 & 83.61 & -0.081 \\
\hline ORF1a polyprotein & QOI53579 & 4405 & undefined & $*$ & \# & 34.56 & 88.12 & -0.029 \\
\hline ORF1ab polyprotein & QOI53578 & 7096 & undefined & $*$ & \# & 32.96 & 86.24 & -0.073 \\
\hline membrane glycoprotein & QJD23261 & 222 & 25217.53 & 9.75 & $\#$ & 38.29 & 119.50 & 0.419 \\
\hline membrane glycoprotein & QJD23252 & 222 & 25116.14 & 9.39 & $\#$ & 36.79 & 115.59 & 0.423 \\
\hline surface glycoprotein & QJD23270 & 1273 & undefined & $*$ & $\#$ & 32.05 & 81.31 & -0.062 \\
\hline surface glycoprotein & QJD23249 & 1273 & undefined & $*$ & $\#$ & 32.44 & 84.29 & -0.057 \\
\hline ORF1a polyprotein, partial & QJD23269 & 4386 & undefined & $*$ & $\#$ & 32.73 & 84.59 & -0.003 \\
\hline ORF1ab polyprotein, partial & QJD23268 & 7077 & undefined & $*$ & $\#$ & 31.69 & 83.20 & -0.062 \\
\hline ORF10 protein & QJD23267 & 38 & 4449.23 & 7.93 & $\mathrm{C}_{206} \mathrm{H}_{312} \mathrm{~N}_{50} \mathrm{O}_{54} \mathrm{~S}_{3}$ & 16.06 & 107.63 & 0.637 \\
\hline nucleocapsid phosphoprotein & QJD23266 & 419 & 45602.42 & 10.05 & $\#$ & 55.12 & 50.91 & -0.974 \\
\hline ORF8 protein & QJD23265 & 121 & 13831.01 & 5.42 & $\mathrm{C}_{633} \mathrm{H}_{961} \mathrm{~N}_{155} \mathrm{O}_{177} \mathrm{~S}_{8}$ & 45.79 & 97.36 & 0.219 \\
\hline ORF7b & QJD23264 & 43 & 5180.27 & 4.17 & $\mathrm{C}_{251} \mathrm{H}_{374} \mathrm{~N}_{50} \mathrm{O}_{60} \mathrm{~S}_{4}$ & 50.96 & 156.51 & 1.449 \\
\hline
\end{tabular}




\begin{tabular}{|c|c|c|c|c|c|c|c|c|}
\hline Protein & Accession no. & Length & MW (Da) & pI & Chemical formula & Instability index & Aliphatic index & $\begin{array}{l}\text { Grand average of } \\
\text { hydropathicity (GRAVY) }\end{array}$ \\
\hline ORF7a protein & QJD23263 & 121 & 13744.17 & 8.23 & $\mathrm{C}_{633} \mathrm{H}_{988} \mathrm{~N}_{156} \mathrm{O}_{171} \mathrm{~S}_{7}$ & 48.66 & 100.74 & 0.318 \\
\hline ORF6 protein & QJD23262 & 61 & 7272.54 & 4.60 & $\mathrm{C}_{334} \mathrm{H}_{532} \mathrm{~N}_{78} \mathrm{O}_{96} \mathrm{~S}_{3}$ & 31.16 & 130.98 & 0.233 \\
\hline envelope protein & QJD23260 & 75 & 8365.04 & 8.57 & $\mathrm{C}_{390} \mathrm{H}_{625} \mathrm{~N}_{91} \mathrm{O}_{103} \mathrm{~S}_{4}$ & 38.68 & 144.00 & 1.128 \\
\hline ORF3a protein & QJD23259 & 275 & 31122.94 & 5.55 & $\mathrm{C}_{1440} \mathrm{H}_{2189} \mathrm{~N}_{343} \mathrm{O}_{404} \mathrm{~S}_{11}$ & 32.96 & 103.42 & 0.275 \\
\hline ORF10 protein & QJD23258 & 38 & 4449.23 & 7.93 & $\mathrm{C}_{206} \mathrm{H}_{312} \mathrm{~N}_{50} \mathrm{O}_{54} \mathrm{~S}_{3}$ & 16.06 & 107.63 & 0.637 \\
\hline nucleocapsid phosphoprotein & QJD23257 & 419 & 45641.74 & 10.07 & $\mathrm{C}_{1972} \mathrm{H}_{3141} \mathrm{~N}_{607} \mathrm{O}_{629} \mathrm{~S}_{7}$ & 55.27 & 53.46 & -0.958 \\
\hline ORF8 protein & QJD23256 & 121 & 13831.01 & 5.42 & $\mathrm{C}_{633} \mathrm{H}_{961} \mathrm{~N}_{155} \mathrm{O}_{177} \mathrm{~S}_{8}$ & 45.79 & 97.36 & 0.219 \\
\hline ORF7b & QJD23255 & 43 & 5180.27 & 4.17 & $\mathrm{C}_{251} \mathrm{H}_{374} \mathrm{~N}_{50} \mathrm{O}_{60} \mathrm{~S}_{4}$ & 50.96 & 156.51 & 1.449 \\
\hline ORF7a protein & QJD23254 & 121 & 13744.17 & 8.23 & $\mathrm{C}_{633} \mathrm{H}_{988} \mathrm{~N}_{156} \mathrm{O}_{171} \mathrm{~S}_{7}$ & 48.66 & 100.74 & 0.318 \\
\hline ORF6 protein & QJD23253 & 61 & 7272.54 & 4.60 & $\mathrm{C}_{334} \mathrm{H}_{532} \mathrm{~N}_{78} \mathrm{O}_{96} \mathrm{~S}_{3}$ & 31.16 & 130.98 & 0.233 \\
\hline envelope protein & QJD23251 & 75 & 8365.04 & 8.57 & $\mathrm{C}_{390} \mathrm{H}_{625} \mathrm{~N}_{91} \mathrm{O}_{103} \mathrm{~S}_{4}$ & 38.68 & 144.00 & 1.128 \\
\hline ORF3a protein & QJD23250 & 275 & 31122.94 & 5.55 & $\mathrm{C}_{1440} \mathrm{H}_{2189} \mathrm{~N}_{343} \mathrm{O}_{404} \mathrm{~S}_{11}$ & 32.96 & 103.42 & 0.275 \\
\hline ORF1a polyprotein & QJD23248 & 4405 & 490035.59 & 6.04 & $\#$ & 35.05 & 88.90 & -0.023 \\
\hline ORF1ab polyprotein & QJD23247 & 7096 & undefined & $*$ & $\#$ & 33.25 & 86.11 & -0.071 \\
\hline ORF10 protein & QJD23246 & 38 & 4449.23 & 7.93 & $\mathrm{C}_{206} \mathrm{H}_{312} \mathrm{~N}_{50} \mathrm{O}_{54} \mathrm{~S}_{3}$ & 16.06 & 107.63 & 0.637 \\
\hline nucleocapsid phosphoprotein & QJD23245 & 419 & 45641.74 & 10.07 & $\mathrm{C}_{1972} \mathrm{H}_{3141} \mathrm{~N}_{607} \mathrm{O}_{629} \mathrm{~S}_{7}$ & 55.27 & 53.46 & -0.958 \\
\hline ORF8 protein & QJD23244 & 121 & 13831.01 & 5.42 & $\mathrm{C}_{633} \mathrm{H}_{961} \mathrm{~N}_{155} \mathrm{O}_{177} \mathrm{~S}_{8}$ & 45.79 & 97.36 & 0.219 \\
\hline ORF7b & QJD23243 & 43 & 5180.27 & 4.17 & $\mathrm{C}_{251} \mathrm{H}_{374} \mathrm{~N}_{50} \mathrm{O}_{60} \mathrm{~S}_{4}$ & 50.96 & 156.51 & 1.449 \\
\hline ORF7a protein & QJD23242 & 121 & 13744.17 & 8.23 & $\mathrm{C}_{633} \mathrm{H}_{988} \mathrm{~N}_{156} \mathrm{O}_{171} \mathrm{~S}_{7}$ & 48.66 & 100.74 & 0.318 \\
\hline ORF6 protein & QJD23241 & 61 & 7272.54 & 4.60 & $\mathrm{C}_{334} \mathrm{H}_{532} \mathrm{~N}_{78} \mathrm{O}_{96} \mathrm{~S}_{3}$ & 31.16 & 130.98 & 0.233 \\
\hline membrane glycoprotein & QJD23240 & 222 & 25146.62 & 9.51 & $\mathrm{C}_{1165} \mathrm{H}_{1823} \mathrm{~N}_{303} \mathrm{O}_{301} \mathrm{~S}_{8}$ & 39.14 & 120.86 & 0.446 \\
\hline envelope protein & QJD23239 & 75 & 8365.04 & 8.57 & $\mathrm{C}_{390} \mathrm{H}_{625} \mathrm{~N}_{91} \mathrm{O}_{103} \mathrm{~S}_{4}$ & 38.68 & 144.00 & 1.128 \\
\hline ORF3a protein & QJD23238 & 275 & 31122.94 & 5.55 & $\mathrm{C}_{1440} \mathrm{H}_{2189} \mathrm{~N}_{343} \mathrm{O}_{404} \mathrm{~S}_{11}$ & 32.96 & 103.42 & 0.275 \\
\hline surface glycoprotein & QJD23237 & 1273 & 141178.47 & 6.24 & $\mathrm{C}_{6336} \mathrm{H}_{9770} \mathrm{~N}_{1656} \mathrm{O}_{1894} \mathrm{~S}_{54}$ & 33.01 & 84.67 & -0.079 \\
\hline ORF1a polyprotein & QJD23236 & 4405 & 490119.11 & 6.07 & $\mathrm{C}_{21990} \mathrm{H}_{34336} \mathrm{~N}_{5658} \mathrm{O}_{6522} \mathrm{~S}_{243}$ & 35.00 & 88.90 & -0.025 \\
\hline ORF1ab polyprotein & QJD23235 & 7096 & 794246.07 & 6.35 & $\mathrm{C}_{35655} \mathrm{H}_{55349} \mathrm{~N}_{9257} \mathrm{O}_{10495} \mathrm{~S}_{394}$ & 33.39 & 86.84 & -0.071 \\
\hline ORF10 protein & QJD23234 & 38 & 4449.23 & 7.93 & $\mathrm{C}_{206} \mathrm{H}_{312} \mathrm{~N}_{50} \mathrm{O}_{54} \mathrm{~S}_{3}$ & 16.06 & 107.63 & 0.637 \\
\hline nucleocapsid phosphoprotein & QJD23233 & 419 & 45641.74 & 10.07 & $\mathrm{C}_{1972} \mathrm{H}_{3141} \mathrm{~N}_{607} \mathrm{O}_{629} \mathrm{~S}_{7}$ & 55.27 & 53.46 & -0.958 \\
\hline ORF8 protein & QJD23232 & 121 & 13831.01 & 5.42 & $\mathrm{C}_{633} \mathrm{H}_{961} \mathrm{~N}_{155} \mathrm{O}_{177} \mathrm{~S}_{8}$ & 45.79 & 97.36 & 0.219 \\
\hline ORF7b & QJD23231 & 43 & 5180.27 & 4.17 & $\mathrm{C}_{251} \mathrm{H}_{374} \mathrm{~N}_{50} \mathrm{O}_{60} \mathrm{~S}_{4}$ & 50.96 & 156.51 & 1.449 \\
\hline ORF7a protein & QJD23230 & 121 & 13744.17 & 8.23 & $\mathrm{C}_{633} \mathrm{H}_{988} \mathrm{~N}_{156} \mathrm{O}_{171} \mathrm{~S}_{7}$ & 48.66 & 100.74 & 0.318 \\
\hline ORF6 protein & QJD23229 & 61 & 7272.54 & 4.60 & $\mathrm{C}_{334} \mathrm{H}_{532} \mathrm{~N}_{78} \mathrm{O}_{96} \mathrm{~S}_{3}$ & 31.16 & 130.98 & 0.233 \\
\hline membrane glycoprotein & QJD23228 & 222 & 25146.62 & 9.51 & $\mathrm{C}_{1165} \mathrm{H}_{1823} \mathrm{~N}_{303} \mathrm{O}_{301} \mathrm{~S}_{8}$ & 39.14 & 120.86 & 0.446 \\
\hline envelope protein & QJD23227 & \begin{tabular}{|l|l|}
75 \\
75
\end{tabular} & 8365.04 & 8.57 & $\mathrm{C}_{390} \mathrm{H}_{625} \mathrm{~N}_{91} \mathrm{O}_{103} \mathrm{~S}_{4}$ & 38.68 & 144.00 & 1.128 \\
\hline ORF3a protein & QJD23226 & 275 & 31122.94 & 5.55 & $\mathrm{C}_{1440} \mathrm{H}_{2189} \mathrm{~N}_{343} \mathrm{O}_{404} \mathrm{~S}_{11}$ & 32.96 & 103.42 & 0.275 \\
\hline surface glycoprotein & QJD23225 & 1273 & 141178.47 & 6.24 & $\mathrm{C}_{6336} \mathrm{H}_{9770} \mathrm{~N}_{1656} \mathrm{O}_{1894} \mathrm{~S}_{54}$ & 33.01 & 84.67 & -0.079 \\
\hline ORF1a polyprotein & QJD23224 & 4405 & 490119.11 & 6.07 & $\mathrm{C}_{21990} \mathrm{H}_{34336} \mathrm{~N}_{5658} \mathrm{O}_{6522} \mathrm{~S}_{243}$ & 35.00 & 88.90 & -0.025 \\
\hline ORF1ab polyprotein & QJD23223 & 7096 & 794216.04 & 6.35 & $\mathrm{C}_{35654} \mathrm{H}_{55347} \mathrm{~N}_{9257} \mathrm{O}_{10494} \mathrm{~S}_{394}$ & 33.36 & 86.84 & -0.071 \\
\hline orf1ab polyprotein (partial) & QIA98594 & 96 & 11239.26 & 8.90 & $\mathrm{C}_{516} \mathrm{H}_{786} \mathrm{~N}_{132} \mathrm{O}_{132} \mathrm{~S}_{9}$ & 29.66 & 89.27 & 0.161 \\
\hline
\end{tabular}

https://biointerfaceresearch.com/ 


\begin{tabular}{l|l|l|l|l|l|l|l|l} 
Protein & Accession no. & Length & MW (Da) & pI & Chemical formula & Instability index & Aliphatic index & $\begin{array}{l}\text { Grand } \\
\text { hydropathicity (GRAVY) }\end{array}$ \\
\hline orf1ab polyprotein (partial) & QIA98593 & 96 & 11239.26 & 8.90 & $\mathrm{C}_{516} \mathrm{H}_{786} \mathrm{~N}_{132} \mathrm{O}_{132} \mathrm{~S}_{9}$ & 29.66 & 89.27 \\
\hline orf1ab polyprotein (partial) & QIA98592 & 96 & 11239.26 & 8.90 & $\mathrm{C}_{516} \mathrm{H}_{786} \mathrm{~N}_{132} \mathrm{O}_{132} \mathrm{~S}_{9}$ & 29.66 & 0.161 \\
\end{tabular}

Table 3. The secondary structure analysis of Malaysia SARS CoV-2 strain's structural and accessory proteins using SOPMA.

\begin{tabular}{|c|c|c|c|c|c|c|c|c|c|c|c|c|}
\hline Protein & Gene Id & $\begin{array}{c}\text { Lengt } \\
\text { h }\end{array}$ & $\begin{array}{l}\text { Alpha helix } \\
\text { (Hh) }\end{array}$ & $\begin{array}{c}3_{10} \text { helix } \\
\text { (Gg) }\end{array}$ & $\begin{array}{l}\text { Pi helix } \\
\text { (Ii) }\end{array}$ & $\begin{array}{c}\text { Beta } \\
\text { bridge } \\
\text { (Bb) }\end{array}$ & $\begin{array}{l}\text { Extended } \\
\text { strand (Ee) }\end{array}$ & $\begin{array}{l}\text { Beta turn } \\
\quad(\mathrm{Tt})\end{array}$ & $\begin{array}{l}\text { Bend } \\
\text { region (Ss) }\end{array}$ & $\begin{array}{l}\text { Random coil } \\
\text { (Cc) }\end{array}$ & $\begin{array}{l}\text { Ambiguou } \\
\text { s states (?) }\end{array}$ & $\begin{array}{l}\text { Other } \\
\text { states }\end{array}$ \\
\hline ORF10 protein & 1914445506 & 38 & $11(28.95 \%)$ & $0(0.00 \%)$ & $0(0.00 \%)$ & $0(0.00 \%)$ & $14(36.84 \%)$ & $2(5.26 \%)$ & $0(0.00 \%)$ & $11(28.95 \%)$ & $0(0.00 \%)$ & $0(0.00 \%)$ \\
\hline $\begin{array}{c}\text { nucleocapsid } \\
\text { phosphoprotein }\end{array}$ & 1914445505 & 419 & $89(21.24 \%)$ & $0(0.00 \%)$ & $0(0.00 \%)$ & $0(0.00 \%)$ & $70(16.71 \%)$ & $29(6.92 \%)$ & $0(0.00 \%)$ & $231(55.13 \%)$ & $0(0.00 \%)$ & $0(0.00 \%)$ \\
\hline ORF8 protein & 1914445504 & 121 & $24(19.83 \%)$ & $0(0.00 \%)$ & $0(0.00 \%)$ & $0(0.00 \%)$ & $43(35.54 \%)$ & $6(4.96 \%)$ & $0(0.00 \%)$ & $48(39.67 \%)$ & $0(0.00 \%)$ & $0(0.00 \%)$ \\
\hline ORF7b & 1914445503 & 43 & $32(74.42 \%)$ & $0(0.00 \%)$ & $0(0.00 \%)$ & $0(0.00 \%)$ & $1(2.33 \%)$ & $1(2.33 \%)$ & $0(0.00 \%)$ & $9(20.93 \%)$ & $0(0.00 \%)$ & $0(0.00 \%)$ \\
\hline ORF7a protein & 1914445502 & 121 & $52(42.98 \%)$ & $0(0.00 \%)$ & $0(0.00 \%)$ & $0(0.00 \%)$ & $23(19.01 \%)$ & $12(9.92 \%)$ & $0(0.00 \%)$ & $34(28.10 \%)$ & $0(0.00 \%)$ & $0(0.00 \%)$ \\
\hline ORF6 protein & 1914445501 & 61 & $43(70.49 \%)$ & $0(0.00 \%)$ & $0(0.00 \%)$ & $0(0.00 \%)$ & $6(9.84 \%)$ & $5(8.20 \%)$ & $0(0.00 \%)$ & $7(11.48 \%)$ & $0(0.00 \%)$ & $0(0.00 \%)$ \\
\hline $\begin{array}{l}\text { membrane } \\
\text { glycoprotein }\end{array}$ & 1914445500 & 222 & $77(34.68 \%)$ & $0(0.00 \%)$ & $0(0.00 \%)$ & $0(0.00 \%)$ & $47(21.17 \%)$ & $15(6.76 \%)$ & $0(0.00 \%)$ & $83(37.39 \%)$ & $0(0.00 \%)$ & $0(0.00 \%)$ \\
\hline envelope protein & 1914445499 & 75 & $33(44.00 \%)$ & $0(0.00 \%)$ & $0(0.00 \%)$ & $0(0.00 \%)$ & $20(26.67 \%)$ & $7(9.33 \%)$ & $0(0.00 \%)$ & $15(20.00 \%)$ & $0(0.00 \%)$ & $0(0.00 \%)$ \\
\hline ORF3a protein & 1914445498 & 275 & $72(26.18 \%)$ & $0(0.00 \%)$ & $0(0.00 \%)$ & $0(0.00 \%)$ & $82(29.82 \%)$ & $\begin{array}{c}28 \\
(10.18 \%)\end{array}$ & $0(0.00 \%)$ & $93(33.82 \%)$ & $0(0.00 \%)$ & $0(0.00 \%)$ \\
\hline surface glycoprotein & 1914445497 & 1273 & $\begin{array}{c}378 \\
(29.69 \%) \\
\end{array}$ & $0(0.00 \%)$ & $0(0.00 \%)$ & $0(0.00 \%)$ & $289(22.70 \%)$ & $\begin{array}{c}40( \\
3.14 \% \\
\end{array}$ & $0(0.00 \%)$ & $566(44.46 \%)$ & $0(0.00 \%)$ & $0(0.00 \%)$ \\
\hline ORF1a polyprotein & 1914445496 & 4405 & $\begin{array}{c}1776 \\
(40.32 \%)\end{array}$ & $0(0.00 \%)$ & $0(0.00 \%)$ & $0(0.00 \%)$ & $909(20.64 \% 0$ & $\begin{array}{c}351 \\
(7.97 \%)\end{array}$ & $0(0.00 \%)$ & $1369(31.08 \%)$ & $0(0.00 \%)$ & $0(0.00 \%)$ \\
\hline ORF1ab polyprotein & 1914445495 & 7096 & $\begin{array}{c}1903 \\
(40.80 \%) \\
\end{array}$ & $0(0.00 \%)$ & $0(0.00 \%)$ & $0(0.00 \%)$ & $938(20.11 \%)$ & $\begin{array}{c}341 \\
(7.31 \%) \\
\end{array}$ & $0(0.00 \%)$ & $1482(31.78 \%)$ & $0(0.00 \%)$ & $0(0.00 \%)$ \\
\hline ORF10 protein & 1914445474 & 38 & $11(28.95 \%)$ & $0(0.00 \%)$ & $0(0.00 \%)$ & $0(0.00 \%)$ & $14(36.84 \%)$ & $2(5.26 \%)$ & $0(0.00 \%)$ & $11(28.95 \%)$ & $0(0.00 \%)$ & $0(0.00 \%)$ \\
\hline $\begin{array}{c}\text { nucleocapsid } \\
\text { phosphoprotein }\end{array}$ & 1914445473 & 419 & $89(21.24 \%)$ & $0(0.00 \%)$ & $0(0.00 \%)$ & $0(0.00 \%)$ & $70(16.71 \%)$ & $29(6.92 \%)$ & $0(0.00 \%)$ & $231(55.13 \%)$ & $0(0.00 \%)$ & $0(0.00 \%)$ \\
\hline ORF8 protein & 1914445472 & 121 & $25(20.66 \%)$ & $0(0.00 \%)$ & $0(0.00 \%)$ & $0(0.00 \%)$ & $42(34.71 \%)$ & $6(4.96 \%)$ & $0(0.00 \%)$ & $48(39.67 \%)$ & $0(0.00 \%)$ & $0(0.00 \%)$ \\
\hline ORF7b & 1914445471 & 43 & $32(74.42 \%)$ & $0(0.00 \%)$ & $0(0.00 \%)$ & $0(0.00 \%)$ & $1(2.33 \%)$ & $1(2.33 \%)$ & $0(0.00 \%)$ & $9(20.93 \%)$ & $0(0.00 \%)$ & $0(0.00 \%)$ \\
\hline ORF7a protein & 1914445470 & 121 & $52(42.98 \%)$ & $0(0.00 \%)$ & $0(0.00 \%)$ & $0(0.00 \%)$ & $23(19.01 \%)$ & $12(9.92 \%)$ & $0(0.00 \%)$ & $34(28.10 \%)$ & $0(0.00 \%)$ & $0(0.00 \%)$ \\
\hline ORF6 protein & 1914445469 & 61 & $43(70.49 \%)$ & $0(0.00 \%)$ & $0(0.00 \%)$ & $0(0.00 \%)$ & $6(9.84 \%)$ & $5(8.20 \%)$ & $0(0.00 \%)$ & $7(11.48 \%)$ & $0(0.00 \%)$ & $0(0.00 \%)$ \\
\hline $\begin{array}{l}\text { membrane } \\
\text { glycoprotein }\end{array}$ & 1914445468 & 222 & $77(34.68 \%)$ & $0(0.00 \%)$ & $0(0.00 \%)$ & $0(0.00 \%)$ & $47(21.17 \%)$ & $15(6.76 \%)$ & $0(0.00 \%)$ & $83(37.39 \%)$ & $0(0.00 \%)$ & $0(0.00 \%)$ \\
\hline envelope protein & 1914445467 & 75 & $33(44.00 \%)$ & $0(0.00 \%)$ & $0(0.00 \%)$ & $0(0.00 \%)$ & $20(26.67 \%)$ & $7(9.33 \%)$ & $0(0.00 \%)$ & $15(20.00 \%)$ & $0(0.00 \%)$ & $0(0.00 \%)$ \\
\hline ORF3a protein & 1914445466 & 275 & $70(25.45 \%)$ & $0(0.00 \%)$ & $0(0.00 \%)$ & $0(0.00 \%)$ & $84(30.55 \%)$ & $\begin{array}{c}28 \\
(10.18 \%)\end{array}$ & $0(0.00 \%)$ & $93(33.82 \%)$ & $0(0.00 \%)$ & $0(0.00 \%)$ \\
\hline surface glycoprotein & 1914445465 & 1273 & $\begin{array}{c}379 \\
(29.77 \%)\end{array}$ & $0(0.00 \%)$ & $0(0.00 \%)$ & $0(0.00 \%)$ & $286(22.47 \%)$ & $48(3.77 \%)$ & $0(0.00 \%)$ & $560(43.99 \%)$ & $0(0.00 \%)$ & $0(0.00 \%)$ \\
\hline
\end{tabular}




\begin{tabular}{|c|c|c|c|c|c|c|c|c|c|c|c|c|}
\hline Protein & Gene Id & $\begin{array}{c}\text { Lengt } \\
\mathbf{h}\end{array}$ & $\begin{array}{l}\text { Alpha helix } \\
\text { (Hh) }\end{array}$ & $\begin{array}{l}310 \text { helix } \\
\text { (Gg) }\end{array}$ & $\begin{array}{l}\text { Pi helix } \\
\text { (Ii) }\end{array}$ & $\begin{array}{c}\text { Beta } \\
\text { bridge } \\
\text { (Bb) }\end{array}$ & $\begin{array}{c}\text { Extended } \\
\text { strand (Ee) }\end{array}$ & $\begin{array}{l}\text { Beta turn } \\
\quad(\mathrm{Tt})\end{array}$ & $\begin{array}{c}\text { Bend } \\
\text { region (Ss) }\end{array}$ & $\begin{array}{l}\text { Random coil } \\
\text { (Cc) }\end{array}$ & $\begin{array}{l}\text { Ambiguou } \\
\text { s states (?) }\end{array}$ & $\begin{array}{l}\text { Other } \\
\text { states }\end{array}$ \\
\hline ORF1a polyprotein & 1914445464 & 4405 & $\begin{array}{c}1763 \\
(40.02 \%)\end{array}$ & $0(0.00 \%)$ & $0(0.00 \%)$ & $0(0.00 \%)$ & $924(20.98 \%)$ & $\begin{array}{c}354 \\
(8.04 \%)\end{array}$ & $0(0.00 \%)$ & $1364(30.96 \%)$ & $0(0.00 \%)$ & $0(0.00 \%)$ \\
\hline ORF1ab polyprotein & 1914445463 & 7096 & $\begin{array}{c}1932 \\
(38.65 \%) \\
\end{array}$ & $0(0.00 \%)$ & $0(0.00 \%)$ & $0(0.00 \%)$ & $1114(22.28 \%)$ & $\begin{array}{c}495 \\
(9.90 \%) \\
\end{array}$ & $0(0.00 \%)$ & $1458(29.17 \%)$ & $0(0.00 \%)$ & $0(0.00 \%)$ \\
\hline $\begin{array}{l}\text { membrane } \\
\text { glycoprotein }\end{array}$ & 1834374001 & 222 & $76(34.23 \%)$ & $0(0.00 \%)$ & $0(0.00 \%)$ & $0(0.00 \%)$ & $48(21.62 \%)$ & $13(5.86 \%)$ & $0(0.00 \%)$ & $85(38.29 \%)$ & $0(0.00 \%)$ & $0(0.00 \%)$ \\
\hline $\begin{array}{l}\text { membrane } \\
\text { glycoprotein }\end{array}$ & 1834373991 & 222 & $75(33.78 \%)$ & $0(0.00 \%)$ & $0(0.00 \%)$ & $0(0.00 \%)$ & $50(22.52 \%)$ & $13(5.86 \%)$ & $0(0.00 \%)$ & $84(37.84 \%)$ & $0(0.00 \%)$ & $0(0.00 \%)$ \\
\hline surface glycoprotein & 1834374010 & 1273 & $\begin{array}{c}408 \\
(32.05 \%) \\
\end{array}$ & $0(0.00 \%)$ & $0(0.00 \%)$ & $0(0.00 \%)$ & $306(24.04 \%)$ & $69(5.42 \%)$ & $0(0.00 \%)$ & $490(38.49 \%)$ & $0(0.00 \%)$ & $0(0.00 \%)$ \\
\hline surface glycoprotein & 1834373988 & 1273 & $\begin{array}{c}365 \\
(28.67 \%) \\
\end{array}$ & $0(0.00 \%)$ & $0(0.00 \%)$ & $0(0.00 \%)$ & $294(23.10 \%)$ & $43(3.38 \%)$ & $0(0.00 \%)$ & $571(44.85 \%)$ & $0(0.00 \%)$ & $0(0.00 \%)$ \\
\hline $\begin{array}{c}\text { ORF1a polyprotein, } \\
\text { partial }\end{array}$ & 1834374009 & 4386 & $\begin{array}{c}1637 \\
(37.32 \%) \\
\end{array}$ & $0(0.00 \%)$ & $0(0.00 \%)$ & $0(0.00 \%)$ & $951(21.68 \%)$ & $\begin{array}{c}420 \\
(9.58 \%) \\
\end{array}$ & $0(0.00 \%)$ & $1378(31.42 \%)$ & $0(0.00 \%)$ & $0(0.00 \%)$ \\
\hline $\begin{array}{c}\text { ORF1ab } \\
\text { polyprotein, partial }\end{array}$ & 1834374008 & 7077 & $\begin{array}{c}1847 \\
(36.97 \%) \\
\end{array}$ & $0(0.00 \%)$ & $0(0.00 \%)$ & $0(0.00 \%)$ & $1092(21.86 \%)$ & $\begin{array}{c}494 \\
(9.89 \%) \\
\end{array}$ & $0(0.00 \%)$ & $1563(31.29 \%)$ & $0(0.00 \%)$ & $0(0.00 \%)$ \\
\hline ORF10 protein & 1834374007 & 38 & $11(28.95 \%)$ & $0(0.00 \%)$ & $0(0.00 \%)$ & $0(0.00 \%)$ & $14(36.84 \%)$ & $2(5.26 \%)$ & $0(0.00 \%)$ & $11(28.95 \%)$ & $0(0.00 \%)$ & $0(0.00 \%)$ \\
\hline $\begin{array}{c}\text { nucleocapsid } \\
\text { phosphoprotein }\end{array}$ & 1834374006 & 419 & $87(20.76 \%)$ & $0(0.00 \%)$ & $0(0.00 \%)$ & $0(0.00 \%)$ & $70(16.71 \%)$ & $30(7.16 \%)$ & $0(0.00 \%)$ & $232(55.37 \%)$ & $0(0.00 \%)$ & $0(0.00 \%)$ \\
\hline ORF8 protein & 1834374005 & 121 & $24(19.83 \%)$ & $0(0.00 \%)$ & $0(0.00 \%)$ & $0(0.00 \%)$ & $43(35.54 \%)$ & $6(4.96 \%)$ & $0(0.00 \%)$ & $48(39.67 \%)$ & $0(0.00 \%)$ & $0(0.00 \%)$ \\
\hline ORF7b & 1834374004 & 43 & $32(74.42 \%)$ & $0(0.00 \%)$ & $0(0.00 \%)$ & $0(0.00 \%)$ & $1(2.33 \%)$ & $1(2.33 \%)$ & $0(0.00 \%)$ & $9(20.93 \%)$ & $0(0.00 \%)$ & $0(0.00 \%)$ \\
\hline ORF7a protein & 1834374003 & 121 & $52(42.98 \%)$ & $0(0.00 \%)$ & $0(0.00 \%)$ & $0(0.00 \%)$ & $23(19.01 \%)$ & $12(9.92 \%)$ & $0(0.00 \%)$ & $34(28.10 \%)$ & $0(0.00 \%)$ & $0(0.00 \%)$ \\
\hline ORF6 protein & 1834374002 & 61 & $43(70.49 \%)$ & $0(0.00 \%)$ & $0(0.00 \%)$ & $0(0.00 \%)$ & $6(9.84 \%)$ & $5(8.20 \%)$ & $0(0.00 \%)$ & $7(11.48 \%)$ & $0(0.00 \%)$ & $0(0.00 \%)$ \\
\hline envelope protein & 1834374000 & 75 & $33(44.00 \%)$ & $0(0.00 \%)$ & $0(0.00 \%)$ & $0(0.00 \%)$ & $20(26.67 \%)$ & $7(9.33 \%)$ & $0(0.00 \%)$ & $15(20.00 \%)$ & $0(0.00 \%)$ & $0(0.00 \%)$ \\
\hline ORF3a protein & 1834373999 & 275 & $72(26.18 \%)$ & $0(0.00 \%)$ & $0(0.00 \%)$ & $0(0.00 \%)$ & $82(29.82 \%)$ & $\begin{array}{c}28 \\
(10.18 \%) \\
\end{array}$ & $0(0.00 \%)$ & $93(33.82 \%)$ & $0(0.00 \%)$ & $0(0.00 \%)$ \\
\hline ORF10 protein & 1834373997 & 38 & $11(28.95 \%)$ & $0(0.00 \%)$ & $0(0.00 \%)$ & $0(0.00 \%)$ & $14(36.84 \%)$ & $2(5.26 \%)$ & $0(0.00 \%)$ & $11(28.95 \%)$ & $0(0.00 \%)$ & $0(0.00 \%)$ \\
\hline $\begin{array}{c}\text { nucleocapsid } \\
\text { phosphoprotein }\end{array}$ & 1834373996 & 419 & $89(21.24 \%)$ & $0(0.00 \%)$ & $0(0.00 \%)$ & $0(0.00 \%)$ & $70(16.71 \%)$ & $29(6.92 \%)$ & $0(0.00 \%)$ & $231(55.13 \%)$ & $0(0.00 \%)$ & $0(0.00 \%)$ \\
\hline ORF8 protein & 1834373995 & 121 & $24(19.83 \%)$ & $0(0.00 \%)$ & $0(0.00 \%)$ & $0(0.00 \%)$ & $43(35.54 \%)$ & $6(4.96 \%)$ & $0(0.00 \%)$ & $48(39.67 \%)$ & $0(0.00 \%)$ & $0(0.00 \%)$ \\
\hline ORF7b & 1834373994 & 43 & $32(74.42 \%)$ & $0(0.00 \%)$ & $0(0.00 \%)$ & $0(0.00 \%)$ & $1(2.33 \%)$ & $1(2.33 \%)$ & $0(0.00 \%)$ & $9(20.93 \%)$ & $0(0.00 \%)$ & $0(0.00 \%)$ \\
\hline ORF7a protein & 1834373993 & 121 & $52(42.98 \%)$ & $0(0.00 \%)$ & $0(0.00 \%)$ & $0(0.00 \%)$ & $23(19.01 \%)$ & $12(9.92 \%)$ & $0(0.00 \%)$ & $34(28.10 \%)$ & $0(0.00 \%)$ & $0(0.00 \%)$ \\
\hline ORF6 protein & 1834373992 & 61 & $43(70.49 \%)$ & $0(0.00 \%)$ & $0(0.00 \%)$ & $0(0.00 \%)$ & $6(9.84 \%)$ & $5(8.20 \%)$ & $0(0.00 \%)$ & $7(11.48 \%)$ & $0(0.00 \%)$ & $0(0.00 \%)$ \\
\hline envelope protein & 1834373990 & 75 & $33(44.00 \%)$ & $0(0.00 \%)$ & $0(0.00 \%)$ & $0(0.00 \%)$ & $20(26.67 \%)$ & $7(9.33 \%)$ & $0(0.00 \%)$ & $15(20.00 \%)$ & $0(0.00 \%)$ & $0(0.00 \%)$ \\
\hline ORF3a protein & 1834373989 & 275 & $72(26.18 \%)$ & $0(0.00 \%)$ & $0(0.00 \%)$ & $0(0.00 \%)$ & $82(29.82 \%)$ & $\begin{array}{c}28 \\
(10.18 \%) \\
\end{array}$ & $0(0.00 \%)$ & $93(33.82 \%)$ & $0(0.00 \%)$ & $0(0.00 \%)$ \\
\hline ORF1a polyprotein & 1834373987 & 4405 & $\begin{array}{c}1778 \\
(40.36 \%)\end{array}$ & $0(0.00 \%)$ & $0(0.00 \%)$ & $0(0.00 \%)$ & $911(20.68 \%)$ & $\begin{array}{c}353 \\
(8.01 \%)\end{array}$ & $0(0.00 \%)$ & $1363(30.94 \%)$ & $0(0.00 \%)$ & $0(0.00 \%)$ \\
\hline
\end{tabular}




\begin{tabular}{|c|c|c|c|c|c|c|c|c|c|c|c|c|}
\hline Protein & Gene Id & $\begin{array}{c}\text { Lengt } \\
\mathrm{h}\end{array}$ & $\begin{array}{l}\text { Alpha helix } \\
\text { (Hh) }\end{array}$ & $\begin{array}{l}310 \text { helix } \\
\text { (Gg) }\end{array}$ & $\begin{array}{l}\text { Pi helix } \\
\text { (Ii) }\end{array}$ & $\begin{array}{c}\text { Beta } \\
\text { bridge } \\
\text { (Bb) }\end{array}$ & $\begin{array}{l}\text { Extended } \\
\text { strand (Ee) }\end{array}$ & $\begin{array}{l}\text { Beta turn } \\
\quad(\mathrm{Tt})\end{array}$ & $\begin{array}{l}\text { Bend } \\
\text { region (Ss) }\end{array}$ & $\begin{array}{l}\text { Random coil } \\
\text { (Cc) }\end{array}$ & $\begin{array}{l}\text { Ambiguou } \\
\text { s states (?) }\end{array}$ & $\begin{array}{l}\text { Other } \\
\text { states }\end{array}$ \\
\hline ORF1ab polyprotein & 1834373986 & 7096 & $\begin{array}{c}1907 \\
(40.64 \%)\end{array}$ & $0(0.00 \%)$ & $0(0.00 \%)$ & $0(0.00 \%)$ & $942(20.08 \%)$ & $\begin{array}{c}349 \\
(7.44 \%)\end{array}$ & $0(0.00 \%)$ & $1494(31.84 \%)$ & $0(0.00 \%)$ & $0(0.00 \%)$ \\
\hline ORF10 protein & 1834373984 & 38 & $11(28.95 \%)$ & $0(0.00 \%)$ & $0(0.00 \%)$ & $0(0.00 \%)$ & $14(36.84 \%)$ & $2(5.26 \%)$ & $0(0.00 \%)$ & $11(28.95 \%)$ & $0(0.00 \%)$ & $0(0.00 \%)$ \\
\hline $\begin{array}{c}\text { nucleocapsid } \\
\text { phosphoprotein }\end{array}$ & 1834373983 & 419 & $89(21.24 \%)$ & $0(0.00 \%)$ & $0(0.00 \%)$ & $0(0.00 \%)$ & $70(16.71 \%)$ & $29(6.92 \%)$ & $0(0.00 \%)$ & $231(55.13 \%)$ & $0(0.00 \%)$ & $0(0.00 \%)$ \\
\hline ORF8 protein & 1834373982 & 121 & $24(19.83 \%)$ & $0(0.00 \%)$ & $0(0.00 \%)$ & $0(0.00 \%)$ & $43(35.54 \%)$ & $6(4.96 \%)$ & $0(0.00 \%)$ & $48(39.67 \%)$ & $0(0.00 \%)$ & $0(0.00 \%)$ \\
\hline ORF7b & 1834373981 & 43 & $32(74.42 \%)$ & $0(0.00 \%)$ & $0(0.00 \%)$ & $0(0.00 \%)$ & $1(2.33 \%)$ & $1(2.33 \%)$ & $0(0.00 \%)$ & $9(20.93 \%)$ & $0(0.00 \%)$ & $0(0.00 \%)$ \\
\hline ORF7a protein & 1834373980 & 121 & $52(42.98 \%)$ & $0(0.00 \%)$ & $0(0.00 \%)$ & $0(0.00 \%)$ & $23(19.01 \%)$ & $12(9.92 \%)$ & $0(0.00 \%)$ & $34(28.10 \%)$ & $0(0.00 \%)$ & $0(0.00 \%)$ \\
\hline ORF6 protein & 1834373979 & 61 & $43(70.49 \%)$ & $0(0.00 \%)$ & $0(0.00 \%)$ & $0(0.00 \%)$ & $6(9.84 \%)$ & $5(8.20 \%)$ & $0(0.00 \%)$ & $7(11.48 \%)$ & $0(0.00 \%)$ & $0(0.00 \%)$ \\
\hline $\begin{array}{l}\text { membrane } \\
\text { glycoprotein }\end{array}$ & 1834373978 & 222 & $77(34.68 \%)$ & $0(0.00 \%)$ & $0(0.00 \%)$ & $0(0.00 \%)$ & $47(21.17 \%)$ & $15(6.76 \%)$ & $0(0.00 \%)$ & $83(37.39 \%)$ & $0(0.00 \%)$ & $0(0.00 \%)$ \\
\hline envelope protein & 1834373977 & 75 & $33(44.00 \%)$ & $0(0.00 \%)$ & $0(0.00 \%)$ & $0(0.00 \%)$ & $20(26.67 \%)$ & $7(9.33 \%)$ & $0(0.00 \%)$ & $15(20.00 \%)$ & $0(0.00 \%)$ & $0(0.00 \%)$ \\
\hline ORF3a protein & 1834373976 & 275 & $72(26.18 \%)$ & $0(0.00 \%)$ & $0(0.00 \%)$ & $0(0.00 \%)$ & $82(29.82 \%)$ & $\begin{array}{c}28 \\
(10.18 \%)\end{array}$ & $0(0.00 \%)$ & $93(33.82 \%)$ & $0(0.00 \%)$ & $0(0.00 \%)$ \\
\hline surface glycoprotein & 1834373975 & 1273 & $\begin{array}{c}364 \\
(28.59 \%) \\
\end{array}$ & $0(0.00 \%)$ & $0(0.00 \%)$ & $0(0.00 \%)$ & $296(23.25 \%)$ & $43(3.38 \%)$ & $0(0.00 \%)$ & $570(44.78 \%)$ & $0(0.00 \%)$ & $0(0.00 \%)$ \\
\hline ORF1a polyprotein & 1834373974 & 4405 & $\begin{array}{c}1776 \\
(40.32 \%) \\
\end{array}$ & $0(0.00 \%)$ & $0(0.00 \%)$ & $0(0.00 \%)$ & $909(20.64 \%)$ & $\begin{array}{c}351 \\
(7.97 \%) \\
\end{array}$ & $0(0.00 \%)$ & $1369(31.08 \%)$ & $0(0.00 \%)$ & $0(0.00 \%)$ \\
\hline ORF1ab polyprotein & 1834373973 & 7096 & $\begin{array}{c}1933 \\
(38.67 \%) \\
\end{array}$ & $0(0.00 \%)$ & $0(0.00 \%)$ & $0(0.00 \%)$ & $1110(22.20 \%)$ & $\begin{array}{c}496 \\
(9.92 \%) \\
\end{array}$ & $0(0.00 \%)$ & $1460(29.21 \%)$ & $0(0.00 \%)$ & $0(0.00 \%)$ \\
\hline ORF10 protein & 1834373971 & 38 & $11(28.95 \%)$ & $0(0.00 \%)$ & $0(0.00 \%)$ & $0(0.00 \%)$ & $14(36.84 \%)$ & $2(5.26 \%)$ & $0(0.00 \%)$ & $11(28.95 \%)$ & $0(0.00 \%)$ & $0(0.00 \%)$ \\
\hline $\begin{array}{c}\text { nucleocapsid } \\
\text { phosphoprotein }\end{array}$ & 1834373970 & 419 & $89(21.24 \%)$ & $0(0.00 \%)$ & $0(0.00 \%)$ & $0(0.00 \%)$ & $70(16.71 \%)$ & $29(6.92 \%)$ & $0(0.00 \%)$ & $231(55.13 \%)$ & $0(0.00 \%)$ & $0(0.00 \%)$ \\
\hline ORF8 protein & 1834373969 & 121 & $24(19.83 \%)$ & $0(0.00 \%)$ & $0(0.00 \%)$ & $0(0.00 \%)$ & $43(35.54 \%)$ & $6(4.96 \%)$ & $0(0.00 \%)$ & $48(39.67 \%)$ & $0(0.00 \%)$ & $0(0.00 \%)$ \\
\hline ORF7b & 1834373968 & 43 & $32(74.42 \%)$ & $0(0.00 \%)$ & $0(0.00 \%)$ & $0(0.00 \%)$ & $1(2.33 \%)$ & $1(2.33 \%)$ & $0(0.00 \%)$ & $9(20.93 \%)$ & $0(0.00 \%)$ & $0(0.00 \%)$ \\
\hline ORF7a protein & 1834373967 & 121 & $52(42.98 \%)$ & $0(0.00 \%)$ & $0(0.00 \%)$ & $0(0.00 \%)$ & $23(19.01 \%)$ & $12(9.92 \%)$ & $0(0.00 \%)$ & $34(28.10 \%)$ & $0(0.00 \%)$ & $0(0.00 \%)$ \\
\hline ORF6 protein & 1834373966 & 61 & $43(70.49 \%)$ & $0(0.00 \%)$ & $0(0.00 \%)$ & $0(0.00 \%)$ & $6(9.84 \%)$ & $5(8.20 \%)$ & $0(0.00 \%)$ & $7(11.48 \%)$ & $0(0.00 \%)$ & $0(0.00 \%)$ \\
\hline $\begin{array}{c}\text { membrane } \\
\text { glycoprotein }\end{array}$ & 1834373965 & 222 & $77(34.68 \%)$ & $0(0.00 \%)$ & $0(0.00 \%)$ & $0(0.00 \%)$ & $47(21.17 \%)$ & $15(6.76 \%)$ & $0(0.00 \%)$ & $83(37.39 \%)$ & $0(0.00 \%)$ & $0(0.00 \%)$ \\
\hline envelope protein & 1834373964 & 75 & $33(44.00 \%)$ & $0(0.00 \%)$ & $0(0.00 \%)$ & $0(0.00 \%)$ & $20(26.67 \%)$ & $7(9.33 \%)$ & $0(0.00 \%)$ & $15(20.00 \%)$ & $0(0$. & $0(0.00 \%)$ \\
\hline ORF3a protein & 1834373963 & 275 & $72(26.18 \%)$ & $0(0.00 \%)$ & $0(0.00 \%)$ & $0(0.00 \%)$ & $82(29.82 \%)$ & $\begin{array}{c}28 \\
(10.18 \%) \\
\end{array}$ & $0(0.00 \%)$ & $93(33.82 \%)$ & $0(0.00 \%)$ & $0(0.00 \%)$ \\
\hline surface glycoprotein & 1834373962 & 1273 & $\begin{array}{c}364 \\
(28.59 \%) \\
\end{array}$ & $0(0.00 \%)$ & $0(0.00 \%)$ & $0(0.00 \%)$ & $296(23.25 \%)$ & $43(3.38 \%)$ & $0(0.00 \%)$ & $570(44.78 \%)$ & $0(0.00 \%)$ & $0(0.00 \%)$ \\
\hline ORF1a polyprotein & 1834373961 & 4405 & $\begin{array}{c}1776 \\
(40.32 \%) \\
\end{array}$ & $0(0.00 \%)$ & $0(0.00 \%)$ & $0(0.00 \%)$ & $909(20.64 \%)$ & $\begin{array}{c}351 \\
(7.97 \%) \\
\end{array}$ & $0(0.00 \%)$ & $1369(31.08 \%)$ & $0(0.00 \%)$ & $0(0.00 \%)$ \\
\hline ORF1ab polyprotein & 1834373960 & 7096 & $\begin{array}{c}1933 \\
(38.67 \%)\end{array}$ & $0(0.00 \%)$ & $0(0.00 \%)$ & $0(0.00 \%)$ & $1110(22.20 \%)$ & $\begin{array}{c}496 \\
(9.92 \%)\end{array}$ & $0(0.00 \%)$ & $1460(29.21 \%)$ & $0(0.00 \%)$ & $0(0.00 \%)$ \\
\hline
\end{tabular}




\begin{tabular}{|c|c|c|c|c|c|c|c|c|c|c|c|c|}
\hline Protein & Gene Id & $\begin{array}{c}\text { Lengt } \\
\mathrm{h}\end{array}$ & $\begin{array}{c}\text { Alpha helix } \\
\text { (Hh) }\end{array}$ & $\begin{array}{c}\text { 310 helix } \\
\text { (Gg) }\end{array}$ & $\begin{array}{l}\text { Pi helix } \\
\text { (Ii) }\end{array}$ & $\begin{array}{c}\text { Beta } \\
\text { bridge } \\
\text { (Bb) }\end{array}$ & $\begin{array}{c}\text { Extended } \\
\text { strand (Ee) }\end{array}$ & $\begin{array}{c}\text { Beta turn } \\
\quad(\mathbf{T t})\end{array}$ & $\begin{array}{c}\text { Bend } \\
\text { region (Ss) }\end{array}$ & $\begin{array}{l}\text { Random coil } \\
(\mathbf{C c})\end{array}$ & $\begin{array}{l}\text { Ambiguou } \\
\text { s states (?) }\end{array}$ & $\begin{array}{l}\text { Other } \\
\text { states }\end{array}$ \\
\hline $\begin{array}{l}\text { orf1ab polyprotein } \\
\text { (partial) }\end{array}$ & 1809484492 & 96 & $39(40.62 \%)$ & $0(0.00 \%)$ & $0(0.00 \%)$ & $0(0.00 \%)$ & $24(25.00 \%)$ & $8(8.33 \%)$ & $0(0.00 \%)$ & $25(26.04 \%)$ & $0(0.00 \%)$ & $0(0.00 \%)$ \\
\hline $\begin{array}{c}\text { orf1ab polyprotein } \\
\text { (partial) }\end{array}$ & 1809484490 & 96 & $38(40.00 \%)$ & $0(0.00 \%)$ & $0(0.00 \%)$ & $0(0.00 \%)$ & $24(25.26 \%)$ & $8(8.42 \%)$ & $0(0.00 \%)$ & $25(26.32 \%)$ & $0(0.00 \%)$ & $0(0.00 \%)$ \\
\hline $\begin{array}{c}\text { orf1ab polyprotein } \\
\text { (partial) }\end{array}$ & 1809484488 & 96 & $39(40.62 \%)$ & $0(0.00 \%)$ & $0(0.00 \%)$ & $0(0.00 \%)$ & $24(25.00 \%)$ & $8(8.33 \%)$ & $0(0.00 \%)$ & $25(26.04 \%)$ & $0(0.00 \%)$ & $0(0.00 \%)$ \\
\hline
\end{tabular}


Thus, 3-D protein structures could not generate for them. GMQE is a quality estimate that combines the target- template alignment properties with the template search method. All the generated target proteins have scored within the range (0-1). Hence, it indicates they were good-quality models.

Table 4. Composition of alpha-helix in Malaysia SARS CoV-2 strain's structural and accessory proteins.

\begin{tabular}{|c|c|c|}
\hline & Gene Id & $\begin{array}{c}\text { Residues of } \\
\text { the alpha } \\
\text { helix (Hh) }\end{array}$ \\
\hline ORF10 protein & 1914445506 & 11 \\
\hline $\begin{array}{c}\text { nucleocapsid } \\
\text { phosphoprotein }\end{array}$ & 1914445505 & 18 \\
\hline ORF8 protein & 1914445504 & 10 \\
\hline ORF7b & 1914445503 & 32 \\
\hline ORF7a protein & 1914445502 & 25 \\
\hline ORF6 protein & 1914445501 & 18 \\
\hline $\begin{array}{l}\text { membrane } \\
\text { glycoprotein }\end{array}$ & 1914445500 & 27 \\
\hline envelope protein & 1914445499 & 29 \\
\hline ORF3a protein & 1914445498 & 24 \\
\hline surface glycoprotein & 1914445497 & 124 \\
\hline ORF1a polyprotein & 1914445496 & 69 \\
\hline ORF1ab polyprotein & 1914445495 & 40 \\
\hline ORF10 protein & 1914445474 & 11 \\
\hline $\begin{array}{c}\text { nucleocapsid } \\
\text { phosphoprotein }\end{array}$ & 1914445473 & 18 \\
\hline ORF8 protein & 1914445472 & 10 \\
\hline ORF7b & 1914445471 & 32 \\
\hline ORF7a protein & 1914445470 & 25 \\
\hline ORF6 protein & 1914445469 & 18 \\
\hline $\begin{array}{l}\text { membrane } \\
\text { glycoprotein }\end{array}$ & 1914445468 & 27 \\
\hline envelope protein & 1914445467 & 29 \\
\hline ORF3a protein & 1914445466 & 24 \\
\hline surface glycoprotein & 1914445465 & 124 \\
\hline ORF1a polyprotein & 1914445464 & 69 \\
\hline ORF1ab polyprotein & 1914445463 & 40 \\
\hline $\begin{array}{c}\text { membrane } \\
\text { glycoprotein }\end{array}$ & 1834374001 & 27 \\
\hline $\begin{array}{c}\text { membrane } \\
\text { glycoprotein }\end{array}$ & 1834373991 & 27 \\
\hline surface glycoprotein & 1834374010 & 81 \\
\hline surface glycoprotein & 1834373988 & 124 \\
\hline $\begin{array}{c}\text { ORF1a polyprotein, } \\
\text { partial }\end{array}$ & 1834374009 & 40 \\
\hline $\begin{array}{l}\text { ORF1ab polyprotein, } \\
\text { partial }\end{array}$ & 1834374008 & 46 \\
\hline ORF10 protein & 1834374007 & 11 \\
\hline $\begin{array}{c}\text { nucleocapsid } \\
\text { phosphoprotein }\end{array}$ & 1834374006 & 18 \\
\hline ORF8 protein & 1834374005 & 10 \\
\hline ORF7b & 1834374004 & 32 \\
\hline ORF7a protein & 1834374003 & 25 \\
\hline ORF6 protein & 1834374002 & 18 \\
\hline envelope protein & 1834374000 & 29 \\
\hline ORF3a protein & 1834373999 & 24 \\
\hline ORF10 protein & 1834373997 & 11 \\
\hline $\begin{array}{c}\text { nucleocapsid } \\
\text { phosphoprotein }\end{array}$ & 1834373996 & 18 \\
\hline ORF8 protein & 1834373995 & 10 \\
\hline ORF7b & 1834373994 & 32 \\
\hline ORF7a protein & 1834373993 & 25 \\
\hline ORF6 protein & 1834373992 & 18 \\
\hline envelope protein & 1834373990 & 29 \\
\hline ORF3a protein & 1834373989 & 24 \\
\hline
\end{tabular}




\begin{tabular}{|c|c|c|}
\hline & Gene Id & $\begin{array}{c}\text { Residues of } \\
\text { the alpha } \\
\text { helix (Hh) }\end{array}$ \\
\hline ORF1a polyprotein & 1834373987 & 69 \\
\hline ORF1ab polyprotein & 1834373986 & 40 \\
\hline ORF10 protein & 1834373984 & 11 \\
\hline $\begin{array}{c}\text { nucleocapsid } \\
\text { phosphoprotein }\end{array}$ & 1834373983 & 18 \\
\hline ORF8 protein & 1834373982 & 10 \\
\hline ORF7b & 1834373981 & 32 \\
\hline ORF7a protein & 1834373980 & 25 \\
\hline ORF6 protein & 1834373979 & 18 \\
\hline $\begin{array}{l}\text { membrane } \\
\text { glycoprotein }\end{array}$ & 1834373978 & 27 \\
\hline envelope protein & 1834373977 & 29 \\
\hline ORF3a protein & 1834373976 & 24 \\
\hline surface glycoprotein & 1834373975 & 124 \\
\hline ORF1a polyprotein & 1834373974 & 69 \\
\hline ORF1ab polyprotein & 1834373973 & 40 \\
\hline ORF10 protein & 1834373971 & 11 \\
\hline $\begin{array}{c}\text { nucleocapsid } \\
\text { phosphoprotein }\end{array}$ & 1834373970 & 18 \\
\hline ORF8 protein & 1834373969 & 10 \\
\hline ORF7b & 1834373968 & 32 \\
\hline ORF7a protein & 1834373967 & 25 \\
\hline ORF6 protein & 1834373966 & 18 \\
\hline $\begin{array}{c}\text { membrane } \\
\text { glycoprotein }\end{array}$ & 1834373965 & 27 \\
\hline envelope protein & 1834373964 & 29 \\
\hline ORF3a protein & 1834373963 & 24 \\
\hline surface glycoprotein & 1834373962 & 124 \\
\hline ORF1a polyprotein & 1834373961 & 69 \\
\hline ORF1ab polyprotein & 1834373960 & 40 \\
\hline $\begin{array}{l}\text { orf1ab polyprotein } \\
\text { (partial) }\end{array}$ & 1809484492 & 22 \\
\hline $\begin{array}{l}\text { orf1ab polyprotein } \\
\text { (partial) }\end{array}$ & 1809484490 & 22 \\
\hline $\begin{array}{c}\text { orf1ab polyprotein } \\
\text { (partial) }\end{array}$ & 1809484488 & 22 \\
\hline
\end{tabular}

Table 5. Identification of PDB templates for generation of the 3-D protein models using comparative modeling

\begin{tabular}{|c|c|c|c|c|c|}
\hline \multirow[b]{2}{*}{$\begin{array}{l}\text { Accession } \\
\text { number }\end{array}$} & \multirow[b]{2}{*}{ Protein } & \multicolumn{3}{|c|}{ or $A b$ initio modeling. } & \multirow[b]{2}{*}{$\begin{array}{l}\text { The final } \\
\text { structure/modeling } \\
\text { method selected }\end{array}$} \\
\hline & & $\begin{array}{l}\text { PDB ID } \\
\text { Template }\end{array}$ & $\begin{array}{l}\text { Identity } \\
(\%)\end{array}$ & QMQE & \\
\hline QIA98592 & orf1ab polyprotein(partial) & $5 \mathrm{c} 8 \mathrm{~s}$ & 94.79 & 0.80 & Comparative modeling \\
\hline QIA98593 & orf1ab polyprotein (partial) & $5 \mathrm{c} 8 \mathrm{~s}$ & 94.79 & 0.80 & Comparative modeling \\
\hline QIA98594 & orf1ab polyprotein (partial) & $5 \mathrm{c} 8 \mathrm{~s}$ & 94.79 & 0.80 & Comparative modeling \\
\hline QJD23224 & ORF1a polyprotein & 6woj & 100 & 0 & Comparative modeling \\
\hline QJD23225 & surface glycoprotein & $6 \mathrm{xr} 8$ & 100 & 0.71 & Comparative modeling \\
\hline QJD23226 & ORF3a protein & $6 \mathrm{xdc}$ & 100 & 0.53 & Comparative modeling \\
\hline QJD23227 & envelope protein & $2 \mathrm{~mm} 4$ & 91.38 & 0.39 & Comparative modeling \\
\hline QJD23228 & membrane glycoprotein & $7 \mathrm{kjr}$ & 17.17 & 0.19 & Ab initio modeling \\
\hline QJD23229 & ORF6 protein & $6 \mathrm{xwx}$ & 14.63 & 0.21 & Ab initio modeling \\
\hline QJD23230 & ORF7a protein & 1 yo4 & 91.57 & 0.45 & Comparative modeling \\
\hline QJD23231 & ORF7b & $5 \mathrm{~h} 2 \mathrm{f}$ & 23.08 & 0.36 & Ab initio modeling \\
\hline QJD23232 & ORF8 protein & $7 \mathrm{jx} 6$ & 100 & 0.68 & Comparative modeling \\
\hline QJD23233 & $\begin{array}{l}\text { nucleocapsid } \\
\text { phosphoprotein }\end{array}$ & $6 w z q$ & 100 & 0.14 & Comparative modeling \\
\hline QJD23236 & ORF1a polyprotein & 6yyt & 100 & 0 & Comparative modeling \\
\hline QJD23237 & surface glycoprotein & $6 x r 8$ & 100 & 0.71 & Comparative modeling \\
\hline QJD23238 & ORF3a protein & $6 \mathrm{xdc}$ & 100 & 0.53 & Comparative modeling \\
\hline QJD23239 & envelope protein & $2 \mathrm{~mm} 4$ & 91.38 & 0.39 & Comparative modeling \\
\hline QJD23240 & membrane glycoprotein & $5 x p d$ & 26.92 & 0 & Ab initio modeling \\
\hline QJD23241 & ORF6 protein & $6 \mathrm{xwx}$ & 14.63 & 0.21 & Ab initio modeling \\
\hline QJD23242 & ORF7a protein & 1yo4 & 91.57 & 0.45 & Comparative modeling \\
\hline QJD23243 & ORF7b & $5 \mathrm{~h} 2 \mathrm{f}$ & 23.08 & 0.36 & Ab initio modeling \\
\hline
\end{tabular}




\begin{tabular}{|c|c|c|c|c|c|}
\hline $\begin{array}{l}\text { Accession } \\
\text { number }\end{array}$ & Protein & $\begin{array}{l}\text { PDB ID } \\
\text { Template }\end{array}$ & $\begin{array}{l}\text { Identity } \\
(\%)\end{array}$ & QMQE & $\begin{array}{l}\text { The final } \\
\text { structure/modeling } \\
\text { method selected }\end{array}$ \\
\hline QJD23244 & ORF8 protein & $7 \mathrm{jx} 6$ & 100 & 0.68 & Comparative modeling \\
\hline QJD23245 & $\begin{array}{l}\text { nucleocapsid } \\
\text { phosphoprotein }\end{array}$ & 4ud1 & 50.93 & 0.18 & Comparative modeling \\
\hline QJD23250 & ORF3a protein & $6 \mathrm{xdc}$ & 100 & 0.53 & Comparative modeling \\
\hline QJD23251 & envelope protein & $2 \mathrm{~mm} 4$ & 91.38 & 0.39 & Comparative modeling \\
\hline QJD23253 & ORF6 protein & 6xwx & 14.63 & 0.21 & Comparative modeling \\
\hline QJD23254 & ORF7a protein & 1yo4 & 91.57 & 0.45 & Comparative modeling \\
\hline QJD23255 & ORF7b & $5 \mathrm{~h} 2 \mathrm{f}$ & 23.08 & 0.36 & Ab initio modeling \\
\hline QJD23256 & ORF8 protein & $7 \mathrm{jx} 6$ & 100 & 0.68 & Comparative modeling \\
\hline QJD23257 & $\begin{array}{l}\text { nucleocapsid } \\
\text { phosphoprotein }\end{array}$ & 6wzq & 100 & 0.14 & Comparative modeling \\
\hline QJD23259 & ORF3a protein & $6 x d c$ & 100 & 0.53 & Comparative modeling \\
\hline QJD23260 & envelope protein & $2 \mathrm{~mm} 4$ & 91.38 & 0.39 & Comparative modeling \\
\hline QJD23262 & ORF6 protein & $6 x w x$ & 14.63 & 0.21 & Comparative modeling \\
\hline QJD23263 & ORF7a protein & 1yo4 & 100 & 0.45 & Comparative modeling \\
\hline QJD23264 & ORF7b & $5 \mathrm{~h} 2 \mathrm{f}$ & 23.08 & 0.36 & Ab initio modeling \\
\hline QJD23265 & ORF8 protein & $7 \mathrm{jx} 6$ & 100 & 0.68 & Comparative modeling \\
\hline QOI53581 & ORF3a protein & $6 x d c$ & 99.64 & 0.53 & Comparative modeling \\
\hline QOI53582 & envelope protein & $2 \mathrm{~mm} 4$ & 91.38 & 0.39 & Comparative modeling \\
\hline QOI53583 & membrane glycoprotein & $7 \mathrm{kjr}$ & 17.17 & 0.19 & Ab initio modeling \\
\hline QOI53584 & ORF6 protein & $6 \mathrm{xwx}$ & 14.63 & 0.21 & Ab initio modeling \\
\hline QOI53585 & ORF7a protein & 1yo4 & 91.54 & 0.45 & Comparative modeling \\
\hline QOI53586 & ORF7b & $5 \mathrm{~h} 2 \mathrm{f}$ & 23.08 & 0.36 & Ab initio modeling \\
\hline QOI53587 & ORF8 protein & $7 \mathrm{jx} 6$ & 99.04 & 0.67 & Comparative modeling \\
\hline QOI53588 & $\begin{array}{l}\text { nucleocapsid } \\
\text { phosphoprotein }\end{array}$ & $6 w z q$ & 100 & 0.14 & Comparative modeling \\
\hline QOI53592 & surface glycoprotein & $6 x r 8$ & 99.92 & 0.72 & Comparative modeling \\
\hline QOI53593 & ORF3a protein & $6 \mathrm{xdc}$ & 100 & 0.53 & Comparative modeling \\
\hline QOI53594 & envelope protein & $2 \mathrm{~mm} 4$ & 91.38 & 0.39 & Comparative modeling \\
\hline QOI53595 & membrane glycoprotein & $5 x p d$ & 26.92 & 0.00 & Ab initio modeling \\
\hline QOI53596 & ORF6 protein & $6 \mathrm{xwx}$ & 14.63 & 0.21 & Ab initio modeling \\
\hline QOI53597 & ORF7a protein & 1yo4 & 91.57 & 0.45 & Comparative modeling \\
\hline QOI53598 & ORF7b & $5 \mathrm{~h} 2 \mathrm{f}$ & 23.08 & 0.36 & Ab initio modeling \\
\hline QOI53599 & ORF8 protein & $7 \mathrm{jx} 6$ & 100 & 0.68 & Comparative modeling \\
\hline QOI53600 & $\begin{array}{l}\text { nucleocapsid } \\
\text { phosphoprotein }\end{array}$ & $6 w z q$ & 100 & 0.14 & Comparative modeling \\
\hline
\end{tabular}

\subsection{Protein model evaluation.}

ERRAT (so-called "overall quality factor") validates models by statistical relation of non-bonded interactions among different atom types based on characteristic atomic interaction, with higher scores indicating higher quality. The generally accepted range is $>50$ for a highquality model [20]. Table 6 illustrates the ERRAT score of predicted models, which ranged from 60.606 to $100 \%$. Thus, all the predicted target protein models were passed the ERRAT validation test, and they were considered stable proteins. The result analysis of ERRAT score revealed that all ORF7b, some membrane glycoprotein (QJD23228, QJD23240, QOI53595), and ORF1a polyprotein (QJD23224) had the highest score (100\%). Thus, it was confirmed that the models had a good quality and high resolution.

Table 6. Verification of the Malaysia SARS-CoV-2 strain's structural and accessory protein structures using ERRAT.

\begin{tabular}{l|l|l} 
Accession number & Protein & Overall Quality Factor $(\%)$ \\
\hline QIA98592 & orf1ab polyprotein(partial) & 83.133 \\
\hline QIA98593 & orf1ab polyprotein (partial) & 83.1325 \\
\hline QIA98594 & orf1ab polyprotein (partial) & 83.1325 \\
\hline QJD23224 & ORF1a polyprotein & 100.000 \\
\hline QJD23225 & surface glycoprotein & 90.906 \\
\hline QJD23226 & ORF3a protein & 98.066 \\
\hline QJD23227 & envelope protein & 68.000 \\
\hline $\begin{array}{l}\text { QJD23228 } \\
\text { https://biointerfaceresearch.com/ }\end{array}$ & membrane glycoprotein & 100.000 \\
& &
\end{tabular}




\begin{tabular}{|c|c|c|}
\hline Accession number & Protein & Overall Quality Factor (\%) \\
\hline QJD23229 & ORF6 protein & 60.606 \\
\hline QJD23230 & ORF7a protein & 77.465 \\
\hline QJD23231 & ORF7b & 100.000 \\
\hline QJD23232 & ORF8 protein & 83.815 \\
\hline QJD23233 & nucleocapsid phosphoprotein & 97.727 \\
\hline QJD23236 & ORF1a polyprotein & 88.372 \\
\hline QJD23237 & surface glycoprotein & 90.906 \\
\hline QJD23238 & ORF3a protein & 98.066 \\
\hline QJD23239 & envelope protein & 68.000 \\
\hline QJD23240 & membrane glycoprotein & 100.000 \\
\hline QJD23241 & ORF6 protein & 60.606 \\
\hline QJD23242 & ORF7a protein & 77.465 \\
\hline QJD23243 & ORF7b & 100.000 \\
\hline QJD23244 & ORF8 protein & 83.815 \\
\hline QJD23245 & nucleocapsid phosphoprotein & 97.727 \\
\hline QJD23250 & ORF3a protein & 98.066 \\
\hline QJD23251 & envelope protein & 68.000 \\
\hline QJD23253 & ORF6 protein & 60.606 \\
\hline QJD23254 & ORF7a protein & 77.465 \\
\hline QJD23255 & ORF7b & 100.000 \\
\hline QJD23256 & ORF8 protein & 83.815 \\
\hline QJD23257 & nucleocapsid phosphoprotein & 97.727 \\
\hline QJD23259 & ORF3a protein & 98.066 \\
\hline QJD23260 & envelope protein & 68.000 \\
\hline QJD23262 & ORF6 protein & 60.606 \\
\hline QJD23263 & ORF7a protein & 77.465 \\
\hline QJD23264 & ORF7b & 100.000 \\
\hline QJD23265 & ORF8 protein & 83.815 \\
\hline QOI53581 & ORF3a protein & 96.961 \\
\hline QOI53582 & envelope protein & 68.000 \\
\hline QOI53583 & membrane glycoprotein & 70.968 \\
\hline QOI53584 & ORF6 protein & 60.606 \\
\hline QOI53585 & ORF7a protein & 77.465 \\
\hline QOI53586 & ORF7b & 100.000 \\
\hline QOI53587 & ORF8 protein & 80.347 \\
\hline QOI53588 & nucleocapsid phosphoprotein & 97.727 \\
\hline QOI53592 & surface glycoprotein & 90.281 \\
\hline QOI53593 & ORF3a protein & 98.066 \\
\hline QOI53594 & envelope protein & 68.000 \\
\hline QOI53595 & membrane glycoprotein & 100.000 \\
\hline QOI53596 & ORF6 protein & 60.606 \\
\hline QOI53597 & ORF7a protein & 77.465 \\
\hline QOI53598 & ORF7b & 100.000 \\
\hline QOI53599 & ORF8 protein & 83.815 \\
\hline QOI53600 & nucleocapsid phosphoprotein & 97.727 \\
\hline
\end{tabular}

The stereochemical quality of the models was further evaluated by Verify 3D analysis. The model was considered 'pass' if $80 \%$ of the amino acids have scored $>=0.2$ in the $3 \mathrm{D} / 1 \mathrm{D}$ profile. Based on Table 7, ORF1a polyprotein (QJD23224), ORF8 protein (QJD23232, QJD23244, QJD23256, QJD23265, QOI53587, QOI53599), and membrane glycoprotein (QOI53583) have passed the evaluation. Hence, it indicates that the sequences were compatible with their protein models.

Table 7. Verify 3D analysis of the Malaysia SARS-CoV-2 strain's structural and accessory protein structures.

\begin{tabular}{l|l|l|l} 
Protein & Accession number & Percentage $(\%)$ & Verification \\
\hline orf1ab polyprotein (partial) & QIA98592 & 59.38 & Fail \\
\hline orf1ab polyprotein (partial) & QIA98593 & 59.38 & Fail \\
\hline orf1ab polyprotein (partial) & QIA98594 & 59.38 & Fail \\
\hline ORF1a polyprotein & QJD23224 & 95.86 & Pass \\
\hline surface glycoprotein & QJD23225 & 72.22 & Fail \\
\hline ORF3a protein & QJD23226 & 39.20 & Fail \\
\hline envelope protein & QJD23227 & 0.00 & Fail \\
\hline membrane glycoprotein & QJD23228 & 0.00 & Fail
\end{tabular}




\begin{tabular}{|c|c|c|c|}
\hline Protein & Accession number & Percentage (\%) & Verification \\
\hline ORF6 protein & QJD23229 & 0.00 & Fail \\
\hline ORF7a protein & QJD23230 & 59.04 & Fail \\
\hline ORF7b & QJD23231 & 0.00 & Fail \\
\hline ORF8 protein & QJD23232 & 85.10 & Pass \\
\hline nucleocapsid phosphoprotein & QJD23233 & 60.53 & Fail \\
\hline ORF1a polyprotein & QJD23236 & 49.46 & Fail \\
\hline surface glycoprotein & QJD23237 & 72.22 & Fail \\
\hline ORF3a protein & QJD23238 & 39.20 & Fail \\
\hline envelope protein & QJD23239 & 0.00 & Fail \\
\hline membrane glycoprotein & QJD23240 & 0.00 & Fail \\
\hline ORF6 protein & QJD23241 & 0.00 & Fail \\
\hline ORF7a protein & QJD23242 & 59.04 & Fail \\
\hline ORF7b & QJD23243 & 0.00 & Fail \\
\hline ORF8 protein & QJD23244 & 85.10 & Pass \\
\hline nucleocapsid phosphoprotein & QJD23245 & 60.53 & Fail \\
\hline ORF3a protein & QJD23250 & 39.20 & Fail \\
\hline envelope protein & QJD23251 & 0.00 & Fail \\
\hline ORF6 protein & QJD23253 & 0.00 & Fail \\
\hline ORF7a protein & QJD23254 & 59.04 & Fail \\
\hline ORF7b & QJD23255 & 0.00 & Fail \\
\hline ORF8 protein & QJD23256 & 85.10 & Pass \\
\hline nucleocapsid phosphoprotein & QJD23257 & 60.53 & Fail \\
\hline ORF3a protein & QJD23259 & 39.20 & Fail \\
\hline envelope protein & QJD23260 & 0.00 & Fail \\
\hline ORF6 protein & QJD23262 & 0.00 & Fail \\
\hline ORF7a protein & QJD23263 & 59.04 & Fail \\
\hline ORF7b & QJD23264 & 0.00 & Fail \\
\hline ORF8 protein & QJD23265 & 85.10 & Pass \\
\hline ORF3a protein & QOI53581 & 39.20 & Fail \\
\hline envelope protein & QOI53582 & 0.00 & Fail \\
\hline membrane glycoprotein & QOI53583 & 85.15 & Pass \\
\hline ORF6 protein & QOI53584 & 0.00 & Fail \\
\hline ORF7a protein & QOI53585 & 59.04 & Fail \\
\hline ORF7b & QOI53586 & 0.00 & Fail \\
\hline ORF8 protein & QOI53587 & 87.98 & Pass \\
\hline nucleocapsid phosphoprotein & QOI53588 & 60.53 & Fail \\
\hline surface glycoprotein & QOI53592 & 72.46 & Fail \\
\hline ORF3a protein & QOI53593 & 39.20 & Fail \\
\hline envelope protein & QOI53594 & 0.00 & Fail \\
\hline membrane glycoprotein & QOI53595 & 0.00 & Fail \\
\hline ORF6 protein & QOI53596 & 0.00 & Fail \\
\hline ORF7a protein & QOI53597 & 59.04 & Fail \\
\hline ORF7b & QOI53598 & 0.00 & Fail \\
\hline ORF8 protein & QOI53599 & 85.10 & Pass \\
\hline nucleocapsid phosphoprotein & QOI53600 & 60.53 & Fail \\
\hline
\end{tabular}

Pass - At least 80 of the amino acids have scored $>=0.2$ in the $3 \mathrm{D} / 1 \mathrm{D}$ profile. Fail - Fewer than 80 of the amino acids have scored $>=0.2$ in the $3 \mathrm{D} / 1 \mathrm{D}$ profile.

For the stereo-chemical quality and the geometry of protein models, they were validated by Ramachandran plot calculations through PROCHECK software. In general, a score close to $100 \%$ implies a good stereo-chemical quality of the model [20]. The 'favorable region' is the region where the amino acid residues mostly reside. The amino acid residues are sometimes found outside the 'favorable region', which is also permitted for the stable protein structure, known as 'allowed region'; and the rest regions in the Ramachandran plot are known as' 'outlier region' $[20,35]$. The results (Table 8 ) confirmed that most protein models' residues are in the most favorable region, more than $80 \%$ except for the protein models of ORF7a, where they scored $66.7 \%$. On the other hand, the predicted model for ORF7b showed $100 \%$ of the residues fall within the most favored region. Therefore, these PROCHECK results suggest that most of the predicted models were of good quality and dependable. 
Table 8. Validation of structural and accessory proteins of Malaysia SARS-CoV-2 strain using PROCHECK.

\begin{tabular}{|c|c|c|c|c|c|c|c|c|}
\hline \multirow[b]{2}{*}{$\begin{array}{c}\text { Accession } \\
\text { number }\end{array}$} & \multirow[t]{2}{*}{ Protein } & \multicolumn{4}{|c|}{ Ramachandran plot statistics (\%) } & \multicolumn{3}{|c|}{ Goodness factor } \\
\hline & & $\begin{array}{c}\text { Most } \\
\text { favored }\end{array}$ & $\begin{array}{l}\text { Additionally } \\
\text { allowed }\end{array}$ & $\begin{array}{l}\text { Generously } \\
\text { allowed }\end{array}$ & Disallowed & $\begin{array}{c}\text { Dihedral } \\
\text { angles }\end{array}$ & $\begin{array}{l}\text { Covalent } \\
\text { forces }\end{array}$ & $\begin{array}{l}\text { Overall } \\
\text { average }\end{array}$ \\
\hline QIA98592 & orf1ab polyprotein (partial) & 91.9 & 8.1 & 0.0 & 0.0 & -0.47 & -0.32 & -0.38 \\
\hline QIA98593 & orf1ab polyprotein (partial) & 91.9 & 8.1 & 0.0 & 0.0 & -0.47 & -0.32 & -0.38 \\
\hline QIA98594 & orf1ab polyprotein (partial) & 91.9 & 8.1 & 0.0 & 0.0 & -0.47 & -0.32 & -0.38 \\
\hline QJD23224 & ORF1a polyprotein & 91.9 & 7.4 & 0.7 & 0.0 & -0.15 & 0.06 & -0.06 \\
\hline QJD23225 & surface glycoprotein & 89.3 & 10.0 & 0.7 & 0.1 & -0.31 & 0.01 & -0.17 \\
\hline QJD23226 & ORF3a protein & 91.8 & 7.7 & 0.5 & 0.0 & -0.28 & 0.02 & -0.15 \\
\hline QJD23227 & envelope protein & 92.6 & 7.4 & 0.0 & 0.0 & -0.26 & -0.10 & -0.18 \\
\hline QJD23228 & membrane glycoprotein & 95.8 & 4.2 & 0.0 & 0.0 & 0.22 & -0.20 & 0.05 \\
\hline QJD23229 & ORF6 protein & 94.9 & 5.1 & 0.0 & 0.0 & 0.14 & -0.06 & 0.08 \\
\hline QJD23230 & ORF7a protein & 66.7 & 26.4 & 4.2 & 2.8 & -0.79 & -0.12 & -0.51 \\
\hline QJD23231 & ORF7b & 100.0 & 0.0 & 0.0 & 0.0 & 0.26 & 0.02 & 0.17 \\
\hline QJD23232 & ORF8 protein & 87.4 & 10.4 & 0.5 & 1.6 & -0.28 & -0.02 & -0.17 \\
\hline QJD23233 & $\begin{array}{c}\text { nucleocapsid } \\
\text { phosphoprotein }\end{array}$ & 95.9 & 4.1 & 0.0 & 0.0 & -0.07 & 0.14 & 0.03 \\
\hline QJD23236 & ORF1a polyprotein & 96.0 & 4.0 & 0.0 & 0.0 & -0.15 & 0.08 & -0.05 \\
\hline QJD23237 & surface glycoprotein & 89.3 & 10.0 & 0.7 & 0.1 & -0.31 & 0.01 & -0.17 \\
\hline QJD23238 & ORF3a protein & 91.8 & 7.7 & 0.5 & 0.0 & -0.28 & 0.02 & -0.15 \\
\hline QJD23239 & envelope protein & 92.6 & 7.4 & 0.0 & 0.0 & -0.26 & -0.10 & -0.18 \\
\hline QJD23240 & membrane glycoprotein & 95.8 & 4.2 & 0.0 & 0.0 & 0.22 & -0.20 & 0.05 \\
\hline QJD23241 & ORF6 protein & 94.9 & 5.1 & 0.0 & 0.0 & 0.14 & -0.06 & 0.08 \\
\hline QJD23242 & ORF7a protein & 66.7 & 26.4 & 4.2 & 2.8 & -0.79 & -0.12 & -0.51 \\
\hline QJD23243 & ORF7b & 100.0 & 0.0 & 0.0 & 0.0 & 0.26 & 0.02 & 0.17 \\
\hline QJD23244 & ORF8 protein & 87.4 & 10.4 & 0.5 & 1.6 & -0.28 & -0.02 & -0.17 \\
\hline QJD23245 & $\begin{array}{c}\text { nucleocapsid } \\
\text { phosphoprotein }\end{array}$ & 95.9 & 4.1 & 0.0 & 0.0 & -0.07 & 0.14 & 0.03 \\
\hline QJD23250 & ORF3a protein & 91.8 & 7.7 & 0.5 & 0.0 & -0.28 & 0.02 & -0.15 \\
\hline QJD23251 & envelope protein & 92.6 & 7.4 & 0.0 & 0.0 & -0.26 & -0.10 & -0.18 \\
\hline QJD23253 & ORF6 protein & 94.9 & 5.1 & 0.0 & 0.0 & 0.14 & -0.06 & 0.08 \\
\hline QJD23254 & ORF7a protein & 66.7 & 26.4 & 4.2 & 2.8 & -0.79 & -0.12 & -0.51 \\
\hline QJD23255 & ORF7b & 100.0 & 0.0 & 0.0 & 0.0 & 0.26 & 0.02 & 0.17 \\
\hline QJD23256 & ORF8 protein & 87.4 & 10.4 & 0.5 & 1.6 & -0.28 & -0.02 & -0.17 \\
\hline QJD23257 & $\begin{array}{c}\text { nucleocapsid } \\
\text { phosphoprotein }\end{array}$ & 95.9 & 4.1 & 0.0 & 0.0 & -0.07 & 0.14 & 0.03 \\
\hline QJD23259 & ORF3a protein & 91.8 & 7.7 & 0.5 & 0.0 & -0.28 & 0.02 & -0.15 \\
\hline QJD23260 & envelope protein & 92.6 & 7.4 & 0.0 & 0.0 & -0.26 & -0.10 & -0.18 \\
\hline QJD23262 & ORF6 protein & 94.9 & 5.1 & 0.0 & 0.0 & 0.14 & -0.06 & 0.08 \\
\hline
\end{tabular}

https://biointerfaceresearch.com/ 


\begin{tabular}{|c|c|c|c|c|c|c|c|c|}
\hline \multirow[b]{2}{*}{$\begin{array}{l}\text { Accession } \\
\text { number }\end{array}$} & \multirow[t]{2}{*}{ Protein } & \multicolumn{4}{|c|}{ Ramachandran plot statistics (\%) } & \multicolumn{3}{|c|}{ Goodness factor } \\
\hline & & $\begin{array}{c}\text { Most } \\
\text { favored }\end{array}$ & $\begin{array}{l}\text { Additionally } \\
\text { allowed }\end{array}$ & $\begin{array}{l}\text { Generously } \\
\text { allowed }\end{array}$ & Disallowed & $\begin{array}{l}\text { Dihedral } \\
\text { angles }\end{array}$ & $\begin{array}{l}\text { Covalent } \\
\text { forces }\end{array}$ & $\begin{array}{l}\text { Overall } \\
\text { average }\end{array}$ \\
\hline QJD23263 & ORF7a protein & 66.7 & 26.4 & 4.2 & 2.8 & -0.79 & -0.12 & -0.51 \\
\hline QJD23264 & ORF7b & 100.0 & 0.0 & 0.0 & 0.0 & 0.26 & 0.02 & 0.17 \\
\hline QJD23265 & ORF8 protein & 87.4 & 10.4 & 0.5 & 1.6 & -0.28 & -0.02 & -0.17 \\
\hline QOI53581 & ORF3a protein & 91.8 & 7.7 & 0.5 & 0.0 & -0.28 & 0.02 & -0.15 \\
\hline QOI53582 & envelope protein & 92.6 & 7.4 & 0.0 & 0.0 & -0.26 & -0.10 & -0.18 \\
\hline QOI53583 & membrane glycoprotein & 88.4 & 8.1 & 3.5 & 0.0 & -0.43 & -0.29 & -0.36 \\
\hline QOI53584 & ORF6 protein & 94.9 & 5.1 & 0.0 & 0.0 & 0.14 & -0.06 & 0.08 \\
\hline QOI53585 & ORF7a protein & 66.7 & 26.4 & 4.2 & 2.8 & -0.79 & -0.12 & -0.51 \\
\hline QOI53586 & ORF7b & 100.0 & 0.0 & 0.0 & 0.0 & 0.26 & 0.02 & 0.17 \\
\hline QOI53587 & ORF8 protein & 86.3 & 12.6 & 1.1 & 0.0 & -0.30 & -0.08 & -0.21 \\
\hline QOI53588 & $\begin{array}{l}\text { nucleocapsid } \\
\text { phosphoprotein }\end{array}$ & 95.9 & 4.1 & 0.0 & 0.0 & -0.07 & 0.14 & 0.03 \\
\hline QOI53592 & surface glycoprotein & 88.8 & 10.5 & 0.7 & 0.0 & -0.28 & 0.04 & -0.14 \\
\hline QOI53593 & ORF3a protein & 91.8 & 7.7 & 0.5 & 0.0 & -0.28 & 0.02 & -0.15 \\
\hline QOI53594 & envelope protein & 92.6 & 7.4 & 0.0 & 0.0 & -0.26 & -0.10 & -0.18 \\
\hline QOI53595 & membrane glycoprotein & 95.8 & 4.2 & 0.0 & 0.0 & 0.22 & -0.20 & 0.05 \\
\hline QOI53596 & ORF6 protein & 94.9 & 5.1 & 0.0 & 0.0 & 0.14 & -0.06 & 0.08 \\
\hline QOI53597 & ORF7a protein & 66.7 & 26.4 & 4.2 & 2.8 & -0.79 & -0.12 & -0.51 \\
\hline QOI53598 & ORF7b & 100.0 & 0.0 & 0.0 & 0.0 & 0.26 & 0.02 & 0.17 \\
\hline QOI53599 & ORF8 protein & 87.4 & 10.4 & 0.5 & 1.6 & -0.28 & -0.02 & -0.17 \\
\hline QOI53600 & $\begin{array}{c}\text { nucleocapsid } \\
\text { phosphoprotein }\end{array}$ & 95.9 & 4.1 & 0.0 & 0.0 & -0.07 & 0.14 & 0.03 \\
\hline
\end{tabular}


Moreover, the stereo-chemical evaluation for goodness factors involves phi/psi dihedral angles, covalent forces, and overall averages. The best quality model has a value close to zero. All the protein models had values within the acceptable range (between -0.5 and 0 ).

\subsection{Biochemical function prediction.}

ProFunc is a metaserver that combines sequence, global structure, and local structurebased methods to obtain a set of function predictions from which one might seek consensus. First, the protein of unknown function is analyzed by numerous sequence searches. BLAST analysis scans both the PDB and UniProt and uses multiple sequence alignment to determine sequence similarities and detect sequence motifs. Gene neighbors are also examined based on the query protein's predicted location within the genome. The genes located near each other are often functionally related or functionally similar [18]. Next, structure-based analyses are performed on the protein of interest. This involves searching some databases for global folds or local structures that are similar to the query protein. The functional analysis of the Malaysia SARS-CoV-2 strain's structural and accessory proteins obtained from the Profunc server is presented in Table 9. The Profunc server was used to predict the protein function by analyzing the functional motif and close relationships to characterized functional proteins. The Profunc comprises the protein name terms, a summary of predicted function with gene ontology terms, a description of the biological process, molecular function, and cellular component of gene products.

Gene ontology revealed that ORF8 protein is actively involved in adaptive immune response; ORF7a protein responsible for mRNA polyadenylation; envelope protein is important for DNA replication; surface glycoprotein plays a vital role in pathogenesis, viral reproduction, and virion attachment to host cell surface receptor evasion by virus of host immune response; nucleocapsid phosphoprotein actively participate in metabolic process, cellular process, primary metabolic process and establishment of localization; membrane glycoprotein mainly involved in tRNA modification, tRNA processing, and tRNA methylation; and ORF1ab plays an important role in polyprotein rRNA processing, methylation, rRNA base methylation, cellular and component biogenesis.

Table 9. Predicted functions of SARS-CoV-2 structural and accessory proteins identified in Malaysia with respective ProFunc scores (shown within parenthesis).

\begin{tabular}{|c|c|c|c|c|}
\hline \multirow{3}{*}{ Protein } & \multirow{3}{*}{ Protein name terms } & \multicolumn{3}{|c|}{ Summary of predicted function } \\
\hline & & \multicolumn{3}{|c|}{ Gene Ontology (GO) terms } \\
\hline & & Cellular component & Biological process & $\begin{array}{l}\text { Biochemical } \\
\text { function }\end{array}$ \\
\hline $\begin{array}{l}\text { ORF1ab } \\
\text { polyprotein } \\
\text { (QIA98592) }\end{array}$ & $\begin{array}{l}\text { Domain (3.96) finger } \\
\text { (1.51) zinc finger } \\
\text { (1.16) catalytic } \\
\text { domain }(1.00) \text { SARS- } \\
\text { CoV nsp10/nsp14 } \\
\text { dynamic }(0.90) \text { SARS } \\
\text { coronavirus nsp14- } \\
\text { nsp10 }(0.90) \\
\text { functional ligands } \\
\text { SAH }(0.90) \text { gpppa } \\
(0.90)\end{array}$ & & $\begin{array}{l}\text { rRNA processing } \\
(0.50) \text { methylation } \\
(0.50) \text { rRNA base } \\
\text { methylation }(0.50) \\
\text { cellular component } \\
\text { biogenesis }(0.50)\end{array}$ & $\begin{array}{l}\text { Metal ion binding } \\
(0.84) \text { binding }(0.84) \\
\text { ion binding }(0.84) \\
\text { cation binding }(0.84)\end{array}$ \\
\hline $\begin{array}{l}\text { ORF1ab } \\
\text { polyprotein } \\
\text { (QIA98593) }\end{array}$ & $\begin{array}{l}\text { Domain (3.96) finger } \\
\text { (1.51) zinc finger } \\
\text { (1.16) catalytic } \\
\text { domain (1.00) SARS- } \\
\text { CoV nsp10/nsp14 } \\
\text { dynamic (0.90) SARS } \\
\text { coronavirus nsp14- }\end{array}$ & & $\begin{array}{l}\text { rRNA processing } \\
(0.50) \text { methylation } \\
(0.50) \text { rRNA base } \\
\text { methylation }(0.50) \\
\text { cellular component } \\
\text { biogenesis }(0.50)\end{array}$ & $\begin{array}{l}\text { Metal ion binding } \\
(0.84) \text { binding }(0.84) \\
\text { ion binding }(0.84) \\
\text { cation binding }(0.84)\end{array}$ \\
\hline
\end{tabular}




\begin{tabular}{|c|c|c|c|c|}
\hline \multirow{3}{*}{ Protein } & \multirow{3}{*}{ Protein name terms } & \multicolumn{3}{|c|}{ Summary of predicted function } \\
\hline & & \multicolumn{3}{|c|}{ Gene Ontology (GO) terms } \\
\hline & & Cellular component & Biological process & $\begin{array}{l}\text { Biochemical } \\
\text { function }\end{array}$ \\
\hline & $\begin{array}{l}\text { nsp10 }(0.90) \\
\text { functional ligands } \\
\text { SAH }(0.90) \text { gpppa } \\
(0.90)\end{array}$ & & & \\
\hline $\begin{array}{l}\text { ORF1ab } \\
\text { polyprotein } \\
\text { (QIA98594) }\end{array}$ & $\begin{array}{l}\text { Domain (3.96) finger } \\
\text { (1.51) zinc finger } \\
\text { (1.16) catalytic } \\
\text { domain }(1.00) \text { SARS- } \\
\text { CoV nsp10/nsp14 } \\
\text { dynamic }(0.90) \text { SARS } \\
\text { coronavirus nsp14- } \\
\text { nsp10 (0.90) } \\
\text { functional ligands } \\
\text { SAH }(0.90) \text { gpppa } \\
(0.90)\end{array}$ & & $\begin{array}{l}\text { rRNA processing } \\
(0.50) \text { methylation } \\
(0.50) \text { rRNA base } \\
\text { methylation }(0.50) \\
\text { cellular component } \\
\text { biogenesis }(0.50)\end{array}$ & $\begin{array}{l}\text { Metal ion binding } \\
(0.84) \text { binding }(0.84) \\
\text { ion binding }(0.84) \\
\text { cation binding }(0.84)\end{array}$ \\
\hline $\begin{array}{l}\text { ORF1a } \\
\text { polyprotein } \\
\text { (QJD23224) }\end{array}$ & $\begin{array}{l}\text { Domain (6.64) macro } \\
(5.61) \text { macro domain } \\
(4.77) \mathrm{nsp} 3(2.73) \\
\text { ADP-ribose }(2.12) \\
\text { coronavirus }(2.01) \\
\text { virus }(1.93) \\
\text { phosphatase }(1.80)\end{array}$ & & $\begin{array}{l}\text { Purine nucleoside } \\
\text { metabolic process } \\
(0.91) \text { response to } \\
\text { antibiotic }(0.91) \\
\text { negative regulation of } \\
\text { ribonuclease activity } \\
(0.91) \text { negative } \\
\text { regulation of } \\
\text { endoribonuclease } \\
\text { activity }(0.91)\end{array}$ & $\begin{array}{l}\text { Purine nucleoside } \\
\text { binding }(0.91) \\
\text { ribonuclease inhibitor } \\
\text { activity }(0.91) \\
\text { hydrolase activity } \\
(0.91) \text { deacetylase } \\
\text { activity }(0.91)\end{array}$ \\
\hline $\begin{array}{l}\text { Surface } \\
\text { glycoprotein } \\
\text { (QJD23225) }\end{array}$ & $\begin{array}{l}\text { Spike (7.15) SARS- } \\
\text { CoV-2 (3.60) domain } \\
(3.40) \text { receptor- } \\
\text { binding domain }(2.93) \\
\text { RBD (2.37) SARS } \\
(2.23) \text { spike } \\
\text { glycoprotein }(2.18) \\
\text { ace2 (2.09) }\end{array}$ & $\begin{array}{l}\text { Membrane }(2.19) \\
\text { integral to membrane } \\
(2.19) \text { virion }(2.19) \\
\text { viral envelope (2.19) }\end{array}$ & $\begin{array}{l}\text { Pathogenesis (2.19) } \\
\text { viral reproduction } \\
\text { (2.19) virion } \\
\text { attachment to host cell } \\
\text { surface receptor (2.19) } \\
\text { evasion by virus of } \\
\text { host immune response } \\
(2.19)\end{array}$ & $\begin{array}{l}\text { Protein binding (2.19) } \\
\text { identical protein } \\
\text { binding (2.19) } \\
\text { binding (2.19) host } \\
\text { cell surface receptor } \\
\text { binding (1.10) }\end{array}$ \\
\hline $\begin{array}{l}\text { ORF3a protein } \\
\text { (QJD23226) }\end{array}$ & $\begin{array}{l}\text { Human }(1.33) \\
\text { covalent }(1.24) \\
\text { domain }(1.23) \\
\text { hydrolase }(0.89) \\
\text { domain human }(0.84) \\
\text { saga dub module } \\
(0.53) \text { usp21 }(0.52) \\
\text { covalent ubiquitin- } \\
\text { usp5 }(0.50)\end{array}$ & $\begin{array}{l}\text { Cell (2.73) cell part } \\
(2.73) \text { nucleus }(2.18) \\
\text { intracellular }(2.18)\end{array}$ & $\begin{array}{l}\text { Metabolic process } \\
\text { (4.00) primary } \\
\text { metabolic process } \\
\text { (3.55) macromolecule } \\
\text { metabolic process } \\
\text { (3.12) biopolymer } \\
\text { metabolic process } \\
(3.12)\end{array}$ & $\begin{array}{l}\text { Binding (4.00) } \\
\text { catalytic activity } \\
(3.57) \text { metal ion } \\
\text { binding (3.05) ion } \\
\text { binding (3.05) }\end{array}$ \\
\hline $\begin{array}{l}\text { Envelope protein } \\
\text { (QJD23227) }\end{array}$ & $\begin{array}{l}\text { Coronavirus }(1.40) \\
\text { Golgi complex- } \\
\text { targeting signal } \\
\text { coronavirus }(0.90) \\
\text { complex-targeting } \\
\text { signal coronavirus } \\
\text { envelope }(0.90) \text { rb69 } \\
(0.51) \text { DNA } \\
\text { polymerase }(0.50) \\
\text { nmr }(0.50) \text { SARS } \\
\text { coronavirus }(0.50) \\
\text { pentameric ion } \\
\text { channel }(0.50)\end{array}$ & & $\begin{array}{l}\text { DNA replication }(0.51) \\
\text { metabolic process } \\
(0.51) \text { cellular process } \\
(0.51) \text { cellular } \\
\text { metabolic process } \\
(0.51)\end{array}$ & $\begin{array}{l}\text { Nucleotide binding } \\
(0.51) \text { DNA binding } \\
(0.51) \text { catalytic } \\
\text { activity }(0.51) \text { DNAl- } \\
\text { directed DNA } \\
\text { polymerase activity } \\
(0.51)\end{array}$ \\
\hline $\begin{array}{l}\text { Membrane } \\
\text { glycoprotein } \\
\text { (QJD23228) }\end{array}$ & $\begin{array}{l}\text { Domain }(0.89) \text { coli } \\
(0.87) \text { truncated } \\
(0.86) \text { human }(0.50) \\
\text { human methionine } \\
\text { aminopeptidase }(0.50) \\
\text { bombyx mori gh13 } \\
\text { sucrose }(0.50) \text { mori } \\
\text { gh13 sucrose } \\
\text { hydrolase }(0.50) \\
\text { human methionine }\end{array}$ & $\begin{array}{l}\text { Cell (2.09) cell part } \\
(2.09) \text { membrane } \\
(1.72) \text { plasma } \\
\text { membrane }(1.36)\end{array}$ & $\begin{array}{l}\text { Cellular process }(2.09) \\
\text { cellular metabolic } \\
\text { process }(1.69) \\
\text { metabolic process } \\
(1.69) \text { cellular } \\
\text { macromolecule } \\
\text { metabolic process } \\
(1.29)\end{array}$ & $\begin{array}{l}\text { Binding (1.39) } \\
\text { protein binding }(1.00) \\
\text { metal ion binding } \\
(0.79) \text { ion binding } \\
(0.79)\end{array}$ \\
\hline
\end{tabular}




\begin{tabular}{|c|c|c|c|c|}
\hline \multirow{3}{*}{ Protein } & \multirow{3}{*}{ Protein name terms } & \multirow{2}{*}{\multicolumn{3}{|c|}{$\begin{array}{c}\text { Summary of predicted function } \\
\text { Gene Ontology (GO) terms }\end{array}$}} \\
\hline & & & & \\
\hline & & Cellular component & Biological process & $\begin{array}{l}\text { Biochemical } \\
\text { function }\end{array}$ \\
\hline & $\begin{array}{l}\text { aminopeptidase type } \\
(0.50)\end{array}$ & & & \\
\hline $\begin{array}{l}\text { ORF6 protein } \\
\text { (QJD23229) }\end{array}$ & $\begin{array}{l}\text { Human }(1.35) \text { domain } \\
(1.18) \text { zf-c } 2 \mathrm{~h} 2 \\
\text { domains }(0.50) \text { human } \\
\text { zinc finger }(0.50) \text { ctr9 } \\
\text { paf1 }(0.50) \text { cdc73 } \\
\text { ternary }(0.50) \\
\text { myceliophthora } \\
\text { thermophila }(0.50) \\
\text { RNP }(0.50)\end{array}$ & $\begin{array}{l}\text { Cell (1.76) cell part } \\
\text { (1.76) cytoplasm } \\
\text { (1.31) intracellular } \\
(1.31)\end{array}$ & $\begin{array}{l}\text { Cellular process (2.16) } \\
\text { localization (1.37) } \\
\text { biological regulation } \\
\text { (1.31) cellular } \\
\text { metabolic process } \\
(1.28)\end{array}$ & $\begin{array}{l}\text { Binding (2.60) metal } \\
\text { ion binding (1.60) ion } \\
\text { binding (1.60) cation } \\
\text { binding }(1.60)\end{array}$ \\
\hline $\begin{array}{l}\text { ORF7a protein } \\
\text { (QJD23230) }\end{array}$ & $\begin{array}{l}\text { Domain (1.57) factor } \\
(1.21) \text { human }(1.19) \\
\text { ORF7a }(1.01) \\
\text { accessory }(1.01) \\
\text { SARS coronavirus } \\
\text { ORF coded }(0.90) \\
\text { SARS-CoV-2 ORF7a } \\
\text { encoded accessory } \\
(0.90) \text { SARS- } \\
\text { coronavirus ORF7a } \\
\text { accessory }(0.90) \\
\end{array}$ & $\begin{array}{l}\text { Cell }(0.90) \text { cell part } \\
(0.90) \text { nucleus }(0.50) \\
\text { mRNA cleavage and } \\
\text { polyadenylation } \\
\text { specificity factor } \\
\text { complex }(0.50)\end{array}$ & $\begin{array}{l}\text { Metabolic process } \\
(1.33) \text { cellular process } \\
(1.00) \text { cellular } \\
\text { metabolic process } \\
(1.00) \text { mRNA } \\
\text { polyadenylation }(0.50)\end{array}$ & $\begin{array}{l}\text { Binding (1.00) } \\
\text { catalytic activity } \\
(0.85) \text { RNA binding } \\
(0.50) \text { nucleic acid } \\
\text { binding }(0.50)\end{array}$ \\
\hline $\begin{array}{l}\text { ORF7b } \\
\text { (QJD23231) }\end{array}$ & $\begin{array}{l}\text { Elegans }(0.88) \text { gamma } \\
\text { lyase }(0.60) \text { human } \\
(0.54) \text { cystathionine } \\
\text { gamma lyase }(0.52) \\
\text { engineered human } \\
(0.52) \text { engineered } \\
\text { human cystathionine } \\
\text { gamma }(0.50) \text { human } \\
\text { cystathionine gamma } \\
\text { lyase }(0.50) \text { e } 339 \mathrm{v} \\
(0.50)\end{array}$ & $\begin{array}{l}\text { Cell (1.75) cell part } \\
(1.75) \text { membrane } \\
(0.73) \text { integral to } \\
\text { membrane }(0.73)\end{array}$ & $\begin{array}{l}\text { Biological regulation } \\
(1.27) \text { cellular process } \\
\text { (1.27) regulation of } \\
\text { molecular function } \\
\text { (1.27) positive } \\
\text { regulation of molecular } \\
\text { function }(1.27)\end{array}$ & $\begin{array}{l}\text { Protein binding (1.27) } \\
\text { binding (1.27) } \\
\text { catalytic activity } \\
(1.27) \text { cystathionine } \\
\text { gammal-lyase activity } \\
(0.62)\end{array}$ \\
\hline $\begin{array}{l}\text { ORF8 protein } \\
\text { (QJD23232) }\end{array}$ & $\begin{array}{l}\text { Human }(2.01) \text { TCR } \\
(1.39) \text { antibody }(1.27) \\
\text { receptor }(0.98) \\
\text { domains }(0.87) \text { t-cell } \\
\text { receptor }(0.86) \text { cell } \\
(0.53) \text { jm22 TCR } \\
(0.52)\end{array}$ & $\begin{array}{l}\text { Plasma membrane } \\
(0.52) \text { membrane } \\
(0.52) \text { T cell receptor } \\
\text { complex }(0.52) \text { alphal- } \\
\text { beta T cell receptor } \\
\text { complex }(0.52)\end{array}$ & $\begin{array}{l}\text { Adaptive immune } \\
\text { response }(0.52) \\
\text { immune system } \\
\text { process }(0.52) \text { immune } \\
\text { response }(0.52) \text { defence } \\
\text { response to Graml- } \\
\text { positive bacterium } \\
(0.52) \\
\end{array}$ & $\begin{array}{l}\text { Protein binding }(0.52) \\
\text { binding }(0.52)\end{array}$ \\
\hline $\begin{array}{l}\text { Nucleocapsid } \\
\text { phosphoprotein } \\
\text { (QJD23233) }\end{array}$ & $\begin{array}{l}\text { Nucleocapsid (4.86) } \\
\text { domain }(4.34) \text { c- } \\
\text { terminal }(3.50) \\
\text { dimerization domain } \\
\text { (2.61) coronavirus } \\
\text { (2.33) c-terminal } \\
\text { domain (1.97) c- } \\
\text { terminal dimerization } \\
\text { domain (1.73) form } \\
(1.70)\end{array}$ & $\begin{array}{l}\text { Plasma membrane } \\
\text { (1.02) membrane } \\
\text { (1.02) cell (1.02) cell } \\
\text { part (1.02) }\end{array}$ & $\begin{array}{l}\text { Metabolic process } \\
\text { (1.76) cellular process } \\
\text { (1.42) primary } \\
\text { metabolic process } \\
\text { (1.17) establishment of } \\
\text { localization (1.02) }\end{array}$ & $\begin{array}{l}\text { Binding }(1.42) \\
\text { catalytic activity } \\
(1.34) \text { protein binding } \\
(1.02) \text { hydrolase } \\
\text { activity }(0.97)\end{array}$ \\
\hline $\begin{array}{l}\text { ORF1a } \\
\text { polyprotein } \\
\text { (QJD23236) }\end{array}$ & $\begin{array}{l}\text { Domain }(2.45) \mathrm{nsp} 7 \\
(0.94) \mathrm{nsp} 8(0.94) \\
\text { bound }(0.93) \mathrm{c}- \\
\text { terminal domain } \\
(0.93) \text { second form } \\
(0.90) \text { c-terminal } \\
\text { domain nsp8 }(0.90) \\
\text { SARS CoV-2 }(0.90)\end{array}$ & $\begin{array}{l}\text { Cell (1.58) cell part } \\
(1.58) \text { membrane } \\
(0.89) \text { integral to } \\
\text { membrane }(0.89)\end{array}$ & $\begin{array}{l}\text { Cellular process }(1.27) \\
\text { establishment of } \\
\text { localization }(1.25) \\
\text { transport }(1.25) \\
\text { localization }(1.25)\end{array}$ & $\begin{array}{l}\text { Binding }(1.25) \\
\text { transporter activity } \\
(0.89) \text { substratel- } \\
\text { specific transporter } \\
\text { activity }(0.89) \\
\text { substratel-specific } \\
\text { transmembrane } \\
\text { transporter activity } \\
(0.89)\end{array}$ \\
\hline $\begin{array}{l}\text { Surface } \\
\text { glycoprotein } \\
\text { (QJD23237) }\end{array}$ & $\begin{array}{l}\text { Spike (7.15) SARS- } \\
\text { CoV-2 (3.60) domain } \\
(3.40) \text { receptor- } \\
\text { binding domain }(2.93) \\
\text { RBD (2.37) SARS } \\
\text { (2.23) spike }\end{array}$ & $\begin{array}{l}\text { Membrane (2.19) } \\
\text { integral to membrane } \\
(2.19) \text { virion }(2.19) \\
\text { viral envelope }(2.19)\end{array}$ & $\begin{array}{l}\text { Pathogenesis ( } 2.19) \\
\text { viral reproduction } \\
\text { (2.19) virion } \\
\text { attachment to host cell } \\
\text { surface receptor }(2.19) \\
\text { evasion by virus of }\end{array}$ & $\begin{array}{l}\text { Protein binding (2.19) } \\
\text { identical protein } \\
\text { binding (2.19) } \\
\text { binding (2.19) host } \\
\text { cell surface receptor } \\
\text { binding (1.10) }\end{array}$ \\
\hline
\end{tabular}




\begin{tabular}{|c|c|c|c|c|}
\hline \multirow{3}{*}{ Protein } & \multirow{3}{*}{ Protein name terms } & \multicolumn{3}{|c|}{ Summary of predicted function } \\
\hline & & \multicolumn{3}{|c|}{ Gene Ontology (GO) terms } \\
\hline & & Cellular component & Biological process & $\begin{array}{l}\text { Biochemical } \\
\text { function }\end{array}$ \\
\hline & $\begin{array}{l}\text { glycoprotein }(2.18) \\
\text { ace2 (2.09) }\end{array}$ & & $\begin{array}{l}\text { host immune response } \\
(2.19)\end{array}$ & \\
\hline $\begin{array}{l}\text { ORF3a protein } \\
\text { (QJD23238) }\end{array}$ & $\begin{array}{l}\text { Human }(1.33) \\
\text { covalent }(1.24) \\
\text { domain }(1.23) \\
\text { hydrolase }(0.89) \\
\text { domain human }(0.84) \\
\text { saga dub module } \\
(0.53) \text { usp21 }(0.52) \\
\text { covalent ubiquitin- } \\
\text { usp5 }(0.50) \\
\end{array}$ & $\begin{array}{l}\text { Cell (2.73) cell part } \\
(2.73) \text { nucleus }(2.18) \\
\text { intracellular }(2.18)\end{array}$ & $\begin{array}{l}\text { Metabolic process } \\
(4.00) \text { primary } \\
\text { metabolic process } \\
\text { (3.55) macromolecule } \\
\text { metabolic process } \\
\text { (3.12) biopolymer } \\
\text { metabolic process } \\
(3.12)\end{array}$ & $\begin{array}{l}\text { Binding (4.00) } \\
\text { catalytic activity } \\
(3.57) \text { metal ion } \\
\text { binding (3.05) ion } \\
\text { binding (3.05) }\end{array}$ \\
\hline $\begin{array}{l}\text { Envelope protein } \\
\text { (QJD23239) }\end{array}$ & $\begin{array}{l}\text { Coronavirus }(1.40) \\
\text { Golgi complex- } \\
\text { targeting signal } \\
\text { coronavirus }(0.90) \\
\text { complex-targeting } \\
\text { signal coronavirus } \\
\text { envelope }(0.90) \text { rb69 } \\
(0.51) \text { DNA } \\
\text { polymerase }(0.50) \\
\text { nmr }(0.50) \text { SARS } \\
\text { coronavirus }(0.50) \\
\text { pentameric ion } \\
\text { channel }(0.50)\end{array}$ & & $\begin{array}{l}\text { DNA replication }(0.51) \\
\text { metabolic process } \\
(0.51) \text { cellular process } \\
(0.51) \text { cellular } \\
\text { metabolic process } \\
(0.51)\end{array}$ & $\begin{array}{l}\text { Nucleotide binding } \\
(0.51) \text { DNA binding } \\
(0.51) \text { catalytic } \\
\text { activity }(0.51) \text { DNAl- } \\
\text { directed DNA } \\
\text { polymerase activity } \\
(0.51)\end{array}$ \\
\hline $\begin{array}{l}\text { Membrane } \\
\text { glycoprotein } \\
\text { (QJD23240) }\end{array}$ & $\begin{array}{l}\text { Domain }(0.89) \text { coli } \\
(0.87) \text { truncated } \\
(0.86) \text { human }(0.50) \\
\text { human methionine } \\
\text { aminopeptidase }(0.50) \\
\text { bombyx mori gh13 } \\
\text { sucrose }(0.50) \text { mori } \\
\text { gh13 sucrose } \\
\text { hydrolase }(0.50) \\
\text { human methionine } \\
\text { aminopeptidase type } \\
(0.50)\end{array}$ & $\begin{array}{l}\text { Cell (2.09) cell part } \\
(2.09) \text { membrane } \\
\text { (1.72) plasma } \\
\text { membrane }(1.36)\end{array}$ & $\begin{array}{l}\text { Cellular process (2.09) } \\
\text { cellular metabolic } \\
\text { process }(1.69) \\
\text { metabolic process } \\
(1.69) \text { cellular } \\
\text { macromolecule } \\
\text { metabolic process } \\
(1.29)\end{array}$ & $\begin{array}{l}\text { Binding (1.39) } \\
\text { protein binding }(1.00) \\
\text { metal ion binding } \\
(0.79) \text { ion binding } \\
(0.79)\end{array}$ \\
\hline $\begin{array}{l}\text { ORF6 protein } \\
\text { (QJD23241) }\end{array}$ & $\begin{array}{l}\text { Human }(1.35) \text { domain } \\
(1.18) \text { zf-c2h2 } \\
\text { domains }(0.50) \text { human } \\
\text { zinc finger }(0.50) \text { ctr9 } \\
\text { paf1 }(0.50) \text { cdc } 73 \\
\text { ternary }(0.50) \\
\text { myceliophthora } \\
\text { thermophila }(0.50) \\
\text { RNP }(0.50)\end{array}$ & $\begin{array}{l}\text { Cell (1.76) cell part } \\
\text { (1.76) cytoplasm } \\
\text { (1.31) intracellular } \\
(1.31)\end{array}$ & $\begin{array}{l}\text { Cellular process }(2.16) \\
\text { localization }(1.37) \\
\text { biological regulation } \\
(1.31) \text { cellular } \\
\text { metabolic process } \\
(1.28)\end{array}$ & $\begin{array}{l}\text { Binding (2.60) metal } \\
\text { ion binding (1.60) ion } \\
\text { binding (1.60) cation } \\
\text { binding }(1.60)\end{array}$ \\
\hline $\begin{array}{l}\text { ORF7a protein } \\
\text { (QJD23242) }\end{array}$ & $\begin{array}{l}\text { Domain (1.57) factor } \\
\text { (1.21) human (1.19) } \\
\text { ORF7a (1.01) } \\
\text { accessory (1.01) } \\
\text { SARS coronavirus } \\
\text { ORF coded }(0.90) \\
\text { SARS-CoV-2 ORF7a } \\
\text { encoded accessory } \\
(0.90) \text { SARS- } \\
\text { coronavirus ORF7a } \\
\text { accessory }(0.90) \\
\end{array}$ & $\begin{array}{l}\text { Cell }(0.90) \text { cell part } \\
(0.90) \text { nucleus }(0.50) \\
\text { mRNA cleavage and } \\
\text { polyadenylation } \\
\text { specificity factor } \\
\text { complex }(0.50)\end{array}$ & $\begin{array}{l}\text { Metabolic process } \\
(1.33) \text { cellular process } \\
(1.00) \text { cellular } \\
\text { metabolic process } \\
(1.00) \text { mRNA } \\
\text { polyadenylation }(0.50)\end{array}$ & $\begin{array}{l}\text { Binding (1.00) } \\
\text { catalytic activity } \\
(0.85) \text { RNA binding } \\
(0.50) \text { nucleic acid } \\
\text { binding }(0.50)\end{array}$ \\
\hline $\begin{array}{l}\text { ORF7b } \\
\text { (QJD23243) }\end{array}$ & $\begin{array}{l}\text { Elegans }(0.88) \text { gamma } \\
\text { lyase }(0.60) \text { human } \\
(0.54) \text { cystathionine } \\
\text { gamma lyase }(0.52) \\
\text { engineered human } \\
(0.52) \text { engineered } \\
\text { human cystathionine } \\
\text { gamma }(0.50) \text { human } \\
\text { cystathionine gamma }\end{array}$ & $\begin{array}{l}\text { Cell (1.75) cell part } \\
(1.75) \text { membrane } \\
(0.73) \text { integral to } \\
\text { membrane }(0.73)\end{array}$ & $\begin{array}{l}\text { Biological regulation } \\
(1.27) \text { cellular process } \\
\text { (1.27) regulation of } \\
\text { molecular function } \\
\text { (1.27) positive } \\
\text { regulation of molecular } \\
\text { function }(1.27)\end{array}$ & $\begin{array}{l}\text { Protein binding (1.27) } \\
\text { binding (1.27) } \\
\text { catalytic activity } \\
(1.27) \text { cystathionine } \\
\text { gammal-lyase activity } \\
(0.62)\end{array}$ \\
\hline
\end{tabular}




\begin{tabular}{|c|c|c|c|c|}
\hline \multirow{3}{*}{ Protein } & \multirow{3}{*}{ Protein name terms } & \multirow{2}{*}{\multicolumn{3}{|c|}{$\begin{array}{c}\text { Summary of predicted function } \\
\text { Gene Ontologv (GO) t trms }\end{array}$}} \\
\hline & & & & \\
\hline & & Cellular component & Biological process & $\begin{array}{l}\text { Biochemical } \\
\text { function }\end{array}$ \\
\hline & $\begin{array}{l}\text { lyase }(0.50) \mathrm{e} 339 \mathrm{v} \\
(0.50)\end{array}$ & & & \\
\hline $\begin{array}{l}\text { ORF8 protein } \\
\text { (QJD23244) }\end{array}$ & $\begin{array}{l}\text { Human }(2.01) \text { TCR } \\
(1.39) \text { antibody }(1.27) \\
\text { receptor }(0.98) \\
\text { domains }(0.87) \text { t-cell } \\
\text { receptor }(0.86) \text { cell } \\
(0.53) \text { jm22 TCR } \\
(0.52)\end{array}$ & $\begin{array}{l}\text { Plasma membrane } \\
(0.52) \text { membrane } \\
(0.52) \text { T cell receptor } \\
\text { complex }(0.52) \text { alphal- } \\
\text { beta T cell receptor } \\
\text { complex }(0.52)\end{array}$ & $\begin{array}{l}\text { Adaptive immune } \\
\text { response }(0.52) \\
\text { immune system } \\
\text { process }(0.52) \text { immune } \\
\text { response }(0.52) \text { defence } \\
\text { response to Graml- } \\
\text { positive bacterium } \\
(0.52) \\
\end{array}$ & $\begin{array}{l}\text { Protein binding }(0.52) \\
\text { binding }(0.52)\end{array}$ \\
\hline $\begin{array}{l}\text { Nucleocapsid } \\
\text { phosphoprotein } \\
\text { (QJD23245) }\end{array}$ & $\begin{array}{l}\text { Nucleocapsid (4.86) } \\
\text { domain }(4.34) \mathrm{c}- \\
\text { terminal }(3.50) \\
\text { dimerization domain } \\
\text { (2.61) coronavirus } \\
\text { (2.33) c-terminal } \\
\text { domain (1.97) c- } \\
\text { terminal dimerization } \\
\text { domain (1.73) form } \\
(1.70)\end{array}$ & $\begin{array}{l}\text { Plasma membrane } \\
(1.02) \text { membrane } \\
(1.02) \text { cell }(1.02) \text { cell } \\
\text { part (1.02) }\end{array}$ & $\begin{array}{l}\text { Metabolic process } \\
\text { (1.76) cellular process } \\
\text { (1.42) primary } \\
\text { metabolic process } \\
\text { (1.17) establishment of } \\
\text { localization (1.02) }\end{array}$ & $\begin{array}{l}\text { Binding (1.42) } \\
\text { catalytic activity } \\
(1.34) \text { protein binding } \\
(1.02) \text { hydrolase } \\
\text { activity }(0.97)\end{array}$ \\
\hline $\begin{array}{l}\text { ORF3a protein } \\
\text { (QJD23250) }\end{array}$ & $\begin{array}{l}\text { Human }(1.33) \\
\text { covalent }(1.24) \\
\text { domain }(1.23) \\
\text { hydrolase }(0.89) \\
\text { domain human }(0.84) \\
\text { saga dub module } \\
(0.53) \text { usp21 }(0.52) \\
\text { covalent ubiquitin- } \\
\text { usp5 }(0.50)\end{array}$ & $\begin{array}{l}\text { Cell (2.73) cell part } \\
(2.73) \text { nucleus }(2.18) \\
\text { intracellular }(2.18)\end{array}$ & $\begin{array}{l}\text { Metabolic process } \\
\text { (4.00) primary } \\
\text { metabolic process } \\
\text { (3.55) macromolecule } \\
\text { metabolic process } \\
\text { (3.12) biopolymer } \\
\text { metabolic process } \\
(3.12)\end{array}$ & $\begin{array}{l}\text { Binding (4.00) } \\
\text { catalytic activity } \\
(3.57) \text { metal ion } \\
\text { binding (3.05) ion } \\
\text { binding (3.05) }\end{array}$ \\
\hline $\begin{array}{l}\text { Envelope protein } \\
\text { (QJD23251) }\end{array}$ & $\begin{array}{l}\text { Coronavirus }(1.40) \\
\text { Golgi complex- } \\
\text { targeting signal } \\
\text { coronavirus }(0.90) \\
\text { complex-targeting } \\
\text { signal coronavirus } \\
\text { envelope }(0.90) \text { rb69 } \\
(0.51) \text { DNA } \\
\text { polymerase }(0.50) \\
\text { nmr }(0.50) \text { SARS } \\
\text { coronavirus }(0.50) \\
\text { pentameric ion } \\
\text { channel }(0.50) \\
\end{array}$ & & $\begin{array}{l}\text { DNA replication }(0.51) \\
\text { metabolic process } \\
(0.51) \text { cellular process } \\
(0.51) \text { cellular } \\
\text { metabolic process } \\
(0.51)\end{array}$ & $\begin{array}{l}\text { Nucleotide binding } \\
(0.51) \text { DNA binding } \\
(0.51) \text { catalytic } \\
\text { activity }(0.51) \text { DNAI- } \\
\text { directed DNA } \\
\text { polymerase activity } \\
(0.51)\end{array}$ \\
\hline $\begin{array}{l}\text { ORF6 protein } \\
\text { (QJD23253) }\end{array}$ & $\begin{array}{l}\text { Human }(1.35) \text { domain } \\
(1.18) \text { zf-c } 2 \mathrm{~h} 2 \\
\text { domains }(0.50) \text { human } \\
\text { zinc finger }(0.50) \text { ctr9 } \\
\text { paf1 }(0.50) \text { cdc } 73 \\
\text { ternary }(0.50) \\
\text { myceliophthora } \\
\text { thermophila }(0.50) \\
\text { RNP }(0.50)\end{array}$ & $\begin{array}{l}\text { Cell (1.76) cell part } \\
\text { (1.76) cytoplasm } \\
\text { (1.31) intracellular } \\
(1.31)\end{array}$ & $\begin{array}{l}\text { Cellular process }(2.16) \\
\text { localization (1.37) } \\
\text { biological regulation } \\
\text { (1.31) cellular } \\
\text { metabolic process } \\
(1.28)\end{array}$ & $\begin{array}{l}\text { Binding (2.60) metal } \\
\text { ion binding (1.60) ion } \\
\text { binding }(1.60) \text { cation } \\
\text { binding }(1.60)\end{array}$ \\
\hline $\begin{array}{l}\text { ORF7a protein } \\
\text { (QJD23254) }\end{array}$ & $\begin{array}{l}\text { Domain (1.57) factor } \\
(1.21) \text { human }(1.19) \\
\text { ORF7a }(1.01) \\
\text { accessory }(1.01) \\
\text { SARS coronavirus } \\
\text { ORF coded }(0.90) \\
\text { SARS-CoV-2 ORF7a } \\
\text { encoded accessory } \\
(0.90) \text { SARS- } \\
\text { coronavirus ORF7a } \\
\text { accessory }(0.90)\end{array}$ & $\begin{array}{l}\text { Cell }(0.90) \text { cell part } \\
(0.90) \text { nucleus }(0.50) \\
\text { mRNA cleavage and } \\
\text { polyadenylation } \\
\text { specificity factor } \\
\text { complex }(0.50)\end{array}$ & $\begin{array}{l}\text { Metabolic process } \\
(1.33) \text { cellular process } \\
(1.00) \text { cellular } \\
\text { metabolic process } \\
(1.00) \text { mRNA } \\
\text { polyadenylation }(0.50)\end{array}$ & $\begin{array}{l}\text { Binding }(1.00) \\
\text { catalytic activity } \\
(0.85) \text { RNA binding } \\
(0.50) \text { nucleic acid } \\
\text { binding }(0.50)\end{array}$ \\
\hline $\begin{array}{l}\text { ORF7b } \\
\text { (QJD23255) }\end{array}$ & $\begin{array}{l}\text { Elegans }(0.88) \text { gamma } \\
\text { lyase }(0.60) \text { human } \\
(0.54) \text { cystathionine } \\
\text { gamma lyase }(0.52)\end{array}$ & $\begin{array}{l}\text { Cell }(1.75) \text { cell part } \\
(1.75) \text { membrane } \\
(0.73) \text { integral to } \\
\text { membrane }(0.73)\end{array}$ & $\begin{array}{l}\text { Biological regulation } \\
\text { (1.27) cellular process } \\
\text { (1.27) regulation of } \\
\text { molecular function }\end{array}$ & $\begin{array}{l}\text { Protein binding (1.27) } \\
\text { binding }(1.27) \\
\text { catalytic activity } \\
(1.27) \text { cystathionine }\end{array}$ \\
\hline ps://bioint & search.com/ & & & 3286 \\
\hline
\end{tabular}




\begin{tabular}{|c|c|c|c|c|}
\hline \multirow{3}{*}{ Protein } & \multirow{3}{*}{ Protein name terms } & \multicolumn{3}{|c|}{$\begin{array}{c}\text { Summary of predicted function } \\
\text { Gene Ontology (GO) terms }\end{array}$} \\
\hline & & \\
\hline & & Cellular component & Biological process & $\begin{array}{l}\text { Biochemical } \\
\text { function }\end{array}$ \\
\hline & $\begin{array}{l}\text { engineered human } \\
(0.52) \text { engineered } \\
\text { human cystathionine } \\
\text { gamma }(0.50) \text { human } \\
\text { cystathionine gamma } \\
\text { lyase }(0.50) \text { e } 339 \mathrm{v} \\
(0.50)\end{array}$ & & $\begin{array}{l}\text { (1.27) positive } \\
\text { regulation of molecular } \\
\text { function }(1.27)\end{array}$ & $\begin{array}{l}\text { gammal-lyase activity } \\
(0.62)\end{array}$ \\
\hline $\begin{array}{l}\text { ORF8 protein } \\
\text { (QJD23256) }\end{array}$ & $\begin{array}{l}\text { Human }(2.01) \text { TCR } \\
(1.39) \text { antibody }(1.27) \\
\text { receptor }(0.98) \\
\text { domains }(0.87) \text { t-cell } \\
\text { receptor }(0.86) \text { cell } \\
(0.53) \text { jm22 TCR } \\
(0.52)\end{array}$ & $\begin{array}{l}\text { Plasma membrane } \\
(0.52) \text { membrane } \\
(0.52) \text { T cell receptor } \\
\text { complex }(0.52) \text { alphal- } \\
\text { beta T cell receptor } \\
\text { complex }(0.52)\end{array}$ & $\begin{array}{l}\text { Adaptive immune } \\
\text { response }(0.52) \\
\text { immune system } \\
\text { process }(0.52) \text { immune } \\
\text { response }(0.52) \text { defence } \\
\text { response to Graml- } \\
\text { positive bacterium } \\
(0.52) \\
\end{array}$ & $\begin{array}{l}\text { Protein binding }(0.52) \\
\text { binding }(0.52)\end{array}$ \\
\hline $\begin{array}{l}\text { Nucleocapsid } \\
\text { phosphoprotein } \\
\text { (QJD23257) }\end{array}$ & $\begin{array}{l}\text { Nucleocapsid (4.86) } \\
\text { domain }(4.34) \mathrm{c}- \\
\text { terminal }(3.50) \\
\text { dimerization domain } \\
\text { (2.61) coronavirus } \\
\text { (2.33) c-terminal } \\
\text { domain (1.97) c- } \\
\text { terminal dimerization } \\
\text { domain (1.73) form } \\
(1.70)\end{array}$ & $\begin{array}{l}\text { Plasma membrane } \\
(1.02) \text { membrane } \\
(1.02) \text { cell }(1.02) \text { cell } \\
\text { part (1.02) }\end{array}$ & $\begin{array}{l}\text { Metabolic process } \\
\text { (1.76) cellular process } \\
(1.42) \text { primary } \\
\text { metabolic process } \\
\text { (1.17) establishment of } \\
\text { localization (1.02) }\end{array}$ & $\begin{array}{l}\text { Binding }(1.42) \\
\text { catalytic activity } \\
(1.34) \text { protein binding } \\
(1.02) \text { hydrolase } \\
\text { activity }(0.97)\end{array}$ \\
\hline $\begin{array}{l}\text { ORF3a protein } \\
\text { (QJD23259) }\end{array}$ & $\begin{array}{l}\text { Human }(1.33) \\
\text { covalent }(1.24) \\
\text { domain }(1.23) \\
\text { hydrolase }(0.89) \\
\text { domain human }(0.84) \\
\text { saga dub module } \\
(0.53) \text { usp21 }(0.52) \\
\text { covalent ubiquitin- } \\
\text { usp5 }(0.50) \\
\end{array}$ & $\begin{array}{l}\text { Cell (2.73) cell part } \\
(2.73) \text { nucleus }(2.18) \\
\text { intracellular }(2.18)\end{array}$ & $\begin{array}{l}\text { Metabolic process } \\
\text { (4.00) primary } \\
\text { metabolic process } \\
\text { (3.55) macromolecule } \\
\text { metabolic process } \\
\text { (3.12) biopolymer } \\
\text { metabolic process } \\
(3.12)\end{array}$ & $\begin{array}{l}\text { Binding (4.00) } \\
\text { catalytic activity } \\
(3.57) \text { metal ion } \\
\text { binding (3.05) ion } \\
\text { binding (3.05) }\end{array}$ \\
\hline $\begin{array}{l}\text { Envelope protein } \\
\text { (QJD23260) }\end{array}$ & $\begin{array}{l}\text { Coronavirus }(1.40) \\
\text { Golgi complex- } \\
\text { targeting signal } \\
\text { coronavirus }(0.90) \\
\text { complex-targeting } \\
\text { signal coronavirus } \\
\text { envelope }(0.90) \text { rb69 } \\
(0.51) \text { DNA } \\
\text { polymerase }(0.50) \\
\text { nmr }(0.50) \text { SARS } \\
\text { coronavirus }(0.50) \\
\text { pentameric ion } \\
\text { channel }(0.50) \\
\end{array}$ & & $\begin{array}{l}\text { DNA replication }(0.51) \\
\text { metabolic process } \\
(0.51) \text { cellular process } \\
(0.51) \text { cellular } \\
\text { metabolic process } \\
(0.51)\end{array}$ & $\begin{array}{l}\text { Nucleotide binding } \\
(0.51) \text { DNA binding } \\
(0.51) \text { catalytic } \\
\text { activity }(0.51) \text { DNAl- } \\
\text { directed DNA } \\
\text { polymerase activity } \\
(0.51)\end{array}$ \\
\hline $\begin{array}{l}\text { ORF6 protein } \\
\text { (QJD23262) }\end{array}$ & $\begin{array}{l}\text { Human }(1.35) \text { domain } \\
(1.18) \text { zf-c2h2 } \\
\text { domains }(0.50) \text { human } \\
\text { zinc finger }(0.50) \text { ctr9 } \\
\text { paf1 }(0.50) \text { cdc } 73 \\
\text { ternary }(0.50) \\
\text { myceliophthora } \\
\text { thermophila }(0.50) \\
\text { RNP }(0.50)\end{array}$ & $\begin{array}{l}\text { Cell (1.76) cell part } \\
\text { (1.76) cytoplasm } \\
(1.31) \text { intracellular } \\
(1.31)\end{array}$ & $\begin{array}{l}\text { Cellular process }(2.16) \\
\text { localization }(1.37) \\
\text { biological regulation } \\
\text { (1.31) cellular } \\
\text { metabolic process } \\
(1.28)\end{array}$ & $\begin{array}{l}\text { Binding (2.60) metal } \\
\text { ion binding (1.60) ion } \\
\text { binding }(1.60) \text { cation } \\
\text { binding }(1.60)\end{array}$ \\
\hline $\begin{array}{l}\text { ORF7a protein } \\
\text { (QJD23263) }\end{array}$ & $\begin{array}{l}\text { Domain (1.57) factor } \\
(1.21) \text { human }(1.19) \\
\text { ORF7a }(1.01) \\
\text { accessory }(1.01) \\
\text { SARS coronavirus } \\
\text { ORF coded }(0.90) \\
\text { SARS-CoV-2 ORF7a } \\
\text { encoded accessory } \\
(0.90) \text { SARS- }\end{array}$ & $\begin{array}{l}\text { Cell }(0.90) \text { cell part } \\
(0.90) \text { nucleus }(0.50) \\
\text { mRNA cleavage and } \\
\text { polyadenylation } \\
\text { specificity factor } \\
\text { complex }(0.50)\end{array}$ & $\begin{array}{l}\text { Metabolic process } \\
(1.33) \text { cellular process } \\
(1.00) \text { cellular } \\
\text { metabolic process } \\
(1.00) \text { mRNA } \\
\text { polyadenylation }(0.50)\end{array}$ & $\begin{array}{l}\text { Binding (1.00) } \\
\text { catalytic activity } \\
(0.85) \text { RNA binding } \\
(0.50) \text { nucleic acid } \\
\text { binding }(0.50)\end{array}$ \\
\hline
\end{tabular}




\begin{tabular}{|c|c|c|c|c|}
\hline \multirow{3}{*}{ Protein } & \multirow{3}{*}{ Protein name terms } & \multicolumn{3}{|c|}{ Summary of predicted function } \\
\hline & & \multicolumn{3}{|c|}{ Gene Ontology (GO) terms } \\
\hline & & Cellular component & Biological process & $\begin{array}{l}\text { Biochemical } \\
\text { function }\end{array}$ \\
\hline & $\begin{array}{l}\text { coronavirus ORF7a } \\
\text { accessory }(0.90)\end{array}$ & & & \\
\hline $\begin{array}{l}\text { ORF7b } \\
\text { (QJD23264) }\end{array}$ & $\begin{array}{l}\text { Elegans }(0.88) \text { gamma } \\
\text { lyase }(0.60) \text { human } \\
(0.54) \text { cystathionine } \\
\text { gamma lyase }(0.52) \\
\text { engineered human } \\
(0.52) \text { engineered } \\
\text { human cystathionine } \\
\text { gamma }(0.50) \text { human } \\
\text { cystathionine gamma } \\
\text { lyase }(0.50) \text { e } 339 \mathrm{v} \\
(0.50)\end{array}$ & $\begin{array}{l}\text { Cell (1.75) cell part } \\
(1.75) \text { membrane } \\
(0.73) \text { integral to } \\
\text { membrane }(0.73)\end{array}$ & $\begin{array}{l}\text { Biological regulation } \\
(1.27) \text { cellular process } \\
\text { (1.27) regulation of } \\
\text { molecular function } \\
\text { (1.27) positive } \\
\text { regulation of molecular } \\
\text { function (1.27) }\end{array}$ & $\begin{array}{l}\text { Protein binding (1.27) } \\
\text { binding (1.27) } \\
\text { catalytic activity } \\
(1.27) \text { cystathionine } \\
\text { gammal-lyase activity } \\
(0.62)\end{array}$ \\
\hline $\begin{array}{l}\text { ORF8 protein } \\
\text { (QJD23265) }\end{array}$ & $\begin{array}{l}\text { Human (2.01) TCR } \\
(1.39) \text { antibody }(1.27) \\
\text { receptor }(0.98) \\
\text { domains }(0.87) \text { t-cell } \\
\text { receptor }(0.86) \text { cell } \\
(0.53) \text { jm22 TCR } \\
(0.52)\end{array}$ & $\begin{array}{l}\text { Plasma membrane } \\
(0.52) \text { membrane } \\
(0.52) \text { T cell receptor } \\
\text { complex }(0.52) \text { alphal- } \\
\text { beta T cell receptor } \\
\text { complex }(0.52)\end{array}$ & $\begin{array}{l}\text { Adaptive immune } \\
\text { response }(0.52) \\
\text { immune system } \\
\text { process }(0.52) \text { immune } \\
\text { response }(0.52) \text { defence } \\
\text { response to Graml- } \\
\text { positive bacterium } \\
(0.52) \\
\end{array}$ & $\begin{array}{l}\text { Protein binding }(0.52) \\
\text { binding }(0.52)\end{array}$ \\
\hline $\begin{array}{l}\text { ORF3a protein } \\
\text { (QOI53581) }\end{array}$ & $\begin{array}{l}\text { Angstrom }(0.88) \\
\text { covalent }(0.88) \\
\text { domain }(0.81) \text { iii } \\
(0.81) \text { plasmodium } \\
\text { falciparum }(0.57) \\
\text { plasmodium } \\
\text { falciparum } \\
\text { dihydrofolate }(0.56) \\
\text { synthase }(0.56) \\
\text { synthase pfdhfr-ts } \\
(0.55) \\
\end{array}$ & $\begin{array}{l}\text { Cell (1.43) cell part } \\
\text { (1.43) intracellular } \\
\text { (1.00) intracellular } \\
\text { part (1.00) }\end{array}$ & $\begin{array}{l}\text { Metabolic process } \\
(2.84) \text { cellular process } \\
(2.84) \text { cellular } \\
\text { metabolic process } \\
\text { (2.84) primary } \\
\text { metabolic process } \\
(2.30)\end{array}$ & $\begin{array}{l}\text { Catalytic activity } \\
(2.30) \text { binding }(2.30) \\
\text { hydrolase activity } \\
(1.50) \text { nucleotide } \\
\text { binding }(1.14)\end{array}$ \\
\hline $\begin{array}{l}\text { Envelope protein } \\
\text { (QOI53582) }\end{array}$ & $\begin{array}{l}\text { Coronavirus }(1.40) \\
\text { Golgi complex- } \\
\text { targeting signal } \\
\text { coronavirus }(0.90) \\
\text { complex-targeting } \\
\text { signal coronavirus } \\
\text { envelope }(0.90) \text { rb69 } \\
(0.51) \text { DNA } \\
\text { polymerase }(0.50) \\
\text { nmr }(0.50) \text { SARS } \\
\text { coronavirus }(0.50) \\
\text { pentameric ion } \\
\text { channel }(0.50)\end{array}$ & & $\begin{array}{l}\text { DNA replication }(0.51) \\
\text { metabolic process } \\
(0.51) \text { cellular process } \\
(0.51) \text { cellular } \\
\text { metabolic process } \\
(0.51)\end{array}$ & $\begin{array}{l}\text { Nucleotide binding } \\
(0.51) \text { DNA binding } \\
(0.51) \text { catalytic } \\
\text { activity }(0.51) \text { DNAI- } \\
\text { directed DNA } \\
\text { polymerase activity } \\
(0.51)\end{array}$ \\
\hline $\begin{array}{l}\text { Membrane } \\
\text { glycoprotein } \\
\text { (QOI53583) }\end{array}$ & $\begin{array}{l}\text { Sortase }(0.87) \text { ycp } \\
(0.52) \text { carfilzomib } \\
(0.52) \text { yeast } 20 \mathrm{~s} \\
\text { proteasome }(0.52) \\
\text { bortezomib }(0.51) \\
\text { yeast } 20 \text { s proteasome } \\
\text { beta5-1 }(0.50) \\
\text { biophysical }(0.50) \\
\text { biochemical analyses } \\
\text { clostridium } \\
\text { perfringens }(0.50)\end{array}$ & $\begin{array}{l}\text { Cell }(0.89) \text { cell part } \\
(0.89) \text { cytoplasm } \\
(0.50) \text { intracellular } \\
(0.50)\end{array}$ & $\begin{array}{l}\text { Metabolic process } \\
(1.25) \text { trna } \\
\text { modification }(0.50) \\
\text { trna processing }(0.50) \\
\text { trna methylation }(0.50)\end{array}$ & $\begin{array}{l}\text { Catalytic activity } \\
(1.25) \text { metal ion } \\
\text { binding }(0.88) \\
\text { binding }(0.88) \text { ion } \\
\text { binding }(0.88)\end{array}$ \\
\hline $\begin{array}{l}\text { ORF6 protein } \\
\text { (QOI53584) }\end{array}$ & $\begin{array}{l}\text { Human (1.35) domain } \\
(1.18) \text { zf-c2h2 } \\
\text { domains }(0.50) \text { human } \\
\text { zinc finger }(0.50) \text { ctr9 } \\
\text { paf1 }(0.50) \text { cdc } 73 \\
\text { ternary }(0.50) \\
\text { myceliophthora } \\
\text { thermophila }(0.50) \\
\operatorname{RNP}(0.50)\end{array}$ & $\begin{array}{l}\text { Cell (1.76) cell part } \\
\text { (1.76) cytoplasm } \\
\text { (1.31) intracellular } \\
(1.31)\end{array}$ & $\begin{array}{l}\text { Cellular process }(2.16) \\
\text { localization }(1.37) \\
\text { biological regulation } \\
(1.31) \text { cellular } \\
\text { metabolic process } \\
(1.28)\end{array}$ & $\begin{array}{l}\text { Binding }(2.60) \text { metal } \\
\text { ion binding }(1.60) \text { ion } \\
\text { binding }(1.60) \text { cation } \\
\text { binding }(1.60)\end{array}$ \\
\hline
\end{tabular}




\begin{tabular}{|c|c|c|c|c|}
\hline \multirow[b]{2}{*}{ Protein } & \multirow[b]{2}{*}{ Protein name terms } & \multicolumn{3}{|c|}{$\begin{array}{c}\text { Summary of predicted function } \\
\text { Gene Ontology (GO) terms }\end{array}$} \\
\hline & & Cellular component & Biological process & $\begin{array}{l}\text { Biochemical } \\
\text { function }\end{array}$ \\
\hline $\begin{array}{l}\text { ORF7a protein } \\
\text { (QOI53585) }\end{array}$ & $\begin{array}{l}\text { Domain (1.57) factor } \\
(1.21) \text { human }(1.19) \\
\text { ORF7a }(1.01) \\
\text { accessory }(1.01) \\
\text { SARS coronavirus } \\
\text { ORF coded }(0.90) \\
\text { SARS-CoV-2 ORF7a } \\
\text { encoded accessory } \\
\text { (0.90) SARS- } \\
\text { coronavirus ORF7a } \\
\text { accessory }(0.90)\end{array}$ & $\begin{array}{l}\text { Cell }(0.90) \text { cell part } \\
(0.90) \text { nucleus }(0.50) \\
\text { mRNA cleavage and } \\
\text { polyadenylation } \\
\text { specificity factor } \\
\text { complex }(0.50)\end{array}$ & $\begin{array}{l}\text { Metabolic process } \\
\text { (1.33) cellular process } \\
(1.00) \text { cellular } \\
\text { metabolic process } \\
(1.00) \text { mRNA } \\
\text { polyadenylation }(0.50)\end{array}$ & $\begin{array}{l}\text { Binding (1.00) } \\
\text { catalytic activity } \\
(0.85) \text { RNA binding } \\
(0.50) \text { nucleic acid } \\
\text { binding }(0.50)\end{array}$ \\
\hline $\begin{array}{l}\text { ORF7b } \\
\text { (QOI53586) }\end{array}$ & $\begin{array}{l}\text { Elegans }(0.88) \text { gamma } \\
\text { lyase }(0.60) \text { human } \\
(0.54) \text { cystathionine } \\
\text { gamma lyase }(0.52) \\
\text { engineered human } \\
(0.52) \text { engineered } \\
\text { human cystathionine } \\
\text { gamma }(0.50) \text { human } \\
\text { cystathionine gamma } \\
\text { lyase }(0.50) \text { e } 339 \mathrm{v} \\
(0.50)\end{array}$ & $\begin{array}{l}\text { Cell (1.75) cell part } \\
(1.75) \text { membrane } \\
(0.73) \text { integral to } \\
\text { membrane }(0.73)\end{array}$ & $\begin{array}{l}\text { Biological regulation } \\
(1.27) \text { cellular process } \\
(1.27) \text { regulation of } \\
\text { molecular function } \\
\text { (1.27) positive } \\
\text { regulation of molecular } \\
\text { function (1.27) }\end{array}$ & $\begin{array}{l}\text { Protein binding (1.27) } \\
\text { binding (1.27) } \\
\text { catalytic activity } \\
(1.27) \text { cystathionine } \\
\text { gammal-lyase activity } \\
(0.62)\end{array}$ \\
\hline $\begin{array}{l}\text { ORF8 protein } \\
\text { (QOI53587) }\end{array}$ & $\begin{array}{l}\text { Domains (2.68) } \\
\text { human }(1.64) \\
\text { fragment }(1.00) \mathrm{n}- \\
\text { terminal }(0.88) \mathrm{fab} \\
(0.87) \\
\text { immunoglobulin } \\
\text { domains }(0.86) \text { il- } \\
\text { 33/st } 2 / \text { il-1racp ternary } \\
(0.50) \text { human nectin-4 } \\
\text { extracellular fragment } \\
(0.50)\end{array}$ & $\begin{array}{l}\text { Membrane }(0.50) \\
\text { integral to membrane } \\
(0.50) \text { cell }(0.50) \text { cell } \\
\text { part }(0.50)\end{array}$ & $\begin{array}{l}\text { Metabolic process } \\
(0.50) \text { lactose catabolic } \\
\text { process }(0.50) \text { cellular } \\
\text { process }(0.50) \text { cellular } \\
\text { metabolic process } \\
(0.50)\end{array}$ & $\begin{array}{l}\text { Betal-galactosidase } \\
\text { activity }(0.50) \\
\text { hydrolase activity } \\
(0.50) \text { hydrolase } \\
\text { activityl, acting on } \\
\text { glycosyl bonds }(0.50) \\
\text { catalytic activity } \\
(0.50)\end{array}$ \\
\hline $\begin{array}{l}\text { Nucleocapsid } \\
\text { phosphoprotein } \\
\text { (QOI53588) }\end{array}$ & $\begin{array}{l}\text { Nucleocapsid (4.86) } \\
\text { domain }(4.34) \text { c- } \\
\text { terminal (3.50) } \\
\text { dimerization domain } \\
(2.61) \text { coronavirus } \\
(2.33) \text { c-terminal } \\
\text { domain }(1.97) \text { c- } \\
\text { terminal dimerization } \\
\text { domain }(1.73) \text { form } \\
(1.70)\end{array}$ & $\begin{array}{l}\text { Plasma membrane } \\
\text { (1.02) membrane } \\
\text { (1.02) cell (1.02) cell } \\
\text { part (1.02) }\end{array}$ & $\begin{array}{l}\text { Metabolic process } \\
\text { (1.76) cellular process } \\
\text { (1.42) primary } \\
\text { metabolic process } \\
\text { (1.17) establishment of } \\
\text { localization (1.02) }\end{array}$ & $\begin{array}{l}\text { Binding }(1.42) \\
\text { catalytic activity } \\
(1.34) \text { protein binding } \\
(1.02) \text { hydrolase } \\
\text { activity }(0.97)\end{array}$ \\
\hline $\begin{array}{l}\text { Surface } \\
\text { glycoprotein } \\
\text { (QOI53592) }\end{array}$ & $\begin{array}{l}\text { Spike (7.20) domain } \\
(4.21) \text { SARS-CoV-2 } \\
(3.60) \text { receptor- } \\
\text { binding domain }(2.70) \\
\text { SARS-CoV spike } \\
\text { (2.04) SARS-CoV } \\
\text { (1.98) spike } \\
\text { glycoprotein (1.96) } \\
\text { SARS (1.96) }\end{array}$ & $\begin{array}{l}\text { Membrane (2.19) } \\
\text { integral to membrane } \\
(2.19) \text { virion }(2.19) \\
\text { viral envelope (2.19) }\end{array}$ & $\begin{array}{l}\text { Pathogenesis (2.19) } \\
\text { viral reproduction } \\
\text { (2.19) virion } \\
\text { attachment to host cell } \\
\text { surface receptor ( } 2.19) \\
\text { evasion by virus of } \\
\text { host immune response } \\
(2.19)\end{array}$ & $\begin{array}{l}\text { Protein binding (2.19) } \\
\text { identical protein } \\
\text { binding (2.19) } \\
\text { binding (2.19) host } \\
\text { cell surface receptor } \\
\text { binding (1.10) }\end{array}$ \\
\hline $\begin{array}{l}\text { ORF3a protein } \\
\text { (QOI53593) }\end{array}$ & $\begin{array}{l}\text { Human }(1.33) \\
\text { Covalent }(1.24) \\
\text { domain }(1.23) \\
\text { hydrolase }(0.89) \\
\text { domain human }(0.84) \\
\text { saga dub module } \\
\text { (0.53) usp21 (0.52) } \\
\text { Covalent ubiquitin- } \\
\text { usp5 }(0.50)\end{array}$ & $\begin{array}{l}\text { Cell (2.73) cell part } \\
(2.73) \text { nucleus }(2.18) \\
\text { intracellular }(2.18)\end{array}$ & $\begin{array}{l}\text { Metabolic process } \\
\text { (4.00) primary } \\
\text { metabolic process } \\
(3.55) \text { macromolecule } \\
\text { metabolic process } \\
\text { (3.12) biopolymer } \\
\text { metabolic process } \\
(3.12)\end{array}$ & $\begin{array}{l}\text { Binding (4.00) } \\
\text { catalytic activity } \\
(3.57) \text { metal ion } \\
\text { binding (3.05) ion } \\
\text { binding (3.05) }\end{array}$ \\
\hline $\begin{array}{l}\text { Envelope protein } \\
\text { (QOI53594) }\end{array}$ & $\begin{array}{l}\text { Coronavirus }(1.40) \\
\text { Golgi complex- } \\
\text { targeting signal } \\
\text { coronavirus }(0.90)\end{array}$ & & $\begin{array}{l}\text { DNA replication }(0.51) \\
\text { metabolic process } \\
(0.51) \text { cellular process } \\
(0.51) \text { cellular }\end{array}$ & $\begin{array}{l}\text { Nucleotide binding } \\
(0.51) \text { DNA binding } \\
(0.51) \text { catalytic } \\
\text { activity }(0.51) \text { DNAl- }\end{array}$ \\
\hline
\end{tabular}




\begin{tabular}{|c|c|c|c|c|}
\hline \multirow{3}{*}{ Protein } & \multirow{3}{*}{ Protein name terms } & \multicolumn{3}{|c|}{$\begin{array}{c}\text { Summary of predicted function } \\
\text { Gene Ontology (GO) terms }\end{array}$} \\
\hline & & & & \\
\hline & & Cellular component & Biological process & $\begin{array}{l}\text { Biochemical } \\
\text { function }\end{array}$ \\
\hline & $\begin{array}{l}\text { complex-targeting } \\
\text { signal coronavirus } \\
\text { envelope }(0.90) \text { rb69 } \\
(0.51) \text { DNA } \\
\text { polymerase }(0.50) \\
\text { nmr }(0.50) \text { SARS } \\
\text { coronavirus }(0.50) \\
\text { pentameric ion } \\
\text { channel }(0.50)\end{array}$ & & $\begin{array}{l}\text { metabolic process } \\
(0.51)\end{array}$ & $\begin{array}{l}\text { directed DNA } \\
\text { polymerase activity } \\
(0.51)\end{array}$ \\
\hline $\begin{array}{l}\text { Membrane } \\
\text { glycoprotein } \\
\text { (QOI53595) }\end{array}$ & $\begin{array}{l}\text { Domain }(0.89) \text { coli } \\
(0.87) \text { truncated } \\
(0.86) \text { human }(0.50) \\
\text { human methionine } \\
\text { aminopeptidase }(0.50) \\
\text { bombyx mori gh13 } \\
\text { sucrose }(0.50) \text { mori } \\
\text { gh13 sucrose } \\
\text { hydrolase }(0.50) \\
\text { human methionine } \\
\text { aminopeptidase type } \\
(0.50)\end{array}$ & $\begin{array}{l}\text { Cell (2.09) cell part } \\
(2.09) \text { membrane } \\
\text { (1.72) plasma } \\
\text { membrane }(1.36)\end{array}$ & $\begin{array}{l}\text { Cellular process }(2.09) \\
\text { cellular metabolic } \\
\text { process }(1.69) \\
\text { metabolic process } \\
(1.69) \text { cellular } \\
\text { macromolecule } \\
\text { metabolic process } \\
(1.29)\end{array}$ & $\begin{array}{l}\text { Binding }(1.39) \\
\text { protein binding }(1.00) \\
\text { metal ion binding } \\
(0.79) \text { ion binding } \\
(0.79)\end{array}$ \\
\hline $\begin{array}{l}\text { ORF6 protein } \\
\text { (QOI53596) }\end{array}$ & $\begin{array}{l}\text { Human (1.35) domain } \\
(1.18) \text { zf-c2h2 } \\
\text { domains }(0.50) \text { human } \\
\text { zinc finger }(0.50) \text { ctr9 } \\
\text { paf1 }(0.50) \text { cdc } 73 \\
\text { ternary }(0.50) \\
\text { myceliophthora } \\
\text { thermophila }(0.50) \\
\text { RNP }(0.50)\end{array}$ & $\begin{array}{l}\text { Cell (1.76) cell part } \\
\text { (1.76) cytoplasm } \\
\text { (1.31) intracellular } \\
(1.31)\end{array}$ & $\begin{array}{l}\text { Cellular process (2.16) } \\
\text { localization (1.37) } \\
\text { biological regulation } \\
\text { (1.31) cellular } \\
\text { metabolic process } \\
(1.28)\end{array}$ & $\begin{array}{l}\text { Binding (2.60) metal } \\
\text { ion binding (1.60) ion } \\
\text { binding }(1.60) \text { cation } \\
\text { binding }(1.60)\end{array}$ \\
\hline
\end{tabular}

\subsection{Functional annotation of sequences.}

The functional annotation was determined using the InterProScan tool server, which provides functional protein analysis by classification into family membership, domain, and important site prediction. InterProScan result shows the family, the number of domains, and domains that were determined for the SARS-CoV-2 strain's structural and accessory proteins (Table 10). For nucleocapsid phosphoprotein, the family membership was nucleocapsid protein, coronavirus (IPR001218) and nucleocapsid protein, betacoronavirus (IPR043505), number of domains was 2, which were N_prot_N_CoV (IPR044345) and N_prot_C_CoV (IPR044344). For surface glycoprotein, the family membership was spike glycoprotein, betacoronavirus (IPR042578); and it contains six domains which were spike_S1_RBD_SARSCoV-2 (IPR044366), spike_S2_CoV (IPR002552), spike_S1_N_SARS-CoV-like (IPR044341), CoV_S1_C (IPR043607), spike_S1_RBD_bCoV (IPR018548) and bCoV_S1_N (IPR032500). For orf1ab polyprotein, partial, only one domain was determined, which was NSP14_CoV (IPR009466).

The nucleocapsid $(\mathrm{N})$ protein plays an important role in replicating the viral genome and regulating cell signaling pathways [36]. It is also involved together with envelope protein (M) in the condensation and packaging of the genome. It has three highly conserved domains (N-terminal domain (NTD), C-terminal domain (CTD), and N3 region). Based on Parker's (1990) study, it has been demonstrated that the NTD and CTD domains from SARS-CoV, infectious bronchitis virus (IBV), human CoV-229E, and mouse hepatic virus (MHV) display similar topological organizations [37]. InterProScan analysis revealed that human nucleocapsid of SARS-CoV-2 shared similar functional units with Middle East respiratory syndrome-related 
coronavirus (MERS-CoV) (N_prot_N_CoV (IPR044345)) and Alphacoronavirus 1 (N_prot_C_CoV (IPR044344)).

Spike (S) can be divided into three chains (S1, S2, and S2'). S1 actively involves the attachment of virion to the cell membrane through communicating with the cell host receptor. It then starts the infection [38]. S2 mediates virion fusion and cellular membranes by acting as a class I viral fusion protein. S2' plays the role of a viral fusion peptide unconcealed following S2 cleavage happening upon endocytosis of virus [39, 40]. According to Qian et al., (2015) study, NTD of SARS-CoV spike had high sequence similarity with human $\mathrm{CoV}$ (HCoV) OC43, avian b-CoV, infectious bronchitis virus (IBV), bovine $\mathrm{CoV}$ (BCov), and mouse hepatitis virus (MHV) [41]. In this study, S glycoprotein (IPR042578) shared high homologous with the Middle East respiratory syndrome-related coronavirus (MERS-CoV) (IPR002552), SARS coronavirus CUHK-L2 ((IPR044341), bat coronavirus RaTG13 (IPR043607), human coronavirus HKU1 (HCoV-HKU1) (IPR018548) and murine hepatitis virus (IPR032500).

Table 10. The functional analysis of SARS-CoV-2 structural and accessory protein sequences by classifying them into families and predicting their domains by the InterProScan tool.

\begin{tabular}{|c|c|c|c|}
\hline Protein Name & Family & $\begin{array}{c}\text { No. of } \\
\text { Domain }\end{array}$ & Domains \\
\hline $\begin{array}{l}\text { Nucleocapsid } \\
\text { phosphoprotein } \\
\text { (QOI53600) }\end{array}$ & $\begin{array}{l}\text { Nucleocapsid protein, coronavirus } \\
\text { (IPR001218) }\end{array}$ & 2 & $\begin{array}{l}\text {-N_prot_N_CoV (IPR044345) } \\
\text { (50-175) } \\
\text { - N_prot_C_CoV (IPR044345) } \\
(258-359)\end{array}$ \\
\hline $\begin{array}{l}\text { ORF8 protein } \\
\text { (QOI53599) }\end{array}$ & $\begin{array}{l}\text { Non-structural protein ORF8, } \\
\text { betacoronavirus } \\
\text { (IPR022722) }\end{array}$ & - & - \\
\hline ORF7b (QOI53598) & $\begin{array}{l}\text { Structural accessory protein ORF7b, } \\
\text { Sarbecovirus } \\
\text { (IPR021532) }\end{array}$ & - & - \\
\hline $\begin{array}{l}\text { ORF7a protein } \\
\text { (QOI53597) }\end{array}$ & $\begin{array}{l}\text { Structural accessory protein ORF7a, } \\
\text { SARS-CoV-like } \\
\text { (IPR014888) }\end{array}$ & - & - \\
\hline $\begin{array}{l}\text { ORF6 protein } \\
\text { (QO153596) }\end{array}$ & $\begin{array}{l}\text { Non-structural protein NS6, } \\
\text { betacoronavirus } \\
\text { (IPR022736) }\end{array}$ & - & - \\
\hline $\begin{array}{l}\text { Membrane glycoprotein } \\
\text { (QOI53595) }\end{array}$ & $\begin{array}{l}\text { M matrix/glycoprotein, coronavirus } \\
\text { (IPR002574) }\end{array}$ & - & - \\
\hline $\begin{array}{l}\text { Envelope protein } \\
\text { (QOI53594) }\end{array}$ & $\begin{array}{l}\text { Envelope small membrane protein, } \\
\text { coronavirus } \\
\text { (IPR003873) }\end{array}$ & - & - \\
\hline $\begin{array}{l}\text { ORF3a protein } \\
\text { (QOI53593) }\end{array}$ & $\begin{array}{l}\text { Protein 3a, betacoronavirus } \\
\text { (IPR024407) }\end{array}$ & - & ( \\
\hline $\begin{array}{l}\text { Surface glycoprotein } \\
\text { (QOI53592) }\end{array}$ & $\begin{array}{l}\text { Spike glycoprotein, betacoronavirus } \\
\text { (IPR0425787) }\end{array}$ & 6 & $\begin{array}{l}\text { - Spike_S1_RBD_SARS-CoV-2 } \\
\text { (IPR044366) } \\
\text { (319-541) } \\
\text { - Spike_S2_CoV (IPR002552) } \\
\text { (711-1232) } \\
\text { - Spike_S1_N_SARS-CoV-like } \\
\text { (IPR044341) } \\
\text { (13-304) } \\
\text { - CoV_S1_C (IPR043607) } \\
\text { (536-592) } \\
\text { - Spike_S1_RBD_bCoV } \\
\text { (IPR018548) } \\
\text { (349-526) } \\
\text { - bCoV_S1_N (IPR032500) } \\
\text { (33-337) }\end{array}$ \\
\hline $\begin{array}{l}\text { Nucleocapsid } \\
\text { phosphoprotein } \\
\text { (QOI53588) }\end{array}$ & $\begin{array}{l}\text { Nucleocapsid protein, coronavirus } \\
\text { (IPR001218) }\end{array}$ & 2 & $\begin{array}{l}\text { - N_prot_N_CoV (IPR044345) } \\
\text { (50-175) } \\
\text { - N_prot_C_CoV (IPR044344) } \\
(258-359)\end{array}$ \\
\hline $\begin{array}{l}\text { ORF8 protein } \\
\text { (QOI53587) }\end{array}$ & $\begin{array}{l}\text { Non-structural protein ORF8, } \\
\text { betacoronavirus }\end{array}$ & - & - \\
\hline
\end{tabular}




\begin{tabular}{|c|c|c|c|}
\hline Protein Name & Family & $\begin{array}{c}\text { No. of } \\
\text { Domain }\end{array}$ & Domains \\
\hline & (IPR022722) & & \\
\hline ORF7b (QOI53586) & $\begin{array}{l}\text { Structural accessory protein ORF7b, } \\
\text { Sarbecovirus } \\
\text { (IPR021532) }\end{array}$ & - & - \\
\hline $\begin{array}{l}\text { ORF7a protein } \\
\text { (QOI53585) }\end{array}$ & $\begin{array}{l}\text { Structural accessory protein ORF7a, } \\
\text { SARS-CoV-like } \\
\text { (IPR014888) }\end{array}$ & - & - \\
\hline $\begin{array}{l}\text { ORF6 protein } \\
\text { (QOI53584) }\end{array}$ & $\begin{array}{l}\text { Non-structural protein NS6, } \\
\text { betacoronavirus } \\
\text { (IPR022736) }\end{array}$ & - & - \\
\hline $\begin{array}{l}\text { Membrane glycoprotein } \\
\text { (QOI53583) }\end{array}$ & $\begin{array}{l}\text { M matrix/glycoprotein, coronavirus } \\
\text { (IPR002574) }\end{array}$ & - & - \\
\hline $\begin{array}{l}\text { Envelope protein } \\
\text { (QOI53582) }\end{array}$ & $\begin{array}{l}\text { Envelope small membrane protein, } \\
\text { coronavirus } \\
\text { (IPR003873) }\end{array}$ & - & - \\
\hline $\begin{array}{l}\text { ORF3a protein } \\
\text { (QOI53581) }\end{array}$ & $\begin{array}{l}\text { Protein 3a, betacoronavirus } \\
\text { (IPR024407) }\end{array}$ & - & - \\
\hline $\begin{array}{l}\text { 18. ORF8 protein } \\
\text { (QJD23265) }\end{array}$ & $\begin{array}{l}\text { Non-structural protein ORF8, } \\
\text { betacoronavirus } \\
\text { (IPR022722) }\end{array}$ & - & - \\
\hline ORF7b (QJD23264) & $\begin{array}{l}\text { Structural accessory protein ORF7b, } \\
\text { Sarbecovirus } \\
\text { (IPR021532) }\end{array}$ & - & - \\
\hline $\begin{array}{l}\text { ORF7a protein } \\
\text { (QJD23263) }\end{array}$ & $\begin{array}{l}\text { Structural accessory protein ORF7a, } \\
\text { SARS-CoV-like } \\
\text { (IPR014888) }\end{array}$ & - & - \\
\hline $\begin{array}{l}\text { ORF6 protein } \\
\text { (QJD23262) }\end{array}$ & $\begin{array}{l}\text { Non-structural protein NS6, } \\
\text { betacoronavirus } \\
\text { (IPR022736) }\end{array}$ & - & - \\
\hline $\begin{array}{l}\text { envelope protein } \\
\text { (QJD23260) }\end{array}$ & $\begin{array}{l}\text { Envelope small membrane protein, } \\
\text { coronavirus } \\
\text { (IPR003873) }\end{array}$ & - & - \\
\hline $\begin{array}{l}\text { ORF3a protein } \\
\text { (QJD23259) }\end{array}$ & $\begin{array}{l}\text { Protein 3a, betacoronavirus } \\
\text { (IPR024407) }\end{array}$ & - & - \\
\hline $\begin{array}{l}\text { Nucleocapsid } \\
\text { phosphoprotein } \\
\text { (QJD23257) }\end{array}$ & $\begin{array}{l}\text { Nucleocapsid protein, coronavirus } \\
\text { (IPR001218) }\end{array}$ & 2 & $\begin{array}{l}\text { - N_prot_N_CoV (IPR044345) } \\
(50-175) \\
\text { - N_prot_C_CoV (IPR044344) } \\
(258-359)\end{array}$ \\
\hline $\begin{array}{l}\text { ORF8 protein } \\
\text { (QJD23256) }\end{array}$ & $\begin{array}{l}\text { Non-structural protein ORF8, } \\
\text { betacoronavirus } \\
\text { (IPR022722) }\end{array}$ & - & - \\
\hline ORF7b (QJD23255) & $\begin{array}{l}\text { Structural accessory protein ORF7b, } \\
\text { Sarbecovirus } \\
\text { (IPR021532) }\end{array}$ & - & - \\
\hline $\begin{array}{l}\text { ORF7a protein } \\
\text { (QJD23254) }\end{array}$ & $\begin{array}{l}\text { Structural accessory protein ORF7a, } \\
\text { SARS-CoV-like } \\
\text { (IPR014888) }\end{array}$ & - & - \\
\hline $\begin{array}{l}\text { ORF6 protein } \\
\text { (QJD23253) }\end{array}$ & $\begin{array}{l}\text { Non-structural protein NS6, } \\
\text { betacoronavirus } \\
\text { (IPR022736) }\end{array}$ & - & - \\
\hline $\begin{array}{l}\text { Envelope protein } \\
\text { (QJD23251) }\end{array}$ & $\begin{array}{l}\text { Envelope small membrane protein, } \\
\text { coronavirus } \\
\text { (IPR003873) }\end{array}$ & - & - \\
\hline $\begin{array}{l}\text { ORF3a protein } \\
\text { (QJD23250) }\end{array}$ & $\begin{array}{l}\text { Protein 3a, betacoronavirus } \\
\text { (IPR024407) }\end{array}$ & - & 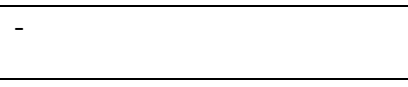 \\
\hline $\begin{array}{l}\text { Nucleocapsid } \\
\text { phosphoprotein } \\
\text { (QJD23245) }\end{array}$ & $\begin{array}{l}\text { Nucleocapsid protein, coronavirus } \\
\text { (IPR001218) }\end{array}$ & 2 & $\begin{array}{l}\text { - N_prot_C_CoV (IPR044344) } \\
(258-359) \\
\text { - N_prot_N_CoV (IPR044345) } \\
(50-175)\end{array}$ \\
\hline $\begin{array}{l}\text { ORF8 protein } \\
\text { (QJD23244) }\end{array}$ & $\begin{array}{l}\text { Non-structural protein ORF8, } \\
\text { betacoronavirus } \\
\text { (IPR022722) }\end{array}$ & - & - \\
\hline ORF7b (QJD23243) & $\begin{array}{l}\text { Structural accessory protein ORF7b, } \\
\text { Sarbecovirus } \\
\text { (IPR021532) }\end{array}$ & - & - \\
\hline $\begin{array}{l}\text { ORF7a protein } \\
\text { (QJD23242) }\end{array}$ & $\begin{array}{l}\text { Structural accessory protein ORF7a, } \\
\text { SARS-CoV-like }\end{array}$ & - & - \\
\hline
\end{tabular}




\begin{tabular}{|c|c|c|c|}
\hline Protein Name & Family & $\begin{array}{l}\text { No. of } \\
\text { Domain }\end{array}$ & Domains \\
\hline & (IPR014888) & & \\
\hline $\begin{array}{l}\text { ORF6 protein } \\
\text { (QJD23241) }\end{array}$ & $\begin{array}{l}\text { Non-structural protein NS6, } \\
\text { betacoronavirus } \\
\text { (IPR022736) }\end{array}$ & - & - \\
\hline $\begin{array}{l}\text { Membrane glycoprotein } \\
\text { (QJD23240) }\end{array}$ & $\begin{array}{l}\text { M matrix/glycoprotein, coronavirus } \\
\text { (IPR002574) }\end{array}$ & - & - \\
\hline $\begin{array}{l}\text { Envelope protein } \\
\text { (QJD23239) }\end{array}$ & $\begin{array}{l}\text { Envelope small membrane protein, } \\
\text { coronavirus } \\
\text { (IPR003873) }\end{array}$ & - & - \\
\hline $\begin{array}{l}\text { ORF3a protein } \\
\text { (QJD23238) }\end{array}$ & $\begin{array}{l}\text { Protein 3a, betacoronavirus } \\
\text { (IPR024407) }\end{array}$ & - & - \\
\hline $\begin{array}{l}\text { Surface glycoprotein } \\
\text { (QJD23237) }\end{array}$ & $\begin{array}{l}\text { Spike glycoprotein, betacoronavirus } \\
\text { (IPR042578) }\end{array}$ & 6 & $\begin{array}{l}\text { - Spike_S2_CoV (IPR002552) } \\
\text { (711-1232) } \\
\text { - Spike_S1_RBD_bCoV } \\
\text { (IPR018548) } \\
\text { (349-526) } \\
\text { - CoV_S1_C (IPR043607) } \\
\text { (536-592) } \\
\text { - Spike_S1_N_SARS-CoV-like } \\
\text { (IPR044341) } \\
\text { (13-304) } \\
\text { - bCoV_S1_N (IPR032500) } \\
\text { (33-337) } \\
\text { - Spike_S1_RBD_SARS-CoV-2 } \\
\text { (IPR044366) } \\
\text { (319-541) }\end{array}$ \\
\hline $\begin{array}{l}\text { Nucleocapsid } \\
\text { phosphoprotein } \\
\text { (QJD23233) }\end{array}$ & $\begin{array}{l}\text { Nucleocapsid protein, coronavirus } \\
\text { (IPR001218) }\end{array}$ & 2 & $\begin{array}{l}\text {-N_prot_N_CoV (IPR044345) } \\
\text { (50-175) } \\
\text { - N_prot_C_CoV (IPR044344) } \\
(258-359)\end{array}$ \\
\hline $\begin{array}{l}\text { ORF8 protein } \\
\text { (QJD23232) }\end{array}$ & $\begin{array}{l}\text { Non-structural protein ORF8, } \\
\text { betacoronavirus } \\
\text { (IPR022722) }\end{array}$ & - & - \\
\hline ORF7b (QJD23231) & $\begin{array}{l}\text { Structural accessory protein ORF7b, } \\
\text { Sarbecovirus } \\
\text { (IPR021532) }\end{array}$ & - & - \\
\hline $\begin{array}{l}\text { ORF7a protein } \\
\text { (QJD23230) }\end{array}$ & $\begin{array}{l}\text { Structural accessory protein ORF7a, } \\
\text { SARS-CoV-like } \\
\text { (IPR014888) }\end{array}$ & - & - \\
\hline $\begin{array}{l}\text { ORF6 protein } \\
\text { (QJD23229) }\end{array}$ & $\begin{array}{l}\text { Non-structural protein NS6, } \\
\text { betacoronavirus } \\
\text { (IPR022736) }\end{array}$ & - & - \\
\hline $\begin{array}{l}\text { Membrane glycoprotein } \\
\text { (QJD23228) }\end{array}$ & $\begin{array}{l}\text { M matrix/glycoprotein, coronavirus } \\
\text { (IPR002574) }\end{array}$ & - & - \\
\hline $\begin{array}{l}\text { Envelope protein } \\
\text { (QJD23227) }\end{array}$ & $\begin{array}{l}\text { Envelope small membrane protein, } \\
\text { coronavirus } \\
\text { (IPR003873) }\end{array}$ & - & - \\
\hline $\begin{array}{l}\text { ORF3a protein } \\
\text { (QJD23226) }\end{array}$ & $\begin{array}{l}\text { Protein 3a, betacoronavirus } \\
\text { (IPR024407) }\end{array}$ & - & - \\
\hline $\begin{array}{l}\text { orf1ab polyprotein, } \\
\text { partial (QIA98594) }\end{array}$ & None predicted & 1 & $\begin{array}{l}\text { - NSP14_CoV (IPR009466) } \\
\text { (1-96) }\end{array}$ \\
\hline $\begin{array}{l}\text { orf1ab polyprotein, } \\
\text { partial (QIA98593) }\end{array}$ & None predicted & 1 & $\begin{array}{l}\text { - NSP14_CoV (IPR009466) } \\
(1-96)\end{array}$ \\
\hline $\begin{array}{l}\text { orf1ab polyprotein, } \\
\text { partial (QIA98592) }\end{array}$ & None predicted & 1 & $\begin{array}{l}\text { - NSP14_CoV (IPR009466) } \\
(1-96)\end{array}$ \\
\hline
\end{tabular}

\subsection{Active site identification.}

The identification of the proteins' active sites was determined using Active Site Prediction of Protein Server (SCFBio), which computes the cavities in the Malaysia SARSCoV-2 structural and accessory proteins based on the size, protein volumes, and the residues 
that are forming a pocket in the active sites. Table 11 shows the predicted active sites of SARSCoV-2 structural and accessory proteins.

Table 11. The active site prediction for Malaysia SARS-CoV-2 strain's structural and accessory protein sequences using Active Site Prediction of Protein Server (SCFBio).

\begin{tabular}{|c|c|c|}
\hline Protein & Volume & Residues that forming pocket \\
\hline $\begin{array}{l}\text { Nucleocapsid phosphoprotein } \\
\text { (QOI53600) }\end{array}$ & 1746 & $\begin{array}{l}\text { ALA1, GLN10, LEU102, LEU103, HIE106, ILE107, ASP108, } \\
\text { LYS11, ARG12, THR13, ALA14, THR15, LYS16, ALA17, TYR18, } \\
\text { ASN19, VAL20, THR21, GLN22, PHE24, GLY25, ARG26, ARG27, } \\
\text { GLY28, PRO29, GLU3, GLN31, THR32, GLN33, GLY34, ASN35, } \\
\text { PHE36, ALA4, LEU41, ILE42, GLN44, GLY45, THR46, ASP47, } \\
\text { TYR48, SER5, TRP51, PRO52, GLN53, ALA55, GLN56, PHE57, } \\
\text { ALA58, PRO59, LYS6, SER60, ALA61, SER62, ALA63, PHE64, } \\
\text { PHE65, MET67, SER68, LYS7, GLY71, PRO8, TRP80, LEU81, } \\
\text { THR82, TYR83, THR84, GLY85, ALA86, ILE87, LEU89, ARG9 }\end{array}$ \\
\hline ORF8 protein (QOI53599) & 1475 & $\begin{array}{l}\text { GLN10, VAL100, LEU101, ASP102, PHE103, ILE104, HIE11, } \\
\text { GLN114, HIE115, ARG135, VAL136, GLY137, ALA138, ARG139, } \\
\text { ALA142, VAL16, ILE161, GLN178, GLU179, PRO180, LYS181, } \\
\text { LEU182, SER184, LEU185, ARG202, VAL204, LEU205, ASP206, } \\
\text { PHE207, ARG31, VAL32, GLY33, LEU5, ILE59, GLY60, ASN61, } \\
\text { TYR62, ASN72, GLN74, GLU75, PRO76, LYS77, LEU78, SER8,, } \\
\text { LEU81, VAL82, THR9, ARG98 }\end{array}$ \\
\hline ORF7b (QOI53598) & - & - \\
\hline ORF7a protein (QOI53597) & 715 & $\begin{array}{l}\text { GLU1, ARG10, GLU26, GLY27, ASN28, SER29, TYR3, PRO30, } \\
\text { HIE4, LEU41, THR42, CYS43, PHE44, SER45, THR46, GLN47, } \\
\text { PHE48, ALA49, TYR5, VAL59, GLN6, TYR60, GLN61, LEU62, } \\
\text { ARG63, ALA64, ARG65, SER66, PRO69, GLU7, LEU71, GLU76, } \\
\text { GLU77, VAL78, GLN79, GLU80, LEU81, TYR82, SER83 }\end{array}$ \\
\hline ORF6 protein (QO153596) & 363 & $\begin{array}{l}\text { PHE1, LEU10, ILE11, ILE12, GLN2, LEU23, ILE26, ILE27, } \\
\text { ASN28, LEU29, VAL3, ILE30, ILE31, LYS32, ASN33, LEU34, } \\
\text { SER35, SER37, LEU38, THR4, ILE5, ALA6, GLU7, ILE8, LEU9 }\end{array}$ \\
\hline $\begin{array}{ll}\begin{array}{l}\text { Membrane } \\
(\text { QOI53595) }\end{array} & \text { glycoprotein } \\
\end{array}$ & - & - \\
\hline Envelope protein (QOI53594) & 388 & $\begin{array}{l}\text { LEU20, LEU21, VAL22, THR23, LEU24, ALA25, ILE26, LEU27, } \\
\text { THR28, ALA29, ARG31, LEU32, TYR35, SER43, LEU44, VAL45, } \\
\text { LYS46, PRO47, SER48, PHE49, TYR50, VAL51, TYR52, VAL55 }\end{array}$ \\
\hline ORF3a protein (QOI53593) & 1790 & $\begin{array}{l}\text { LEU100, TYR102, ASP103, ALA104, ASN105, TYR106, PHE107, } \\
\text { PRO120, TYR121, ASN122, SER123, VAL124, LEU14, TYR150, } \\
\text { SER166, TYR167, PHE168, THR169, GLN18, SER21, VAL215, } \\
\text { PHE216, GLN217, SER218, ALA219, LYS22, SER220, LYS22,, } \\
\text { ILE222, ILE223, THR224, LEU225, LYS226, LYS227, ARG228, } \\
\text { TRP229, LEU231, ALA232, LEU233, SER234, LYS235, GLY236, } \\
\text { VAL237, HIE238, PHE239, ILE24, CYS241, ASN242, LEU26, } \\
\text { ARG282, PRO29,, LEU299, LEU300, TYR301, ASP302, ALA303, } \\
\text { ASN304, LEU32, GLY348, TYR349, SER35, LYS36, GLY37, } \\
\text { HIE39, PHE40, CYS42, ASN43, LEU44, LEU47, LEU72, PHE75, } \\
\text { LEU76, GLN77, SER78, ILE79, ASN80, PHE81, VAL82, ARG83, } \\
\text { ILE84, ILE85, MET86, ARG87, LEU88, TRP89, LEU90, ASN98, } \\
\text { PRO99 }\end{array}$ \\
\hline $\begin{array}{ll}\begin{array}{l}\text { Surface } \\
(\text { QOI53592) }\end{array} & \text { glycoprotein } \\
\end{array}$ & - & - \\
\hline $\begin{array}{l}\text { Nucleocapsid phosphoprotein } \\
\text { (QOI53588) }\end{array}$ & 1746 & $\begin{array}{l}\text { ALA1, GLN10, LEU102, LEU103, HIE106, ILE107, ASP108, } \\
\text { LYS11, ARG12, THR13, ALA14, THR15, LYS16, ALA17, TYR18, } \\
\text { ASN19, VAL20, THR21, GLN22, PHE24, GLY25, ARG26, ARG27, } \\
\text { GLY28, PRO29, GLU3, GLN31, THR32, GLN33, GLY34, ASN35, } \\
\text { PHE36, ALA4, LEU41, ILE42, GLN44, GLY45, THR46, ASP47, } \\
\text { TYR48, SER5, TRP51, PRO52, GLN53, ALA55, GLN56, PHE57, } \\
\text { ALA58, PRO59, LYS6, SER60, ALA61, SER62, ALA63, PHE64, } \\
\text { PHE65, MET67, SER68, LYS7, GLY71, PRO8, TRP80, LEU81, } \\
\text { THR82, TYR83, THR84, GLY85, ALA86, ILE87, LEU89, ARG9, }\end{array}$ \\
\hline
\end{tabular}




\begin{tabular}{|c|c|c|}
\hline Protein & Volume & Residues that forming pocket \\
\hline ORF8 protein (QOI53587) & 1390 & $\begin{array}{l}\text { GLN10, VAL100, LEU101, PHE103, LEU109, HIE11, SER111, } \\
\text { THR113, GLN114, HIE115, GLY137, ALA138, GLN178, GLU17,, } \\
\text { PRO180, LYS181, LEU182, GLY183, SER184, LEU185, ARG202, } \\
\text { VAL204, LEU205, ASP206, PHE207, ILE208, ARG31, VAL32, } \\
\text { GLY33, ARG35, LYS36, SER37, ALA38, PRO39, LEU40, ILE41, } \\
\text { ILE57, ASP58, ILE59, GLY60, ASN61, TYR62, GLN74, GLU75, } \\
\text { PRO76, LYS77, LEU78, GLY79, SER80, LEU81, VAL82, ASP96, } \\
\text { ARG98 }\end{array}$ \\
\hline ORF7b (QOI53586) & - & - \\
\hline ORF7a protein (QOI53585) & 715 & $\begin{array}{l}\text { GLU1, ARG10, GLU26, GLY27, ASN28, SER29, TYR3, PRO30, } \\
\text { HIE4, LEU41, THR42, CYS43, PHE44, SER45, GLN47, PHE48, } \\
\text { ALA49, TYR5, VAL59, GLN6, TYR60, GLN61, LEU62, ARG63, } \\
\text { ALA64, ARG65, SER66, PRO69, GLU7, LEU71, GLU76, GLU77, } \\
\text { VAL78, GLN79, GLU80, LEU81, TYR82, SER83 }\end{array}$ \\
\hline ORF6 protein (QOI53584) & 363 & $\begin{array}{l}\text { PHE1, LEU10, ILE11, ILE12, GLN2, LEU23, ILE26, ILE27, } \\
\text { ASN28, LEU29, VAL3, ILE30, ILE31, LYS32, ASN33, LEU34, } \\
\text { SER35, SER37, LEU38, THR4, ILE5, ALA6, GLU7, ILE8, LEU9 }\end{array}$ \\
\hline $\begin{array}{ll}\text { Membrane } & \text { glycoprotein } \\
\text { (QOI53583) } & \end{array}$ & 896 & $\begin{array}{l}\text { GLY100, ASN101, ASN19, ALA2, VAL20, PRO21, LEU22, HIE23, } \\
\text { THR25, ILE26, LEU27, THR28, ARG3, SER34, ILE38, GLY39, } \\
\text { THR4, LEU47, ARG5, ARG56, ILE59, LYS60, ASP61, LEU62, } \\
\text { PRO63, LYS64, } \\
\text { GLU65, ILE66, THR67, VAL68, ALA69, THR70, THR73, LEU74, } \\
\text { SER75, TYR76, TYR77, LYS78, LEU79, GLY80, SER82, TYR94, } \\
\text { ARG96, TYR97, ARG98, ILE99 }\end{array}$ \\
\hline Envelope protein (QOI53582) & 388 & $\begin{array}{l}\text { LEU20, LEU21, VAL22, THR23, LEU24, ALA25, ILE26, LEU27, } \\
\text { THR28, ALA29, ARG31, LEU32, TYR35, SER43, LEU44, VAL45, } \\
\text { LYS46, PRO47, SER48, PHE49, TYR50, VAL51, TYR52, VAL55 }\end{array}$ \\
\hline ORF3a protein (QOI53581) & 1777 & $\begin{array}{l}\text { LEU100, LEU101, TYR102, ASP103, ALA104, ASN105, TYR106, } \\
\text { PHE107, PRO120, TYR121, ASN122, SER123, VAL124, LEU14, } \\
\text { TYR150, SER166, TYR167, PHE168, THR169, HIE18, SER21, } \\
\text { PHE216, HIE217, SER218, ALA219, LYS22, SER220, LYS221, } \\
\text { ILE222, ILE223, THR224, LEU225, LYS226, LYS227, ARG228, } \\
\text { TRP229, LEU231, ALA232, LEU233, SER234, LYS235, GLY236, } \\
\text { VAL237, HIE238, PHE239, ILE24, CYS241, ASN242, LEU26, } \\
\text { ARG282, PRO298, LEU299, LEU300, TYR301, ASP302, ALA303, } \\
\text { ASN304, LEU32, GLY348, TYR349, SER35, LYS36, GLY37, } \\
\text { HIE39, PHE40, CYS42, ASN43, LEU44, LEU47, LEU72, PHE75, } \\
\text { LEU76, GLN77, SER78, ILE79, ASN80, PHE81, VAL82, ARG83, } \\
\text { ILE84, ILE85, MET86, ARG87, LEU88, TRP89, LEU90, ASN98, } \\
\text { PRO99 }\end{array}$ \\
\hline ORF8 protein (QJD23265) & 1475 & $\begin{array}{l}\text { GLN10, VAL100, LEU101, ASP102, PHE103, ILE104, HIE11, } \\
\text { GLN114, HIE115, ARG135, VAL136, GLY137, ALA138, ARG139, } \\
\text { ALA142, VAL16, ILE161, GLN178, GLU179, PRO180, LYS181, } \\
\text { LEU182, SER184, LEU185, ARG202, VAL204, LEU205, ASP206, } \\
\text { PHE207, ARG31, VAL32, GLY33, LEU5, ILE59, GLY60, ASN61, } \\
\text { TYR62, ASN72, GLN74, GLU75, PRO76, LYS77, LEU78, SER8,, } \\
\text { LEU81, VAL82, THR9, ARG98 }\end{array}$ \\
\hline ORF7b (QJD23264) & - & - \\
\hline ORF7a protein (QJD23263) & 715 & $\begin{array}{l}\text { GLU1, ARG10, GLU26, GLY27, ASN28, SER29, TYR3, PRO30, } \\
\text { HIE4, LEU41, THR42, CYS43, PHE44, SER45, THR46, GLN47, } \\
\text { PHE48, ALA49, TYR5, VAL59, GLN6, TYR60, GLN61, LEU62, } \\
\text { ARG63, ALA64, ARG65, SER66, PRO69, GLU7, LEU71, GLU76, } \\
\text { GLU77, VAL78, GLN79, GLU80, LEU81, TYR82, SER83 }\end{array}$ \\
\hline ORF6 protein (QJD23262) & 363 & $\begin{array}{l}\text { PHE1, LEU10, ILE11, ILE12, GLN2, LEU23, ILE26, ILE27, } \\
\text { ASN28, LEU29, VAL3, ILE30, ILE31, LYS32, ASN33, LEU34, } \\
\text { SER35, SER37, LEU38, THR4, ILE5 } \\
\text { ALA6, GLU7, ILE8, LEU9 }\end{array}$ \\
\hline envelope protein (QJD23260) & 388 & $\begin{array}{l}\text { LEU20, LEU21, VAL22, THR23, LEU24, ALA25, ILE26, LEU27, } \\
\text { THR28, ALA29, ARG31, LEU32, TYR35, SER43, LEU44, VAL45, }\end{array}$ \\
\hline
\end{tabular}




\begin{tabular}{|c|c|c|}
\hline Protein & Volume & Residues that forming pocket \\
\hline & & LYS46, PRO47, SER48, PHE49, TYR50, VAL51, TYR52, VAL55 \\
\hline ORF3a protein (QJD23259) & 1790 & $\begin{array}{l}\text { LEU100, LEU101, TYR102, ASP103, ALA104, ASN105, TYR106, } \\
\text { PHE107, PRO120, TYR121, ASN122, SER123, VAL124,LEU14, } \\
\text { TYR150, PHE168, } \\
\text { THR169, GLN18,SER21, VAL215, PHE216, GLN217, SER218, } \\
\text { ALA219, LYS22, SER220, LYS221, ILE222, ILE223, THR224, } \\
\text { LEU225, LYS226, LYS227, ARG228, TRP229, LEU231, ALA232, } \\
\text { LEU233, SER234, LYS235, GLY236, VAL237, HIE238, PHE23,, } \\
\text { ILE24, CYS241, ASN242, LEU26, ARG282, PRO298, LEU29,, } \\
\text { LEU300, TYR301, ASP302, ALA303, ASN304, LEU32, GLY348, } \\
\text { TYR349, SER35, LYS36, GLY37, HIE39, PHE40, CYS42, ASN43, } \\
\text { LEU44, LEU47, LEU72, PHE75, LEU76, GLN77, SER78, ILE79, } \\
\text { ASN80, PHE81, VAL82, ARG83, ILE84, ILE85, MET86, ARG87, } \\
\text { LEU88, TRP89, LEU90, ASN98, PRO99 }\end{array}$ \\
\hline $\begin{array}{l}\text { Nucleocapsid phosphoprotein } \\
\text { (QJD23257) }\end{array}$ & 1746 & $\begin{array}{l}\text { ALA1, GLN10, LEU102, LEU103, HIE106, ILE107, ASP108, } \\
\text { LYS11, ARG12, THR13, ALA14, THR15, LYS16, ALA17, TYR18, } \\
\text { ASN19, VAL20, THR21, GLN22, PHE24, GLY25, ARG26, ARG27, } \\
\text { GLY28, PRO29, GLU3, GLN31, THR32, GLN33, GLY34, ASN35, } \\
\text { PHE36, ALA4, LEU41, ILE42, GLN44, GLY45, THR46, THR46, } \\
\text { ASP4, TYR48, SER5, TRP51, PRO52, GLN53, ALA55, GLN56, } \\
\text { PHE57, ALA58, PRO59, LYS6, SER60, ALA61, SER62, ALA63, } \\
\text { PHE64, PHE65, MET67, SER68, LYS7, GLY71, PRO8, TRP80, } \\
\text { LEU81, THR82, TYR83, THR84, GLY85, ALA86, ILE87, LEU8,, } \\
\text { ARG9 }\end{array}$ \\
\hline ORF8 protein (QJD23256) & 1475 & $\begin{array}{l}\text { GLN10, VAL100, LEU101, ASP102, PHE103, ILE104, HIE11, } \\
\text { GLN114, HIE115, ARG135, ARG135, VAL136, GLY137, ALA138, } \\
\text { ARG139, ALA142, VAL16, ILE161, GLN178, GLU179, PRO180, } \\
\text { LYS181, LEU182, SER184, LEU185, ARG202, VAL204, LEU205, } \\
\text { ASP206, PHE207, ARG31, VAL32, GLY33, LEU5, ILE59, GLY60, } \\
\text { ASN61, TYR62, ASN72, GLN74, GLU75, PRO76, LYS77, LEU78, } \\
\text { SER80, LEU81, VAL82, THR9, ARG98 }\end{array}$ \\
\hline ORF7b (QJD23255) & - & - \\
\hline ORF7a protein (QJD23254) & 715 & $\begin{array}{l}\text { GLU1, ARG10, GLU26, GLY27, ASN28, SER29, TYR3, PRO30, } \\
\text { HIE4, LEU41, THR42, CYS43, PHE44, SER45, THR46, GLN47, } \\
\text { PHE48, ALA49, TYR5, VAL59, GLN6, TYR60, GLN61, LEU62, } \\
\text { ARG63, ALA64, ARG65, SER66, PRO69, GLU7, LEU71, GLU76, } \\
\text { GLU77, VAL78, GLN79, GLU80, LEU81, TYR82, SER83 }\end{array}$ \\
\hline ORF6 protein (QJD23253) & 363 & $\begin{array}{l}\text { PHE1, LEU10, ILE11, ILE12, GLN2, LEU23, ILE26, ILE27, } \\
\text { ASN28, LEU29, VAL3, ILE30, ILE31, LYS32, ASN33, LEU34, } \\
\text { SER35, SER37, LEU38, THR4, ILE5 } \\
\text { ALA6, GLU7, ILE8, LEU9 }\end{array}$ \\
\hline Envelope protein (QJD23251) & 388 & $\begin{array}{l}\text { LEU20, LEU21, VAL22, THR23, LEU24, ALA25, ILE26, LEU27, } \\
\text { THR28, ALA29, ARG31, LEU32, TYR35, SER43, LEU44, VAL45, } \\
\text { LYS46, PRO47, SER48, PHE49, TYR50, VAL51, TYR52, VAL55 }\end{array}$ \\
\hline ORF3a protein (QJD23250) & 1790 & $\begin{array}{l}\text { LEU100, LEU101, TYR102, ASP103, ALA104, ASN105, TYR106, } \\
\text { PHE107, PRO120, TYR121, ASN122, SER123, VAL124,LEU14, } \\
\text { TYR150, PHE168, } \\
\text { THR169, GLN18,SER166, TYR167, } \\
\text { ALA219, LYS22, SER220, LYS221, ILE222, ILE223, THR224, } \\
\text { LEU225, LYS226, LYS227, ARG228, TRP229, LEU231, ALA232, } \\
\text { LEU233, SER234, LYS235, GLY236, VAL237, HIE238, PHE23,, } \\
\text { ILE24, CYS241, ASN242, LEU26, ARG282, PRO298, LEU29,, } \\
\text { LEU300, TYR301, ASP302, ALA303, ASN304, LEU32, GLY348, } \\
\text { TYR349, SER35, LYS36, GLY37, HIE39, PHE40, CYS42, ASN43, } \\
\text { LEU44, LEU47, LEU72, PHE75, LEU76, GLN77, SER78, ILE79, } \\
\text { ASN80, PHE81, VAL82, ARG83, ILE84, ILE85, MET86, ARG87, } \\
\text { LEU88, TRP89, LEU90, ASN98, PRO99 }\end{array}$ \\
\hline $\begin{array}{l}\text { Nucleocapsid phosphoprotein } \\
\text { (QJD23245) }\end{array}$ & 1032 & $\begin{array}{l}\text { THR10, GLY108, THR109, ALA11, ARG110, ASN111, PRO112, } \\
\text { ALA 116, ALA117, VAL119, SER12, LEU120, TYR133, }\end{array}$ \\
\hline
\end{tabular}




\begin{tabular}{|c|c|c|}
\hline Protein & Volume & Residues that forming pocket \\
\hline & & $\begin{array}{l}\text { GLU135, PHE14, THR15, ALA16, THR18, GLN19, HIE20, ASP24, } \\
\text { LEU25, ARG49, ARG50, ALA51, THR52, ARG53, ARG54, ILE55, } \\
\text { ARG56, GLY57, ASP64, LEU65, SER66, PRO67, ARG68, TRP } \\
\quad \text { 69, PRO 7, TYR70, TYR72, TYR73, THR76, PRO78, } \\
\text { GLU79, ASN8, ALA } \quad \text { 80, GLY81, LYS88, ASP89, ASN9, } \\
\text { GLY90, ILE91, ILE92 }\end{array}$ \\
\hline ORF8 protein (QJD23244) & 1475 & $\begin{array}{l}\text { GLN10, VAL100, LEU101, ASP102, PHE103, ILE104, HIE11, } \\
\text { GLN114, HIE115, ARG135, ARG135, VAL136, GLY137, ALA138, } \\
\text { ARG139, ALA142, VAL16, ILE161, GLN178, GLU179, PRO180, } \\
\text { LYS181, LEU182, SER184, LEU185, ARG202, VAL204, LEU205, } \\
\text { ASP206, PHE207, ARG31, VAL32, GLY33, LEU5, ILE59, GLY60, } \\
\text { ASN61, TYR62, ASN72, GLN74, GLU75, PRO76, LYS77, LEU7,, } \\
\text { SER80, LEU81, VAL82, THR9, ARG98 }\end{array}$ \\
\hline ORF7b (QJD23243) & - & - \\
\hline ORF7a protein (QJD23242) & 715 & $\begin{array}{l}\text { GLU1, ARG10, GLU26, GLY27, ASN28, SER29, TYR3, PRO30, } \\
\text { HIE4, LEU41, THR42, CYS43, PHE44, SER45, THR46, GLN47, } \\
\text { PHE48, ALA49, TYR5, VAL59, GLN6, TYR60, GLN61, LEU62, } \\
\text { ARG63, ALA64, ARG65, SER66, PRO69, GLU7, LEU71, GLU76, } \\
\text { GLU77, VAL78, GLN79, GLU80, LEU81, TYR82, SER83 }\end{array}$ \\
\hline ORF6 protein (QJD23241) & 363 & $\begin{array}{l}\text { PHE1, LEU10, ILE11, ILE12, GLN2, LEU23, ILE26, ILE27, } \\
\text { ASN28, LEU29, VAL3, ILE30, ILE31, LYS32, ASN33, LEU34, } \\
\text { SER35, SER37, LEU38, THR4, ILE5 } \\
\text { ALA6, GLU7, ILE8, LEU9 }\end{array}$ \\
\hline $\begin{array}{ll}\begin{array}{l}\text { Membrane } \\
\text { (QJD23240) }\end{array} & \text { glycoprotein } \\
\end{array}$ & - & - \\
\hline Envelope protein (QJD23239) & 388 & $\begin{array}{l}\text { LEU20, LEU21, VAL22, THR23, LEU24, ALA25, ILE26, LEU27, } \\
\text { THR28, ALA29, ARG31, LEU32, TYR35, SER43, LEU44, VAL45, } \\
\text { LYS46, PRO47, SER48, PHE49, TYR50, VAL51, TYR52, VAL55 }\end{array}$ \\
\hline ORF3a protein (QJD23238) & 1790 & $\begin{array}{l}\text { LEU100, LEU101, TYR102, ASP103, ALA104, ASN105, TYR106, } \\
\text { PHE107, PRO120, TYR121, ASN122, SER123, VAL124,LEU14, } \\
\text { TYR150, PHE168, } \text { SER166, TYR167, } \\
\text { THR169, GLN18,SER21,VAL215, PHE216, GLN217, SER218, } \\
\text { ALA219, LYS22, SER220, LYS221, ILE222, ILE223, THR224, } \\
\text { LEU225, LYS226, LYS227, ARG228, TRP229, LEU231, ALA232, } \\
\text { LEU233, SER234, LYS235, GLY236, VAL237, HIE238, PHE23,, } \\
\text { ILE24, CYS241, ASN242, LEU26, ARG282, PRO298, LEU299, } \\
\text { LEU300, TYR301, ASP302, ALA303, ASN304, LEU32, GLY348, } \\
\text { TYR349, SER35, LYS36, GLY37, HIE39, PHE40, CYS42, ASN43, } \\
\text { LEU44, LEU47, LEU72, PHE75, LEU76, GLN77, SER78, ILE79, } \\
\text { ASN80, PHE81, VAL82, ARG83, ILE84, ILE85, MET86, ARG87, } \\
\text { LEU88, TRP89, LEU90, ASN98, PRO99 }\end{array}$ \\
\hline $\begin{array}{ll}\begin{array}{l}\text { Surface } \\
(\text { QJD23237) }\end{array} & \text { glycoprotein } \\
\end{array}$ & - & - \\
\hline $\begin{array}{l}\text { Nucleocapsid phosphoprotein } \\
\text { (QJD23233) }\end{array}$ & 1746 & $\begin{array}{l}\text { ALA1, GLN10, LEU102, LEU103, HIE106, ILE107, ASP108, } \\
\text { LYS11, ARG12, THR13, ALA14, THR15, LYS16, ALA17, TYR18, } \\
\text { ASN19, VAL20, THR21, GLN22, PHE24, GLY25, ARG26, ARG27, } \\
\text { GLY28, PRO29, GLU3, GLN31, THR32, GLN33, GLY34, ASN35, } \\
\text { PHE36, ALA4, LEU41, ILE42, GLN44, GLY45, THR46, THR46, } \\
\text { ASP4, TYR48, SER5, TRP51, PRO52, GLN53, ALA55, GLN56, } \\
\text { PHE57, ALA58, PRO59, LYS6, SER60, ALA61, SER62, ALA63, } \\
\text { PHE64, PHE65, MET67, SER68, LYS7, GLY71, PRO8, TRP8,, } \\
\text { LEU81, THR82, TYR83, THR84, GLY85, ALA86, ILE87, LEU89, } \\
\text { ARG9 }\end{array}$ \\
\hline ORF8 protein (QJD23232) & 1475 & $\begin{array}{l}\text { GLN10, VAL100, LEU101, ASP102, PHE103, ILE104, HIE11, } \\
\text { GLN114, HIE115, ARG135, ARG135, VAL136, GLY137, ALA138, } \\
\text { ARG139, ALA142, VAL16, ILE161, GLN178, GLU179, PRO180, } \\
\text { LYS181, LEU182, SER184, LEU185, ARG202, VAL204, LEU205, } \\
\text { ASP206, PHE207, ARG31, VAL32, GLY33, LEU5, ILE59, GLY60, } \\
\text { ASN61, TYR62, ASN72, GLN74, GLU75, PRO76, LYS77, LEU7,, } \\
\text { SER80, LEU81, VAL82, THR9, ARG98 }\end{array}$ \\
\hline
\end{tabular}




\begin{tabular}{|c|c|c|}
\hline Protein & Volume & Residues that forming pocket \\
\hline 42. ORF7b (QJD23231) & - & - \\
\hline 43. ORF7a protein (QJD23230) & 715 & $\begin{array}{l}\text { GLU1, ARG10, GLU26, GLY27, ASN28, SER29, TYR3, PRO30, } \\
\text { HIE4, LEU41, THR42, CYS43, PHE44, SER45, THR46, GLN47, } \\
\text { PHE48, ALA49, TYR5, VAL59, GLN6, TYR60, GLN61, LEU62, } \\
\text { ARG63, ALA64, ARG65, SER66, PRO69, GLU7, LEU71, GLU76, } \\
\text { GLU77, VAL78, GLN79, GLU80, LEU81, TYR82, SER83 }\end{array}$ \\
\hline ORF6 protein (QJD23229) & - & - \\
\hline $\begin{array}{ll}\text { Membrane } & \text { glycoprotein } \\
\text { (QJD23228) } & \end{array}$ & 896 & $\begin{array}{l}\text { GLY100, ASN101, ASN19, ALA2, VAL20, PRO21, LEU22, HIE23, } \\
\text { THR25, ILE26, LEU27, THR28, ARG3, SER34, ILE38, GLY39, } \\
\text { THR4, LEU47, ARG5, ARG56, ILE59, LYS60, ASP61, LEU62, } \\
\text { PRO63, LYS64, } \\
\text { GLU65, ILE66, THR67, VAL68, ALA69, THR70, THR73, LEU74, } \\
\text { SER75, TYR76, TYR77, LYS78, LEU79, GLY80, SER82, TYR94, } \\
\text { ARG96, TYR97, ARG98, ILE99 }\end{array}$ \\
\hline Envelope protein (QJD23227) & 388 & $\begin{array}{l}\text { LEU20, LEU21, VAL22, THR23, LEU24, ALA25, ILE26, LEU27, } \\
\text { THR28, ALA29, ARG31, LEU32, TYR35, SER43, LEU44, VAL45, } \\
\text { LYS46, PRO47, SER48, PHE49, TYR50, VAL51, TYR52, VAL55 }\end{array}$ \\
\hline ORF3a protein (QJD23226) & 1790 & $\begin{array}{l}\text { LEU100, LEU101, TYR102, ASP103, ALA104, ASN105, TYR106, } \\
\text { PHE107, PRO120, TYR121, ASN122, SER123, VAL124,LEU14, } \\
\text { TYR150, PHE168, } \\
\text { THR169, GLN18,SER21,VAL215, PHE216, GLN217, SER218, } \\
\text { ALA219, LYS22, SER220, LYS221, ILE222, ILE223, THR224, } \\
\text { LEU225, LYS226, LYS227, ARG228, TRP229, LEU231, ALA23,, } \\
\text { LEU233, SER234, LYS235, GLY236, VAL237, HIE238, PHE23,, } \\
\text { ILE24, CYS241, ASN242, LEU26, ARG282, PRO298, LEU299, } \\
\text { LEU300, TYR301, ASP302, ALA303, ASN304, LEU32, GLY34,, } \\
\text { TYR349, SER35, LYS36, GLY37, HIE39, PHE40, CYS42, ASN43, } \\
\text { LEU44, LEU47, LEU72, PHE75, LEU76, GLN77, SER78, ILE7,, } \\
\text { ASN80, PHE81, VAL82, ARG83, ILE84, ILE85, MET86, ARG87, } \\
\text { LEU88, TRP89, LEU90, ASN98, PRO99 }\end{array}$ \\
\hline $\begin{array}{l}\text { orf1ab polyprotein, partial } \\
\text { (QIA98594) }\end{array}$ & 1089 & $\begin{array}{l}\text { LEU11, TRP13, VAL16, ARG17, ILE18, LYS19, HIE2, ILE20, } \\
\text { GLN22, MET23, LEU24, SER25, ASP26, THR27, LEU28, LEU3, } \\
\text { ASN30, LEU31, SER32, ARG34, VAL35, VAL36, PHE37, VAL38, } \\
\text { LEU39, TRP40, ALA41, HIE42, GLY43, PHE44, GLU45, LEU46, } \\
\text { THR47, SER48, MET49, LYS50, TYR51, PHE52, VAL53, ILE55, } \\
\text { LEU6, TRP81, TYR89, ASN92, PRO93, PHE94, MET95, ILE96 }\end{array}$ \\
\hline $\begin{array}{l}\text { orf1ab polyprotein, partial } \\
\text { (QIA98593) }\end{array}$ & 1089 & $\begin{array}{l}\text { LEU11, TRP13, VAL16, ARG17, ILE18, LYS19, HIE2, ILE20, } \\
\text { GLN22, MET23, LEU24, SER25, ASP26, THR27, LEU28, LEU3, } \\
\text { ASN30, LEU31, SER32, ARG34, VAL35, VAL36, PHE37, VAL38, } \\
\text { LEU39, TRP40, ALA41, HIE42, GLY43, PHE44, GLU45, LEU46, } \\
\text { THR47, SER48, MET49, LYS50, TYR51, PHE52, VAL53, ILE55, } \\
\text { LEU6, TRP81, TYR89, ASN92, PRO93, PHE94, MET95, ILE96 }\end{array}$ \\
\hline $\begin{array}{l}\text { orf1ab polyprotein, partial } \\
\text { (QIA98592) }\end{array}$ & 1089 & $\begin{array}{l}\text { LEU11, TRP13, VAL16, ARG17, ILE18, LYS19, HIE2, ILE20, } \\
\text { GLN22, MET23, LEU24, SER25, ASP26, THR27, LEU28, LEU3, } \\
\text { ASN30, LEU31, SER32, ARG34, VAL35, VAL36, PHE37, VAL38, } \\
\text { LEU39, TRP40, ALA41, HIE42, GLY43, PHE44, GLU45, LEU46, } \\
\text { THR47, SER48, MET49, LYS50, TYR51, PHE52, VAL53, ILE55, } \\
\text { LEU6, TRP81, TYR89, ASN92, PRO93, PHE94, MET95, ILE96 }\end{array}$ \\
\hline
\end{tabular}

\subsection{Molecular phylogenetic analysis.}

The molecular phylogenetic analysis was conducted based on statistics on molecular evolution and for phylogenetic tree construction by using MEGA X software. The evolutionary history phylogenetic tree was constructed based on the Maximum Parsimony Tree method, and the heuristic search for the initial phylogenetic tree was constructed based on the NeighborJoining method [18]. For the ORF 10 protein and ORF8 protein, Maximum Parsimony and Neighbor-Joining Trees were constructed with five different coronaviruses such SARS-CoV2, SARS-CoV A022, Bat SARS CoV Rp3/2004, SARS coronavirus civet 020, and Pangolin 
coronavirus. However, Maximum Parsimony and Neighbor-Joining Trees were constructed with four different coronaviruses such as SARS-CoV-2, Severe acute respiratory syndromerelated coronavirus, Bat SARS CoV Rm1/2004, and Pangolin coronavirus for ORF6 protein.

The Neighbor-Joining method finds pairs of operational taxonomic units (OTUs [= neighbors]) that minimize the total branch length at each stage of clustering of OTUs starting with a starlike tree. The Neighbor-Joining Tree for ORF10 is shown in Figure 1. Pangolin coronavirus shared 30\% homology with SARS-CoV-2 while bat SARS-CoV Rp3/2004, SARS coronavirus civet020, and SARS coronavirus A022 had 90\% sequence identity with SARSCoV-2. Figure 2 shows the Neighbor-Joining Tree for ORF8. Pangolin coronavirus shared 82\% genetic similarity with SARS-CoV-2. According to Xiao et al. (2020) study, pangolin acts as a zoonotic reservoir and ideal intermediate host for the SARS-CoV-2 like coronaviruses [42]. However, bat SARS-CoV Rp3/2004, SARS coronavirus civet020, and SARS coronavirus A022 had 93\% sequence similarity with SARS-CoV-2. Based on Tiwari et al. (2020) study, it has been reported that bats and civets were the recent carriers for human $\mathrm{CoV}$ infection [43]. Figure 3 explains the Neighbor-Joining Tree for ORF6. Pangolin coronavirus, severe acute respiratory syndrome-related coronavirus, and bat SARS-CoV Rm1/2004 shared 97\% genetic similarity with SARS-CoV-2.

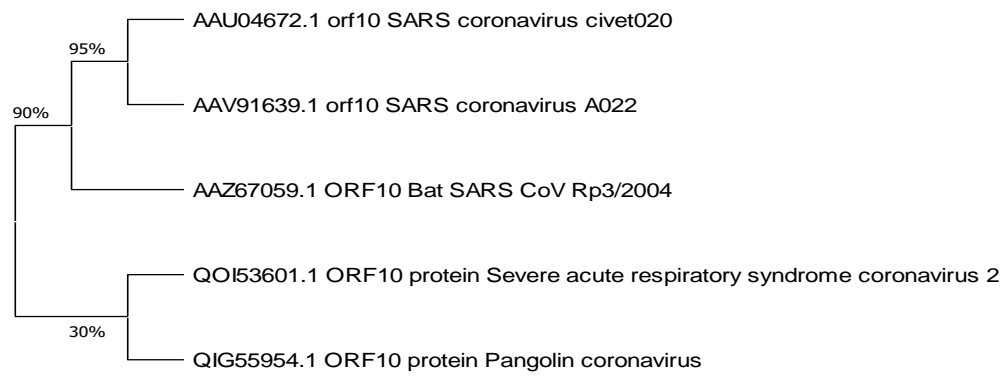

Figure 1. Evolutionary analysis of ORF10 protein of SARS-CoV-2 by Neighbor-Joining method.

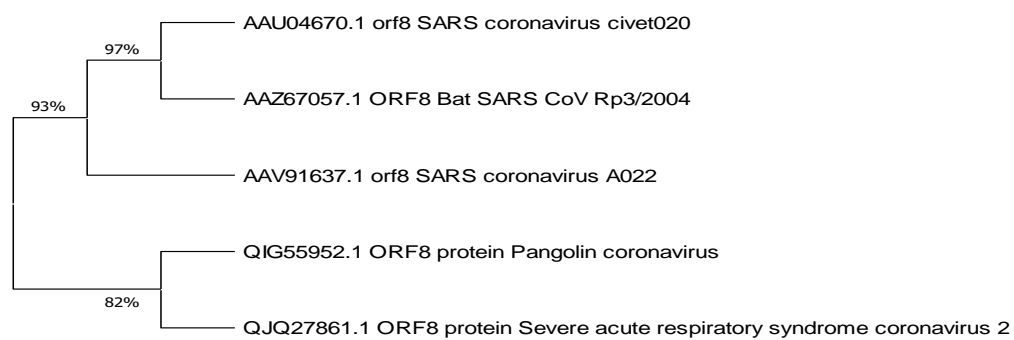

Figure 2. Evolutionary analysis of ORF8 protein of SARS-CoV-2 by Neighbor-Joining method.

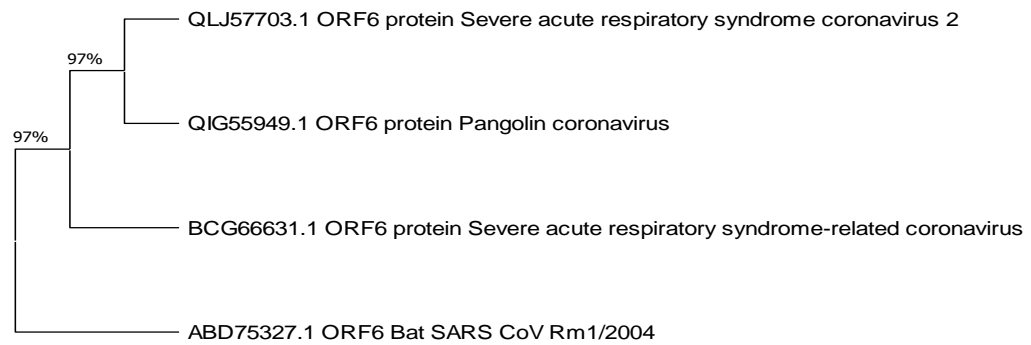

Figure 3. Evolutionary analysis of ORF6 protein of SARS-CoV-2 by Neighbor-Joining method. 
Maximum Parsimony (MP) is a character-based method for inferring a phylogenetic tree by reducing the sum number of evolutionary steps required to explain a set of data on the leaves. It forecasts the evolutionary tree or trees that take the fewest steps to produce the observed variation in sequences from common ancestor sequences. The method is commonly referred to as the minimum evolution method because of this. MP entails looking for a tree with the fewest amino acid (or nucleotide character) alterations that can explain observed discrepancies in protein (gene) sequences. This method is best suited for quite similar sequences and are limited to small numbers of sequences [44].

The Maximum Parsimony Trees for ORF10 and ORF8 were shown in Figures 4 and 5, respectively. Pangolin coronavirus, bat SARS-CoV Rp3/2004, SARS coronavirus civet020, and SARS coronavirus A022 shared 100\% sequence identity with SARS-CoV-2. ORF6 of SARS-CoV-2 had $100 \%$ genetic similarity with pangolin coronavirus, severe acute respiratory syndrome-related coronavirus, and bat SARS-CoV Rm1/2004 (Figure 6).

The phylogenetic tree constructions revealed that the amino acid sequence of the human SARS-CoV-2 ORF10, ORF8, and ORF6 proteins had the closest evolutionary relationship with bat SARS-CoV Rm1/2004 and SARS-CoV Rp3/2004. The Chinese scientists found that the genome sequence of SARS-CoV-2 was about $96.3 \%$ genetically similar to a Yunnan Rhinolophus affinis (bat) coronavirus RaTG13 in 2013 [45]. Research studies have been reported that SARS-CoV-2 was more closely related to bat SARS-like-virus-CoVZC45 (MG772933.1) and bat-SL-CoVZXC21 (MG772934) ((Moreno et al., 2017; Xu et al., 2020; Song et al., 2019). Bat SARS-like-virus-CoVZC45 shared $85 \%$ sequence identity with SARSCoV-2, while bat-SL-CoVZXC21 had 89\% homology identity with SARS-CoV-2. Bat-SLCoVZXC21 found from Southwest of China. Researchers identified that bats were the natural reservoirs for human pathogenic diseases like SARS, MERS, and COVID-19 [46-48].



Figure 4. Evolutionary analysis of ORF6 protein of SARS-CoV-2 by Maximum Parsimony Tree method.

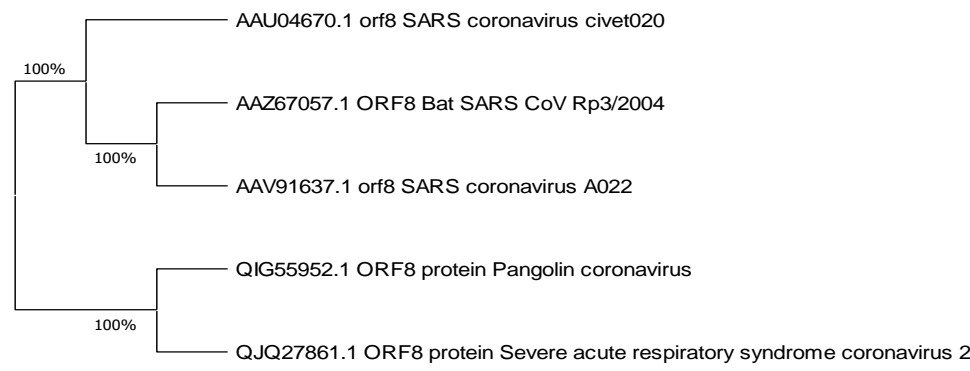

Figure 5. Evolutionary analysis of ORF8 protein of SARS-CoV-2 by Maximum Parsimony Tree method. 


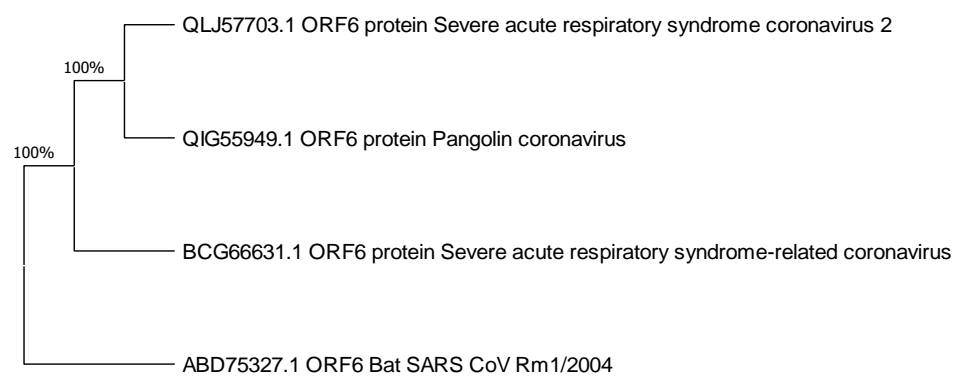

Figure 6. Evolutionary analysis of ORF6 protein of SARS-CoV-2 by Maximum Parsimony Tree method.

\section{Conclusions}

The current study reported physiochemical analysis, secondary structure analysis, structure prediction, functional characterization, active site identification, and evolutionary analysis based on the amino acid sequences of 75 Malaysia SARS-CoV-2 strain's structural and accessory proteins retrieved from the NCBI protein database. Molecular phylogenetic analysis proved that human SARS-CoV-2 had the closest evolutionary relationship with bat coronavirus. The computational biology analyses will help understand pathogenic mechanisms of virus and virulence for structure-based drug design (SBDD) or to develop potential vaccines against SARS-CoV-2 without the presence of a complete and 3-D crystal structure experimental protein models.

\section{Funding}

This research received no external funding.

\section{Acknowledgments}

We want to thank the front-liners who work hard to overcome this COVID-19 pandemic.

\section{Conflicts of Interest}

The authors declare no conflict of interest.

\section{References}

1. Pradhan, D.; Biswasroy, P.; Naik, P. K.; Ghosh, G.; Rath, G. A review of current interventions for COVID19 prevention. Archives of Medical Research 2020, 51, 363-374, https://doi.org/10.1016/j.arcmed.2020.04.020.

2. Guo, Y. R.; Cao, Q. D.; Hong, Z. S.; Tan, Y. Y.; Chen, S. D.; Jin, H. J.;Yan, Y. The origin, transmission and clinical therapies on coronavirus disease 2019 (COVID-19) outbreak- an update on the status. Military Medical Research 2020, 7, 1-10, https://doi.org/10.1186/s40779-020-00240-0.

3. World Health Organization. Coronavirus disease (COVID-2019) situation reports. 2020. Available online: https://www.who.int/emergencies/diseases/novel-coronavirus-2019/situation-reports (accessed on 16 November 2020).

4. Bialek, S.; Boundy, E.; Bowen, V.; Sauber-Schatz, E. CDC COVID-19 Response Team, CDC COVID-19 Response Team, CDC COVID-19 Response Team. Severe outcomes among patients with coronavirus disease 2019 (COVID-19)-United States, February 12-March 16, 2020. Morbidity and mortality weekly report 2020, 69, 343-346, https://www.cdc.gov/mmwr/volumes/69/wr/mm6912e2.htm.

5. Coronavirus Outbreak. COVID-19 Coronavirus Pandemic. 2020. Available online: https://www.worldometers.info/coronavirus/ (accessed on 16 November 2020).

6. World Health Organization. Origin of SARS-CoV-2. 2020, https://apps.who.int/iris/handle/10665/332197. 
7. Kumar, S.; Nyodu, R.; Maurya, V. K.; Saxena, S. K. Morphology, Genome Organization, Replication, and Pathogenesis of Severe Acute Respiratory Syndrome Coronavirus (SARS-CoV-2). In Coronavirus Disease 2019 (COVID-19). Springer Singapore 2020, 23-31, https://doi.org/10.1007/978-981-15-4814-7_3.

8. Xiuyuan, Ou; Yan, Liu; Xiaobo, Lei; Pei, Li; Dan, Mi; Lili, Ren; Li, Guo; Ruixuan, Guo; Ting, Chen; Jiaxin, Hu; Zichun, Xiang; Zhixia, Mu; Xing, Chen; Jieyong, Chen; Keping, Hu; Qi, Jin; Jianwei, Wang; \& Zhaohui, Qian. Characterization of spike glycoprotein of SARSCoV-2 on virus entry and its immune cross-reactivity with SARS-CoV. Nature Communication 2020, 11, 1620, https://doi.org/10.1038/s41467-021-22614-1.

9. Cascella, M.; Rajnik, M.; Cuomo, A.; Dulebohn, S. C.; Di Napoli, R. Features, evaluation and treatment coronavirus (COVID-19). In Statpear ls StatPearls Publishing 2020, https://www.ncbi.nlm.nih.gov/books/NBK554776/.

10. Shah, A.; U. M.; Safri, S.; N. A.; Thevadas, R.; Noordin, N. K.; Abd Rahman, A.; Sekawi, Z.; Sultan, M.; T. H. COVID-19 outbreak in Malaysia: Actions taken by the Malaysian government. International Journal of Infectious Diseases 2020, 97, 108-116, https://doi.org/10.1016/j.ijid.2020.05.093.

11. World Health Organization. Modes of transmission of virus causing COVID-19: implications for IPC precaution recommendations. 2020, Available online: https://www.who.int/newsroom/commentaries/detail/modes-of-transmission-of-virus-causing-covid-19-implications-for-ipcprecaution-recommendations (accessed on 16 November 2020).

12. Cucinotta, D.; Vanelli, M. WHO declares COVID-19 a pandemic. Acta Bio Medica: Atenei Parmensis 2020, 91, 157, https://doi.org/10.23750/abm.v91i1.9397.

13. Covid-19 (Maklumat Terkini). Ministry of Health (Malaysia). 2021, http://covid-19.moh.gov.my/.

14. World Health Organization. Solidarity Trial for COVID-19 Treatments. 2021. https://www.who.int/emergencies/diseases/novel-coronavirus-2019/global-research-on-novel-coronavirus2019-ncov/solidarity-clinical-trial-for-covid-19-treatments.

15. $\mathrm{MOH}$ starts Ivermectin trial for high-risk Covid-19 patients. 2021. https://themalaysianreserve.com/2021/06/06/moh-starts-ivermectin-trial-for-high-risk-covid-19patients.

16. National Center for Biotechnology Information (NCBI). 2020, https://www.ncbi.nlm.nih.gov/protein/.

17. Gasteiger, E.; Hoogland, C.; Gattiker, A.; Wilkins, M.R.; Appel, R.D.; Bairoch, A. Protein identification and analysis tools on the ExPASy server The Proteomics Protocols Handbook. Springer 2005, 571-607, https://doi.org/10.1385/1-59259-890-0:571.

18. Bruah, C.; Devi. P.; Sharma, D.K. Sequence Analysis and Structure Prediction of SARS-CoV-2 Accessory Proteins 9b and ORF14: Evolutionary Analysis Indicates Close Relatedness to Bat Coronavirus. Hindawi BioMed Research International 2020, 1, 1-13, https://doi.org/10.1155/2020/7234961.

19. Geourjon, C.; Deleage, G. SOPMA: significant improvements in protein secondary structure prediction by consensus prediction from multiple alignments. Bioinformatics 1995, 11, 681-684, https://doi.org/10.1093/bioinformatics/11.6.681.

20. Kasilingam, T.; Elengoe, A. In silico molecular modeling and docking of apigenin against the lung cancer. Asian Journal of Pharmacautical and Clinical Research 2018, 11, 246-252, https://doi.org/10.22159/ajpcr.2018.v11i9.26649.

21. Biasini, M.; Bienert, S.; Waterhouse, A.; Arnold, K.; Studer, G.; Schmidt, T.; Bordoli, L. SWISS-MODEL: modelling protein tertiary and quaternary structure using evolutionary information. Nucleic acids research 2014, 42, W252-W258, https://doi.org/10.1093/nar/gku340.

22. Colovos, C.; Yeates, T.O. Verification of protein structures: patterns of non-bonded atomic interactions. Protein Science 1993, 2, 1511-1519, https://doi.org/10.1002/pro.5560020916.

23. Eisenberg, D.; Lüthy, R.; Bowie, J.U. VERIFY3D: assessment of protein models with three- dimensional profiles. Methods in Enzymology 1993, 277, 396-404, https://doi.org/10.1016/s0076-6879(97)77022-8.

24. Laskowski, R.A.; MacArthur, M.W.; Moss, D.S.; Thornton, J.M. PROCHECK: a program to check the stereochemical quality of protein structures. Journal of Applied Crystallography 1993, 26, 283-291, https://doi.org/10.1107/S0021889892009944.

25. Laskowski, R.A.; Watson, J.D.; Thornton, J.M. ProFunc: a server for predicting protein function from 3D structure. Nucleic Acids Research 2005, 33, W89-93, https://doi.org/10.1093/nar/gki414.

26. Mulder. N.; Apweiler, R. InterPro and InterProScan: Tools for protein sequence classification and comparison. Methods in Molecular Biology 2007, 2, 59-70, https://doi.org/10.1007/978-1-59745-515-2_5.

27. Singh, T.; Biswas, D.; Jayaram, B. AADS - An Automated Active Site Identification, Docking, and Scoring Protocol for Protein Targets Based on Physicochemical Descriptors. Journal of Chemical Information and Modeling 2011, 51, 2515-2527, https://doi.org/10.1021/ci200193z. 
28. Kumar, S.; Stecher, G.; Li, M.; Knyaz, C.; Tamura, K. MEGA X: molecular evolutionary genetics analysis across computing platforms. Molecular Biology and Evolution 2018, 35, 1547-1549, https://doi.org/10.1093/molbev/msy096.

29. First case of Malaysian positive for coronavirus. Bernama. 2020, https://www.bernama.com/en/general/news_covid-19.php?id=1811373.

30. Coronavirus: Malaysia records first local transmission. Bernama, 2020, https://www.bernama.com/en/general/news.php?id=1811990.

31. Covid-19 (Maklumat Terkini). Ministry of Health (Malaysia). 2020, http://www.moh.gov.my/index.php/pages/view/2019-ncov-wuhan.

32. Barker, A. Coronavirus COVID-19 cases spiked across Asia after a mass gathering in Malaysia. This is how it caught the countries by surprise. ABC News. 2020, https://www.abc.net.au/news/2020-03-19/coronavirusspread-from-malaysian-eventtomultiplecountries/12066092.

33. Sukumaran, T. Coronavirus: Malaysia in partial lockdown from March 18 to limit outbreak. South China Morning Post. 2020, https:/www.scmp.com/week-asia/health-environment/article/3075456/coronavirusmalaysias-prime-minister-muhyiddin-yassin.

34. Petkso, G.A.; Ringe, D. Protein Structure \& Function, New Science Press Ltd. 2004, https://global.oup.com/academic/product/protein-structure-and-function-9780199556847?cc=za\&lang=es.

35. Suhaibun, S.R.; Elengoe, A.; Poddar, R. Technology Advance in Drug Design Using Computational Biology Tool. Malaysian Journal of Medicine and Health Sciences 2020, 16, 18-24, https://www.researchgate.net/publication/349289403_Technology_Advance_in_Drug_Design_Using_Com putational_Biology_Tool.

36. Elengoe, A. COVID-19 outbreak in Malaysia. Osong Public Health and Research Perspectives 2020, 11, 93, https://doi.org/10.24171/j.phrp.2020.11.3.08.

37. Parker, M.M.; Masters, P.S. Sequence comparison of the $\mathrm{N}$ genes of five strains of the coronavirus mouse hepatitis virus suggests a three domain structure for the nucleocapsid protein. Virology 1990, 179, 463-468, https://doi.org/10.1016/0042-6822(90)90316-j.

38. Elengoe, A. Indian spices boost the immune system against COVID-19. The Annals of the University Dunarea de Jos of Galati. Fascicle VI-Food Technology 2020, 44, 189-206, https://doi.org/10.35219/foodtechnology.2020.2.12.

39. Binns, M.M.; Boursnell, M.E.; Cavanagh, D.; Pappin, D.J.; Brown, T.D.J. Cloning and sequencing of the gene encoding the spike protein of the coronavirus IBV. Journal of General Virology 1985, 66, 719-726, https://doi.org/10.1099/0022-1317-66-4-719.

40. Belouzard, S.; Chu, V.C.; Whittaker, G.R. Activation of the SARS coronavirus spike protein via sequential proteolytic cleavage at two distinct sites. Proc. Natl. Acad. Sci. U.S.A. 2009,106, 5871-5876, https://doi.org/10.1073/pnas.0809524106.

41. Qian, Z.; Ou, X.; Goes, L.G.; Osborne, C.; Castano, A.; Holmes, K.V.; Dominguez, S.R.; Identification of the Receptor-Binding Domain of the Spike Glycoprotein of Human Betacoronavirus HKU1. Journal of Virology 2015, 89, 8816-8827, https://doi.org/10.1128/JVI.03737-14.

42. Xiao, K.; Zhai, J.; Feng, Y.; Zhou, N.; Zhang, X.; Zou, J.; Li. N.; Guo, Y.; Li, X.; Shen, X.; Zhang, Z.; Shu, F.; Huang, W.; Li, Y.; Shen, Y. Z. J. Isolation of SARS-CoV-2-related coronavirus from Malayan pangolins. Nature 2020, 583, 286-289, https://www.nature.com/articles/s41586-020-2313-X.

43. Tiwari, R.; Dhama, K.; Sharun, K.; Yatoo, M.; Malik, Y.; Singh, R.; Michalak, I.; Sah, R.; Aldana, D.; Morales, A. COVID-19: animals, veterinary and zoonotic links. Veterinary Quarterly 2020, 40, 169-182, https://doi.org/10.1080/01652176.2020.1766725.

44. David, W. Mount. Phylogenetic Prediction, Chapter 7, in Bioinformatics: Sequence and Genome Analysis, $2^{\text {nd }}$ edition, by David W. Mount. Cold Spring Harbor Laboratory Press, Cold Spring Harbor, NY, USA. 2004, https://www.cshlpress.com/default.tpl?cart=1626626815218812516\&fromlink=T\&linkaction=full\&linksort by=oop_title\&--eqSKUdatarq=466.

45. Singhal, T. A review of coronavirus disease-2019 (COVID-19). The Indian Journal of Pediatrics 2020, 1-6, https://doi.org/10.1007/s12098-020-03263-6.

46. Moreno, A.; Lelli, D.; De Sabato, L.; Zaccaria, G.; Boni, A.; Sozzi, E.; Prosperi, A.; Lavazza, A.; Cella, E.; Castrucci, M.R.; Ciccozzi, M. Detection and full genome characterization of two beta CoV viruses related to Middle East respiratory syndrome from bats in Italy. Virology Journal 2017, 14, 239, https://doi.org/10.1186/s12985-017-0907-1. 
47. Xu, J.; Zhao, S.; Teng, T.; Abdalla, A.E.; Zhu, W.; Xie, L., Wang, Y.; Guo, X. Systematic comparison of two animal-to-human transmitted human coronaviruses: SARS-CoV-2 and SARS-CoV. Viruses 2020, 12, 244, https://doi.org/10.3390/v12020244.

48. Song, Z.; Xu, Y.; Bao, L.; Zhang, L.; Yu, P.; Qu, Y.; Zhu, H.; Zhao, W.; Han, Y.; Qin, C.From SARS to MERS, thrusting coronaviruses into the spotlight. Viruses 2019, 11, 59, https://doi.org/10.3390/v11010059. 